\title{
Medium- and high-temperature latent and thermochemical heat storage using metals and metallic compounds as heat storage media: A technical review
}

This is the ACCEPTED version of this article.

The final, published version of the article can be found at:

https://doi.org/10.1016/j.apenergy.2020.115950

\author{
Y. Zhao a,b, C. Y. Zhao a, ${ }^{,}$C. N. Markides ${ }^{b}$, H. Wangc and W. Lic \\ a Institute of Engineering Thermophysics, School of Mechanical Engineering, Shanghai Jiao Tong University, Shanghai 200240, China \\ ${ }^{b}$ Clean Energy Processes (CEP) Laboratory, Department of Chemical Engineering, Imperial College London, London SW7 2AZ, UK \\ c Pioneer Energy (Jiangsu) Co., Ltd., Suzhou 215634, China
}

\section{Highlight:}

- Medium- and high- temperature latent and thermochemical heat storage are reviewed.

- Metals and metallic compounds as heat storage media are discussed.

- Technical issues in latent and thermochemical heat storage are presented.

- Heat transfer enhancement from three levels in latent heat storage is highlighted.

- Continuous thermochemical heat storage is suitable for seasonal heat storage.

\begin{abstract}
Latent and thermochemical heat storage are receiving increased attention due to their important role in addressing the challenges of variable renewable energy generation and waste heat availability, as well as the mismatch between energy supply and demand in time and space. However, as the operating storage temperature increases, a series of challenging technical problems arise, such as complex heat transfer mechanisms, increased corrosion, material failure, reduced strength, and high-temperature measurement difficulties, especially for metals and metallic compounds as heat storage media. This paper reviews the latest research progress in medium- and high-temperature latent and thermochemical heat storage using metals and metallic compounds as storage media from a technical perspective and provides useful information for researchers and engineers in the field of energy storage. In this paper, the status and challenges of mediumand high-temperature latent and thermochemical heat storage are first introduced, followed by an assessment of metals and metallic compounds as heat storage media in latent and thermochemical heat storage applications. This is followed by a comprehensive review of three key issues associated with medium/high-temperature latent heat storage applications: heat transfer enhancement, stability and corrosion, as well as a discussion of four key issues associated with medium/hightemperature thermochemical heat storage: heat transfer, cycling stability, mechanical property and reactor/system design. Finally, the prospects of medium/high-temperature latent and thermochemical heat storage are summarized.
\end{abstract}

\section{Keywords:}

thermal energy storage, latent heat storage, thermochemical heat storage, metals, metallic compounds, mediumand high-temperature heat

\footnotetext{
${ }^{*}$ Corresponding author. Email address: changying.zhao@sjtu.edu.cn
} 


\section{Introduction}

\subsection{Global energy situation}

Energy is the basis of human survival and development, and a crucial element of highly complex applications such as aerospace, advanced manufacturing, military technology, as well as everyday activities such as transportation, heating and air conditioning, lighting and food.

\subsubsection{Global energy demand and structure}

Economic development, population growth and improvements in living standards all rely upon increased energy consumption, and given its importance, many international organisations have conducted studies and forecasts of global energy demand. According to BP, in the Evolving transition scenario, the global primary energy consumption increased at an annual growth rate of 2.1\% from 8.6 gigatons of oil equivalent (Gtoe) in 1995 to 13.5 Gtoe in 2017, and was expected to continue to rise at an annual growth rate of $1.2 \%$, reaching 17.9 Gtoe by 2040 [1]. In another important study, the EIA concluded that from 2010 to 2018, the global energy consumption increased from 537.5 quadrillion Btu to 620.0 quadrillion Btu, and forecasted that by 2050 the energy demand would reach 910.7 quadrillion Btu at an annual growth rate of 1.2\% [2]. REN21 also pointed out that though global primary energy intensity decreased more than 10\% between 2013 and 2018, the world's total primary energy demand still grew at an annual growth rate of 1.3\% over this period [3]. According to these projections, although the growth of energy demand slows with improvements in energy efficiency, it will still be expected to increase at an annual growth rate of 1-2\% over the next 20-30 years.

Generally, primary energy includes fossil fuels, nuclear energy and renewable energy. According to BP, the consumption of fossil fuels increased from 7.4 Gtoe in 1995 to 11.4 Gtoe in 2017, but the fraction of the total primary energy consumption decreased from $87 \%$ to $85 \%$, and was projected to reduce further to $73.0 \%$ by 2040 . Nuclear energy generation rose from 526 Mtoe to 596 Mtoe at an annual growth rate of $0.6 \%$ from 1995 to 2017 and would continue to increase to 770 Mtoe by 2040 with unchanged shares in primary energy consumptions [1]. Since the energy crisis in the 1970s, countries have begun to pay increasing attention to renewable energy. From 1995 to 2017, renewable energy generation (excluding hydropower) increased at an annual growth rate of 12.3\% from 45 Mtoe to 571 Mtoe, and was expected to reach 2.7 Gtoe at an annual growth rate of about 7.1\% by 2040 [1]. Most sources agreed that renewable energy (including hydropower) would continue to be the fastest-growing source of electricity from 2018 to 2050 with an annual growth rate of $3.6 \%$, providing almost half of the total global electricity by 2050 [2]. Given the energy system infrastructure over the next 20-30 years, it is most likely that fossil fuels will still account for the largest proportion of energy consumption, while the installed capacity of nuclear power will continue to increase. Although the share of renewable energy is still small, technological progress, policy support and reducing costs will be increasingly important to continued growth.

\subsubsection{Renewable energy}

Over the next 20-30 years, global energy demand will continue to increase and fossil fuels will continue to play a major role as primary energy resources. However, fossil-fuel reserves are limited, and high rates of consumption are not sustainable, or secure, in the long term. Figure 1 shows the changes in the proven reserves of the world's major fossil-fuel sources and their corresponding annual growth rates from 2010 to 2019. According to their estimated production rates, the proven reserves of oil, coal and natural gas can be maintained for about 50 years, 132 years and 50 years, respectively [4]. With the advancement of technology, the proven reserves of fossil fuels will increase, but new development prospects are uncertain, introducing an unreliable factor in our continued use of these 
resources, whose price has fluctuated significantly in recent years, especially that of crude oil.

Moreover, greenhouse gases (GHGs) and pollutants generated during the combustion of fossil fuels cause serious health and environmental problems. Driven by $\mathrm{CO}_{2}$ emissions from fuel combustion, energy-related $\mathrm{GHG}$ emissions increased by $12.6 \mathrm{GtCO}_{2}$ equivalent from 1990 to 2015, and also represented around three quarters of total GHG emissions in 2015 [5]. It was further pointed out that the $\mathrm{CO}_{2}$ emissions from fuel combustion increased to 32.8 billion tons in 2017, an increase of $60 \%$ compared to 1990 emissions, and $\mathrm{CO}_{2}$ generated in the utilization of oil, coal and natural gas in 2017 accounted for $34.6 \%, 44.2 \%$ and $20.5 \%$ of the total $\mathrm{CO}_{2}$ emissions, respectively [5]. In addition, a large amount of other harmful gases ( $\mathrm{SO}_{\mathrm{x}}, \mathrm{NO}_{\mathrm{x}}, \mathrm{CO}$, etc.), unburnt hydrocarbons as well as harmful particulates are produced during the combustion of fossil fuels, which can cause air pollution, smog and have been linked to health concerns [6].

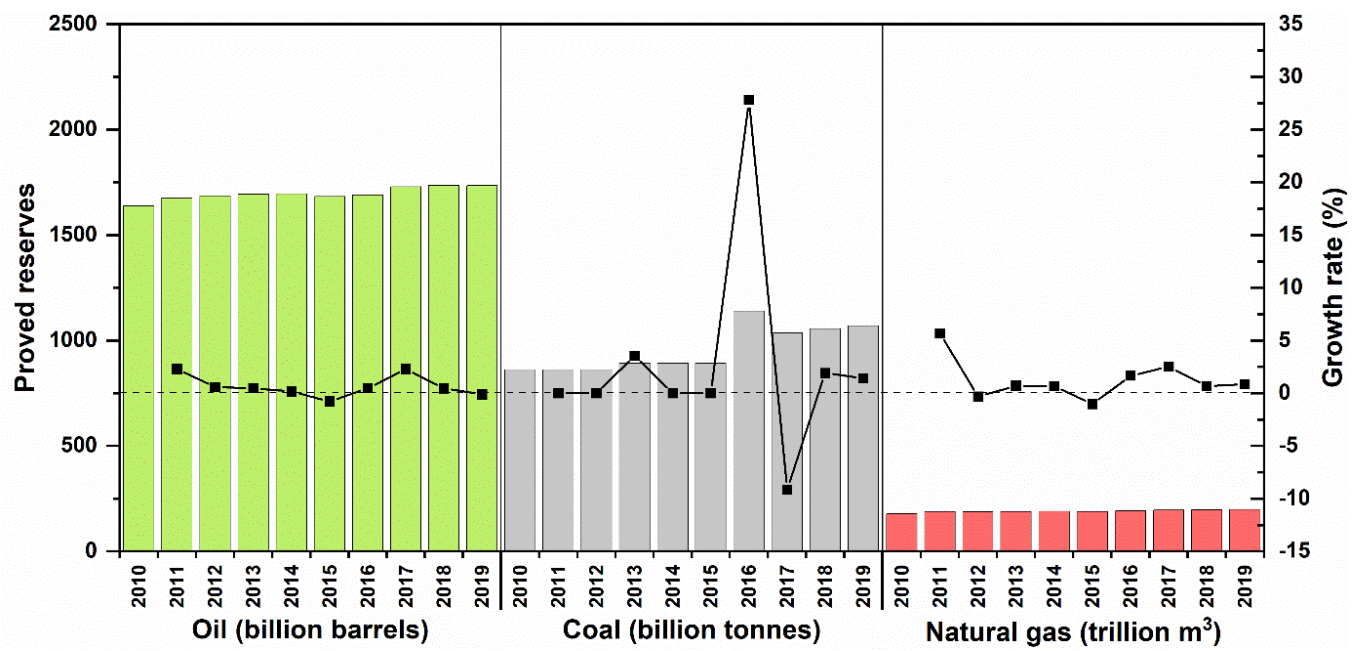

Figure 1. Proven reserves of the world's major fossil fuels and their corresponding annual growth rates, 2010-2019 [4]

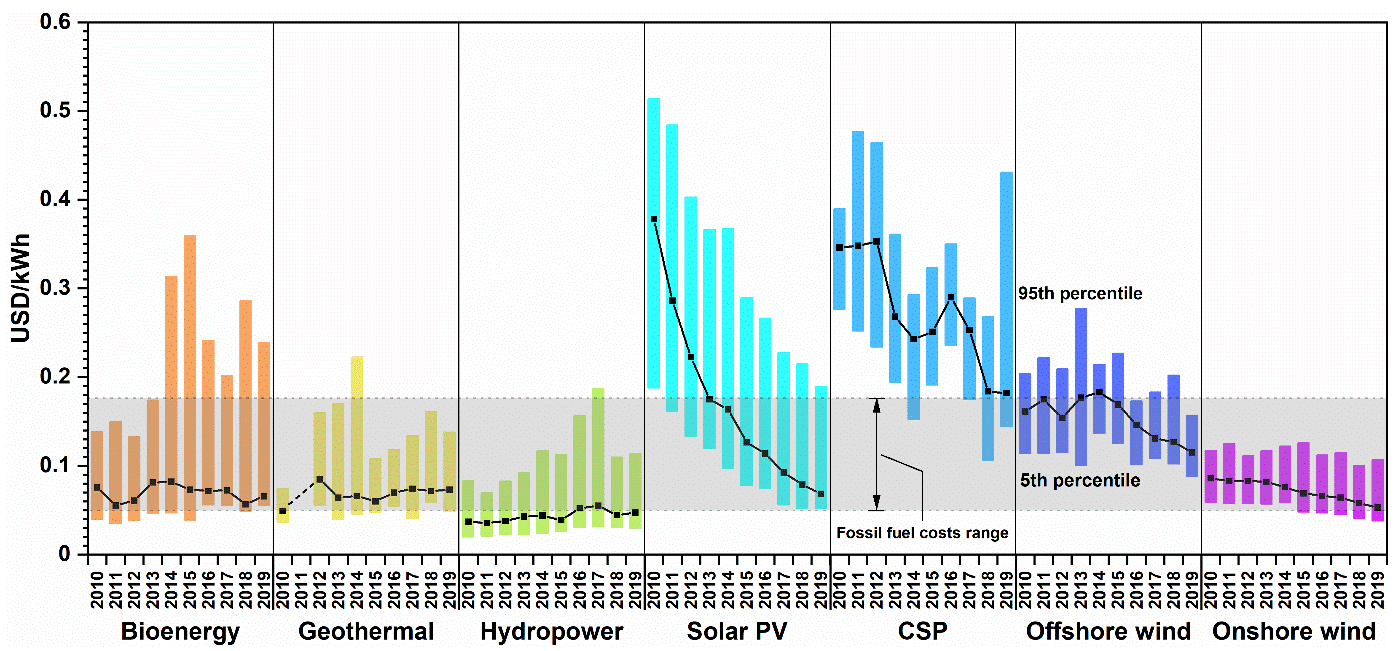

Figure 2. Global weighted average LCOE for renewable power generation, 2010-2019 [7]

For the above reasons, renewable energy (in particular, solar energy and wind) is considered to be a particularly promising alternative for achieving sustainable energy development in the future. Moreover, in recent years, the falling costs of renewable energy technologies driven by significant market growth have made these technologies increasingly costly competitive, to the extent that as of now, renewable generation is in some cases more cost-effective than conventional generation even without further incentives. Figure 2 shows the global weighted average levelised costs of electricity (LCOE) for renewable power generation from 2010 to 2019. The 
black thick lines represent the global weighted average LCOE by year. The grey single band represents the fossil fuel-fired power generation cost range of USD $0.05-0.177 / \mathrm{kWh}$ in 2019 , while the bands for each technology and year represent the 5th and 95th percentile bands for renewable projects. The LCOEs of solar and wind power generation have dropped significantly over this period, such that solar photovoltaic (PV) power, onshore and offshore wind power now have LCOEs in the range of fossil fuels on average. Of particular interest in this figure is the LCOE of concentrating solar power (CSP), which fell by an astounding 47\% from 2010 to 2019.

\subsubsection{Waste heat sources}

Waste heat sources are widely distributed in power generation, industrial manufacturing, transportation, commercial and residential activities. It has been estimated that approximately $20-50 \%$ of the useful generated heat is ultimately wasted in the form of exhaust gases, cooling water streams or simple dissipation in industry without being recovered in the United States [8]. In China, the heat wasted in the steel, cement, glass, ammonia, caustic soda, calcium carbide and sulfuric acid industries has been estimated to correspond to 340 million tons of standard coal per year, accounting for about $30 \%$ of total national energy consumption [9].

Although waste-heat recovery and utilization is an area of growing interest, the evaluation of the potential of industrial waste heat still lacks uniform standards, and there are few data on waste-heat sources across nations and sectors, especially in relation to power generation, transportation and commercial/residential activities. Forman et al. [10] provided an evaluation of the heat wasted globally in power generation, industrial production, transportation, commercial and residential activities and classified major heat sources based on temperature. Figure 3 shows the total estimated global waste heat in 2012. The total amount of waste heat in 2012 was 246 PJ, which corresponds to $52 \%$ of primary energy consumption, with $51 \mathrm{PJ}$ being classed as high-temperature (or, grade) heat, $39 \mathrm{PJ}$ as intermediate, and $156 \mathrm{PJ}$ as low-temperature heat, respectively.

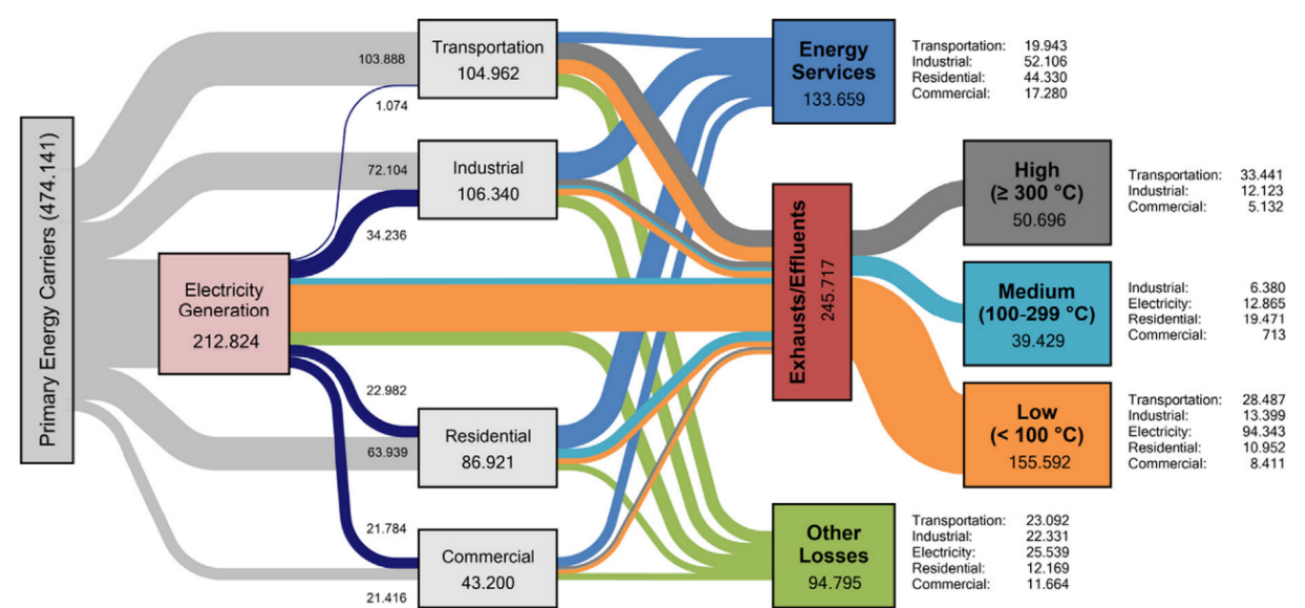

Figure 3. Estimated global waste heat distribution in 2012 [10]

\subsection{Importance of thermal energy storage}

\subsubsection{Energy storage technologies}

Due to their availability and large reserves, wide distribution and environmental benefits, renewable energy and waste heat have attracted considerable attention in recent decades. However, renewable energy (e.g., solar and wind energy) and waste heat (e.g., from industrial sources) are discontinuous and variable due to the effects of day-night conversion, weather changes (overcast and sunny, wind speed) and process requirements, which makes it difficult to obtain a stable and reliable energy output, thus hindering subsequent use (e.g., integration to the 
power grid or end-users). Moreover, there usually exists a mismatch between energy demand and supply in time and space, causing insufficient energy utilization and low efficiency.

Energy storage, which can be divided into electrical energy storage (EES) and thermal energy storage (TES), is key to solving the above challenges. EES technologies are often grouped into mechanical (e.g., pumped hydroelectric storage, flywheels), thermomechanical (e.g., compressed air energy storage, pumped thermal electricity storage, liquid air energy storage), electrochemical (e.g., batteries, flow batteries, fuel cells), and other electricity storage concepts (superconducting magnetic energy storage, supercapacitors), while TES technologies are classed as sensible heat storage (SHS), latent heat storage (LHS) and thermochemical heat storage (THS) technologies.

The difference between EES and TES lies in the quality of the stored energy and the rate of energy transfer: (1) according to the second law of thermodynamics, the grade of electrical energy stored in EES is higher than that of thermal energy stored in TES; (2) the energy transfer rate in TES is lower than that in EES due to the large difference in the speeds between the thermal movement of microscopic particles or lattices and the directional movement of free electrons.

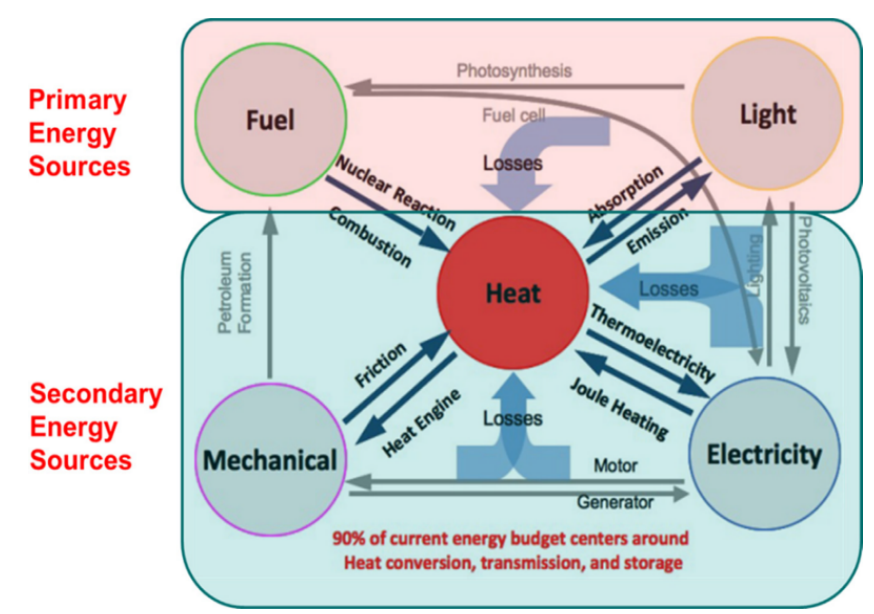

Figure 4. Thermal energy at the heart of energy chain [11]

Yet, although TES is at a disadvantage concerning the quality of the stored energy and charge/discharge rates, it is still indispensable. Figure 4 shows that heat can be considered as being at the heart of the entire energy transmission, conversion and storage chain, acting as a link between primary and secondary energy. Almost $90 \%$ of the energy budget centres on heat conversion, transmission and storage [11], and nearly 50\% of energy demand and consumption are for heat, which often changes in time and space [12]. In solar thermal and waste heat applications, the energy provided from the source principally takes the form of heat, which can be directly stored by TES. Moreover, TES has a higher level of maturity, lower costs and much longer storage durations, making it suitable for larger-scale and longer-duration applications.

\subsubsection{Thermal energy storage}

Sensible heat storage (SHS) is the most mature and widely used TES option due to its simple principle and low costs, however, it also has the lowest heat storage density among the three types of TES. In SHS, heat is stored by raising the temperature of a liquid or solid and released by decreasing the temperature when necessary. The amount of stored thermal energy depends on specific heat capacity, material mass and temperature difference, as shown in Eq. (1):

$$
Q=\int_{T_{1}}^{T_{2}} m c_{\mathrm{p}} d T
$$

where $m, c_{\mathrm{p}}$ and $T$ are the mass, specific heat capacity and temperature of the SHS media; and subscripts ' 1 ' and ' 2 ' indicate the beginning and end of the heat transfer process. Common materials include water, thermal oils, molten salts, concretes and rocks. 
Latent heat storage (LHS) stores and releases heat through solid-liquid phase change. The heat storage medium is also referred to as a phase change material (PCM). The thermal energy stored in LHS usually comprises three parts: solid sensible heat, latent heat and liquid sensible heat:

$$
Q=\int_{T_{1}}^{T_{\mathrm{m}}} m c_{\mathrm{p}, \mathrm{s}} d T+m \Delta h+\int_{T_{\mathrm{m}}}^{T_{2}} m c_{\mathrm{p}, \mathrm{l}} d T
$$

where $m, c_{\mathrm{p}}$ and $T$ are the is the mass, specific heat capacity and temperature of the PCM; $\Delta h$ is its phase-change enthalpy per unit mass; subscripts ' 1 ' and ' 2 ' indicate the beginning and the end of the heat transfer process, respectively; and subscripts ' $s$ ', ' $m$ ' and ' $\mathrm{l}$ ' refer to the solid phase, the melting process and the liquid phase, respectively. Ordinarily, LHS has a higher heat storage density than SHS, which can effectively reduce the volume of storage tanks. Furthermore, the temperature stays approximately constant during the phase change process along with similarly small volume changes, making operation simple and safe. Common PCMs are paraffin, fatty acids, alcohols, esters, salt hydrates, inorganic salts and metals, etc.

Thermochemical heat storage (THS) can realize heat storage and release through reversible chemical sorption or reaction. The principle is shown below:

$$
n_{\mathrm{AB}} \cdot A B(\mathrm{~s})+Q \mathrm{E} \quad n_{\mathrm{A}} \cdot A(\mathrm{~s})+n_{\mathrm{B}} \cdot B(\mathrm{~g})
$$

where $n$ is the stoichiometric coefficient; and $Q$ is the reaction heat. A reactant $A B(\mathrm{~s})$ decomposes into a solid $A(\mathrm{~s})$ and a vapour phase $B(\mathrm{~g})$ with the supply of external heat $Q$. After separation of the products, the solid $\mathrm{A}(\mathrm{s})$ can be stored under ambient conditions and enables very long-term heat storage and long-distance transportation. Moreover, the heat storage density of THS is considered to be the highest among the TES technologies. The range of different reaction types, such as dehydration of salt hydrates, dehydration of metal hydroxides, dehydrogenation of metal hydrides, decarboxylation of metal carbonates and redox reactions of oxides enable a very wide range of applications at different temperatures. However, the reaction processes of THS are much more complicated than those of SHS and LHS and require precise control. Table 1 compares these three types of TES. Given its high maturity and low heat storage density, SHS will not be further discussed in this paper.

Table 1. Comparison of three thermal energy storage technologies

\begin{tabular}{cccc}
\hline & Sensible heat storage & Latent heat storage & Thermochemical heat storage \\
\hline \multirow{2}{*}{ Heat storage density } & $\sim 50 \mathrm{kWh} / \mathrm{m}^{3}$ & $\sim 100 \mathrm{kWh} / \mathrm{m}^{3}$ & $\sim 500 \mathrm{kWh} / \mathrm{m}^{3}$ \\
& $\sim 0.02-0.03 \mathrm{kWh} / \mathrm{kg}$ & $\sim 0.05-0.1 \mathrm{kWh} / \mathrm{kg}$ & $\sim 0.5-1 \mathrm{kWh} / \mathrm{kg}$ \\
Storage time & Limited & Limited & Long-term \\
Transmission distance & Short & Short & Long \\
Maturity & Commercialization & Pilot plant & Laboratory \\
Technical difficulty & Easy & Moderate & Difficult \\
\hline
\end{tabular}

\subsubsection{Medium/high-temperature latent and thermochemical heat storage}

TES is usually divided according to the operating temperature into low-temperature TES $\left(T<100^{\circ} \mathrm{C}\right)$, medium-temperature $\operatorname{TES}\left(100^{\circ} \mathrm{C} \leq T \leq 300^{\circ} \mathrm{C}\right)$ and high-temperature TES $\left(T>300^{\circ} \mathrm{C}\right)$. At temperatures below $100^{\circ} \mathrm{C}$, TES technology has been gradually commercialized and is widely used in heating, air conditioning, thermal control, domestic hot water and other applications. Common heat storage media used for low-temperature LHS mainly include paraffin, fatty acids, alcohols, esters and hydrated salts, with reversible chemical sorption involving hydrated salts used for low-temperature THS.

However, as the operating temperature increases above $100{ }^{\circ} \mathrm{C}$, the thermal movement of the microscopic particles inside the substance becomes more intense with increasing instability, leading to a series of challenging 
technical issues, such as more complicated heat transfer mechanisms, increased corrosion, material failure, reduced strength, while challenges in high-temperature measurement arise. Medium/high-temperature PCMs are mainly metals or inorganic salts, while medium/high-temperature THS mainly uses oxide/hydroxide reversible reactions, metal/metal hydride reactions, oxide/carbonate reactions and redox reactions, involving oxides, hydroxides, metals, metal hydrides, carbonates, and so on. All the above heat storage media are metals and metallic compounds, and may make the above technical issues more complicated. To date, medium/high-temperature LHS technologies are at the pilot stage and have not yet seen commercialization, while medium/high-temperature THS technologies are less mature and still at the lab-test stage. Moreover, higher temperatures correspond to higher thermal energy grades and greater development values, meaning that medium/high-temperature TES can make extensive use of high-grade thermal energy (e.g., solar thermal energy, industrial waste heat and geothermal heat) and realize the flexible energy utilization that integrates power generation and heat supply. Due to these technologies being at early stages of development and their broad application prospects, technical breakthroughs are urgently needed to promote the further development of commercial medium/high-temperature LHS and THS solutions.

\subsection{Aim and structure of the paper}

In recent years, medium/high-temperature LHS and THS technologies have been a hot and cutting-edge research topic, and have been summarized and reviewed in detail from different perspectives. For example, Kuravi et al. [13] presented a review of TES system design methodologies and the factors to be considered at different hierarchical levels for CSP applications. Zhang et al. [14] reviewed the development and design of high-temperature SHS, LHS and THS technologies, including suitable heat storage media, heat carriers, containment and systems. Li et al. [15] considered the heat transfer performance and enhancement techniques for shell-and-tube type TES containing molten-salt-based PCMs at medium/high temperatures, while Carrillo et al. [16] analysed the status, major challenges and future perspectives of THS, covering the numerous strategies proposed for the improvement of materials and thermochemical reactors. However, to the best knowledge of the authors, there has not been a comprehensive review focusing on the progress and opportunities in medium/high-temperature LHS and THS technologies from a technical perspective. The main objective of this paper is to address this knowledge gap by summarizing the latest technical progress and future promise of medium/hightemperature LHS and THS technologies using metals and metallic compounds as storage media.

This paper comprises five sections. In Section 1, we introduce TES systems and explain their importance in the context of medium/high-temperature LHS and THS technologies. In Section 2, we present a variety of storage media for medium/high-temperature LHS and THS applications. In Section 3, we focus on three core technical issues (heat transfer enhancement, stability, corrosion) faced by medium/high-temperature LHS technologies. Heat transfer enhancement specifically for inorganic salt PCMs is reviewed at material, component and system levels, respectively. In Section 4, we proceed to discuss four core technical issues (heat transfer, cycling stability, mechanical property, reactor/system design) faced by medium/high-temperature THS technology. Finally, in Section 5, we provide a summary and present the prospects for future research and the further development of medium/high-temperature LHS and THS technologies.

\section{Metals and metallic compounds as heat storage media}

\subsection{Latent heat storage media}

In general, ideal PCMs should satisfy the following criteria: a suitable melting temperature, a large latent heat, a large specific heat capacity, a high thermal conductivity, a good thermal and cycling stability, low corrosivity, little volume expansion, no phase separation and undercooling, non-flammable and non-toxic, a low cost and so on. However, each kind of PCMs has its unique physical and chemical properties, making it difficult to meet all the criteria. 


\subsubsection{Metals and alloys}

When used as PCMs, metals and metal alloys usually have a high heat storage density per volume, a high thermal conductivity, good stability, low undercooling, a low vapour pressure and a small volume change [17]. However, their high corrosivity at high temperature and relatively high costs make them fail to get enough attention for a long time. Recently, with the development of solar thermal power and industrial waste heat recovery, metals and alloys are gaining more attention as PCMs. Common metallic PCMs are $\mathrm{Al}, \mathrm{Cu}, \mathrm{Mg}, \mathrm{Zn}$, Fe and their alloys, some of which are listed in Table 2.

Research on metals and alloys as high-temperature PCMs was first proposed in the 1970s and mainly focused on Al-based alloys. Birchenall and Riechman et al. [18] investigated the thermophysical properties of several binary and ternary eutectic alloys containing elements $\mathrm{Al}, \mathrm{Cu}, \mathrm{Mg}, \mathrm{Si}, \mathrm{Zn}$, and found that alloys rich in $\mathrm{Al}$ or Si had large heat storage density. Farkas and Birchenall [19] further extended the investigation to eutectic alloys containing elements Ca and P. Cherneeva et al. [20] studied the heat storage performance of Al-based alloys and found that the heat storage density per unit volume could reach $1600 \mathrm{~kJ} / \mathrm{L}$ with good stability. Achard et al. [21] measured the thermophysical properties of $\mathrm{Al}-\mathrm{Mg}$ alloys and found that $\mathrm{Al}-\mathrm{Mg}$ alloys were suitable for $723 \mathrm{~K}$, but had strong corrosivity. Wang et al. [22] studied the heat storage performance of eutectic and hypereutectic Al-Si alloys and found that the eutectic Al-Si alloy was suitable with a large latent heat and a high thermal conductivity. Wang et al. [23] measured the thermophysical properties of eutectic and hypereutectic Al-Si alloys and obtained the relations between thermophysical properties and Si mass ratios as well as temperatures. Li et al. [24] further added Fe to AlSi alloys based on mixed entropy principle to increase the latent heat. The latent heat of obtained ternary alloy 45 mol\% $\mathrm{Al}-40 \mathrm{~mol} \% \mathrm{Si}-15 \mathrm{~mol} \% \mathrm{Fe}$ was $17 \%$ higher than that of eutectic Al-Si alloys. Wei et al. [25] prepared ten Al-based alloys and found that adding $\mathrm{Cu}, \mathrm{Zn}$, and $\mathrm{Si}$ to Al-based alloys could reduce the melting temperature, while adding heavy metal elements could increase heat storage per unit volume.

Table 2. Thermophysical properties of selected metallic PCMs (mole ratio) [18]

\begin{tabular}{cccccc}
\hline Materials & $\begin{array}{c}T_{\mathrm{m}} \\
\mathrm{K}\end{array}$ & $\begin{array}{c}\Delta h \\
\mathrm{~kJ} / \mathrm{kg}\end{array}$ & $\begin{array}{c}c_{\mathrm{p}} \\
\mathrm{kJ} /(\mathrm{kg} \cdot \mathrm{K})\end{array}$ & $\begin{array}{c}\rho \\
\mathrm{kg} / \mathrm{m}^{3}\end{array}$ & $\begin{array}{c}k \\
\mathrm{~W} /(\mathrm{m} \cdot \mathrm{K})\end{array}$ \\
\hline $\mathrm{Li}$ & 452 & 663 & 3.98 & 534 & -- \\
$71 \% \mathrm{Mg}-29 \% \mathrm{Zn}$ & 616 & 138 & 1.04 & 4900 & $80(\mathrm{~s}) / 50(\mathrm{l})$ \\
$\mathrm{Zn}$ & 693 & 112 & 0.45 & 7140 & -- \\
62.5\% Al - 37.5\% Mg & 724 & 310 & 1.73 & 2300 & $80(\mathrm{~s}) / 50(\mathrm{l})$ \\
$66.8 \% \mathrm{Al}-17 \% \mathrm{Cu}-16.2 \% \mathrm{Mg}$ & 779 & 360 & 1.09 & 3050 & $115(\mathrm{~s}) / 75(\mathrm{l})$ \\
$82.5 \% \mathrm{Al}-17.5 \% \mathrm{Cu}$ & 821 & 351 & 1.11 & 3424 & $130(\mathrm{~s}) / 80(\mathrm{l})$ \\
$82.3 \% \mathrm{Al}-12.6 \% \mathrm{Si}-5.1 \% \mathrm{Mg}$ & 833 & 545 & 1.39 & 2300 & $200(\mathrm{~s}) / 70(\mathrm{l})$ \\
$87 \% \mathrm{Al}-13 \% \mathrm{Si}$ & 852 & 515 & 1.49 & 2250 & $180(\mathrm{~s}) / 70(\mathrm{l})$ \\
$\mathrm{Mg}$ & 922 & 368 & 1.34 & 1590 & 131 \\
$\mathrm{Al}$ & 934 & 400 & 1.29 & 2370 & 204 \\
$41.1 \% \mathrm{Mg}-52.9 \% \mathrm{Si}$ & 1219 & 774 & -- & 2000 & $26(\mathrm{~s}) / 20(\mathrm{l})$ \\
\hline
\end{tabular}

In addition to Al-based alloys, Mg-based alloys are also studied. Rodríguez-Aseguinolaza et al. [26] performed theoretical and experimental studies on the phase change behaviour of eutectic Mg-Zn alloys and found that there existed two phase-change peaks due to the eutectoid reaction of MgZn mesophase/Mg phase and the solid-liquid phase change, respectively. Fang et al. [27] prepared three kinds of Mg-Bi alloys with different mass ratios and studied their heat storage characteristics, showing that the melting temperatures and latent heat ranged from $819 \mathrm{~K}$ to $821 \mathrm{~K}$ and from $48.7 \mathrm{~kJ} / \mathrm{kg}$ to $180.5 \mathrm{~kJ} / \mathrm{kg}$, respectively. 


\subsubsection{Inorganic salts and their eutectics}

Inorganic salts are suitable medium/high-temperature PCMs with a wide temperature coverage (423 K-1953 K), high latent heat (68 kJ/kg-1041 kJ/kg), low vapour pressure, no obvious undercooling/phase separation and low costs. However, inorganic salts and their eutectics suffer from heat transfer and corrosion problems, which are discussed in Section 3. Common pure inorganic salts include nitrates, carbonates, chlorates, fluorides and so on. Table 3 shows the thermophysical properties of some pure inorganic salts as PCMs. However, due to the wide temperature coverage and limited material types, there exist large uncovered temperature gaps, which requires inorganic salt eutectics to fill.

Table 3. Thermophysical properties of selected pure inorganic salts as PCMs [28]

\begin{tabular}{cccccc}
\hline \multirow{2}{*}{ Materials } & $\begin{array}{c}T_{\mathrm{m}} \\
\mathrm{K}\end{array}$ & $\begin{array}{c}\Delta h \\
\mathrm{~kJ} / \mathrm{kg}\end{array}$ & $\begin{array}{c}c_{\mathrm{p}} \\
\mathrm{kJ} /(\mathrm{kg} \cdot \mathrm{K})\end{array}$ & $\begin{array}{c}\rho \\
\mathrm{kg} / \mathrm{m}^{3}\end{array}$ & $\begin{array}{c}k \\
\mathrm{~W} /(\mathrm{m} \cdot \mathrm{K})\end{array}$ \\
\hline $\mathrm{NaNO}_{3}$ & $579-583$ & $172-199$ & $1.1(\mathrm{~s}) / 1.82(\mathrm{l})$ & $2257-2261$ & $0.5(\mathrm{~s})$ \\
$\mathrm{KNO}_{3}$ & $603-609$ & $88-266$ & $0.935(\mathrm{~s}) / 1.22(\mathrm{l})$ & $2109-2110$ & $0.5(\mathrm{~s}) / 0.5(\mathrm{l})$ \\
$\mathrm{MgCl}_{2}$ & 987 & $452-454$ & -- & 2140 & -- \\
$\mathrm{NaCl}$ & $1073-1075$ & $466.7-492$ & -- & 2160 & $5(\mathrm{~s})$ \\
$\mathrm{LiF}$ & $1121-1141$ & $932-1041$ & -- & -- & -- \\
$\mathrm{Na}_{2} \mathrm{CO}_{3}$ & $1127-1131$ & $165-275.7$ & -- & 2533 & $2(\mathrm{~s})$ \\
$\mathrm{KF}$ & $1130-1131$ & $452-507$ & -- & 2370 & -- \\
$\mathrm{K}_{2} \mathrm{CO}_{3}$ & $1170-1173$ & $200-235.8$ & -- & 2290 & $2(\mathrm{~s})$ \\
\hline
\end{tabular}

Nitrates and their eutectics usually melt at relatively low temperatures and decompose above $773 \mathrm{~K}$ with little corrosion and low costs, which makes them ideal heat transfer fluids (HTFs) and SHS media in solar thermal power generation [29]. Commercial nitrates and their eutectics, such as Solar Salt, Hitec and Hitec XL, have been extensively investigated in this context. However, when used as PCMs, more attention should be paid to their melting temperature and latent heat. Iverson et al. [30] studied the solid-liquid phase change characteristics of Solar Salt, Hitec and Na-K-Li-Ca nitrate, measured their thermophysical properties and evaluated their performance as PCMs. Roget et al. [31] measured the melting temperature, latent heat and density of $\mathrm{KNO}_{3}-\mathrm{LiNO}_{3}$ eutectics and $\mathrm{KNO}_{3}$ $\mathrm{NaNO}_{3}-\mathrm{LiNO}_{3}$ eutectics and obtained that the corresponding heat storage densities were $89 \mathrm{kWh} / \mathrm{m}^{3}$ and $86 \mathrm{kWh} / \mathrm{m}^{3}$. Zhao et al. [32] prepared $\mathrm{NaNO}_{3}-\mathrm{Ca}\left(\mathrm{NO}_{3}\right)_{2}$ eutectics and obtained that melting temperature and latent heat were $491 \mathrm{~K}$ and $135.8 \mathrm{~kJ} / \mathrm{kg}$, respectively, with a cost $35 \%$ lower than solar salt.

Compared to nitrates, chlorides and their eutectics have higher melting temperatures and severer corrosivity. Chlorides and their eutectics are also mainly studied as HTFs with insufficient research on their phase-change properties. Myers et al. [33] evaluated and selected single and binary chlorides suitable for PCMs based on the criteria that the cost was lower than $\$ 0.2 / \mathrm{kJ}$ latent heat. Du et al. [34] prepared $\mathrm{NaCl}-\mathrm{CaCl}_{2}-\mathrm{MgCl}_{2}$ eutectics and measured melting temperature, latent heat and specific heat capacity to be $694 \mathrm{~K}, 201.5 \mathrm{~kJ} / \mathrm{kg}$ and $1.49 \mathrm{~kJ} /(\mathrm{kg} \cdot \mathrm{K})$, respectively, with good thermal stability at $923 \mathrm{~K}$.

Different from nitrates and chlorides, carbonates and their eutectics have a high viscosity coefficient and are easy to decompose at high temperatures. Ren et al. [35] prepared 36 kinds of carbonates by mixing $\mathrm{K}_{2} \mathrm{CO}_{3}, \mathrm{Li}_{2} \mathrm{CO}_{3}$ and $\mathrm{Na}_{2} \mathrm{CO}_{3}$ according to different mass proportions, six kinds of which were considered to be the optimal selection as PCMs in solar thermal power generation with their costs lower than $\$ 100 / \mathrm{kWh}$ and larger latent heat.

Fluorides and their eutectics usually have high melting points and large latent heats, and can be used in space thermal management systems. Misra [36] studied the thermophysical properties of fluoride salts and recommended fluoride salts for four temperature ranges between $1000 \mathrm{~K}$ and $1400 \mathrm{~K}$ based on melting temperature and heat storage density. Although the heat storage density of these salts is high, they experience relatively severe undercooling and corrosion problems. 


\subsection{Thermochemical heat storage media}

\subsubsection{Metallic oxides/hydroxides}

\subsubsection{1 $\mathrm{CaO} / \mathrm{Ca}(\mathrm{OH})_{2}$}

The reversible chemical reaction is:

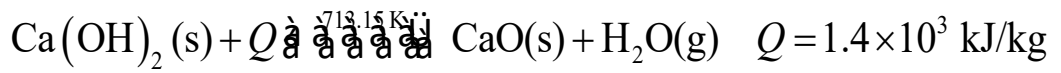

So far, $\mathrm{CaO} / \mathrm{Ca}(\mathrm{OH})_{2}$ reversible reaction equilibrium has been extensively studied. Schaube et al. [37] measured the decomposition process of $\mathrm{Ca}(\mathrm{OH})_{2}$ under $\mathrm{N}_{2}$ and obtained that the decomposition rate of $\mathrm{Ca}(\mathrm{OH})_{2}$ was affected by the ambient temperature, the reaction gas pressure and the reaction process. The synthesis process of $\mathrm{CaO}$ and water vapour was also experimentally carried out, which showed that the hydration rate was related to the ambient temperature, the vapour pressure and the reaction process. Criado et al. [38] measured the reaction rate of $\mathrm{Ca}(\mathrm{OH})_{2}$ decomposition and synthesis processes at a water vapour pressure of 0-100 $\mathrm{kPa}$ and an ambient temperature of $723 \mathrm{~K}$ and obtained the corresponding reaction governing equations of decomposition and synthesis processes.

Moreover, some additives can change the decomposition behaviour of $\mathrm{Ca}(\mathrm{OH})_{2}$. Murthy et al. [39] compared the decomposition of $\mathrm{Ca}(\mathrm{OH})_{2}$ with the addition of $\mathrm{Ni}(\mathrm{OH})_{2}, \mathrm{Zn}(\mathrm{OH})_{2}$ and $\mathrm{Al}(\mathrm{OH})_{3}$ and found that the changes in chemical reaction rates and decomposition temperatures were due to the lattice defects and the potential nucleation sites caused by the additives. Fujii etal. [40] studied the effect of pure metal particles as additives on the decomposition of $\mathrm{Ca}(\mathrm{OH})_{2}$ particles and found that only $\mathrm{Al}$ and $\mathrm{Zn}$ particles could greatly increase the decomposition rate at $723 \mathrm{~K}$. The reason is that $\mathrm{Zn}$ particles could reduce the activation energy of $\mathrm{Ca}(\mathrm{OH})_{2}$ interface reaction, while Al particles could form a new substance $\mathrm{Ca}_{3} \mathrm{Al}_{2}(\mathrm{OH})_{12}$.

\subsubsection{2 $\mathrm{MgO} / \mathrm{Mg}(\mathrm{OH})_{2}$}

The reversible chemical reaction is:

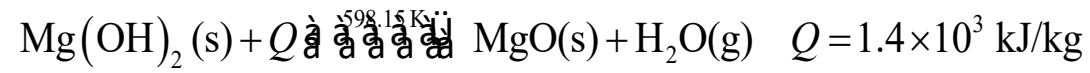

Compared to $\mathrm{CaO} / \mathrm{Ca}(\mathrm{OH})_{2}, \mathrm{MgO} / \mathrm{Mg}(\mathrm{OH})_{2}$ can store heat above $573 \mathrm{~K}$ and be applied to a lower temperature. Kato et al. [41] first introduced the $\mathrm{MgO} / \mathrm{Mg}(\mathrm{OH})_{2}$ reversible thermochemical reaction to TES applications. Kato et al. [42] found that the reaction equilibrium between $\mathrm{MgO}$ and $\mathrm{Mg}(\mathrm{OH})_{2}$ was related to the ambient temperature and the vapour pressure, which belonged to the second type of equilibrium in Brunauer's chemical reaction equilibrium.

Adding other elements to form composite $\mathrm{Mg}(\mathrm{OH})_{2}$ materials can also reduce the decomposition temperature and increase the decomposition rate of $\mathrm{Mg}(\mathrm{OH})_{2}$. Junichi et al. [43] added $6.8 \mathrm{wt} \% \mathrm{LiCl}, 6.4 \mathrm{wt} \% \mathrm{NaCl}$ and $16.0 \mathrm{wt} \%$ $\mathrm{CaCl}_{2}$ to $\mathrm{Mg}(\mathrm{OH})_{2}$ and found the decomposition temperatures decreased to $506 \mathrm{~K}, 540 \mathrm{~K}$ and $544 \mathrm{~K}$, respectively. The reason is that the additives could reduce the activation energy of $\mathrm{Mg}(\mathrm{OH})_{2}$ decomposition and have a strong ability to adsorb water. Kato et al. [44] added $\mathrm{Ni}(\mathrm{OH})_{2}$ to $\mathrm{Mg}(\mathrm{OH})_{2}$ and found the decomposition temperature depended on the mass ratios of $\mathrm{Ni}(\mathrm{OH})_{2}$ and $\mathrm{Mg}(\mathrm{OH})_{2}$. Shkatulov et al. [45] found that doping expanded vermiculite into $\mathrm{Mg}(\mathrm{OH})_{2}$ could also reduce the decomposition temperature by about $50 \mathrm{~K}$, but the mechanism was still unclear.

\subsubsection{Metals/metal hydrides}

Among the metals/metal hydrides, $\mathrm{Mg} / \mathrm{MgH}_{2}$ receives the most attention due to the large heat storage density and wide heat storage temperature ranges. The reversible chemical reaction is:

$$
\mathrm{MgH}_{2}(\mathrm{~s})+Q \text { 主 }
$$

Bogdanović et al. [46] first proposed that the $\mathrm{Mg} / \mathrm{MgH}_{2}$ system could be used for heat storage and successfully 
accelerated the rate of decomposition and hydrogen absorption by adding Ni powders. Chaise et al. [47] experimentally obtained the reaction equilibrium parameters of $\mathrm{Mg} / \mathrm{MgH}_{2}$ and found that the synthesis process of $\mathrm{Mg}$ and $\mathrm{H}_{2}$ followed two different governing equations when the $\mathrm{H}_{2}$ pressure was more than twice the equilibrium pressure or close to the equilibrium pressure.

\subsubsection{Oxides/carbonates}

\subsubsection{1 $\mathrm{CaO} / \mathrm{CaCO}_{3}$}

The reversible chemical reaction is:

$$
\mathrm{CaCO}_{3}(\mathrm{~s})+Q \text { 安 }
$$

Barker [39] proposed the use of a reversible reaction between $\mathrm{CaO}$ and $\mathrm{CaCO}_{3}$ to achieve high heat storage density, and performed tests to show that $\mathrm{CaCO}_{3}$ could decompose and store heat above $1139 \mathrm{~K}$. The decomposition process of $\mathrm{CaCO}_{3}$ can be $100 \%$ completed in the cycle, while the synthesis of $\mathrm{CO}_{2}$ and $\mathrm{CaO}$ is reduced significantly after multiple cycles. However, it was also found that particles with a diameter below $44 \mathrm{~nm}$ could relatively improve the cycling stability.

\subsubsection{Other oxides/carbonates}

$\mathrm{PbCO}_{3}$ and $\mathrm{SrCO}_{3}$ are also potential THS materials. The reversible chemical reactions are:

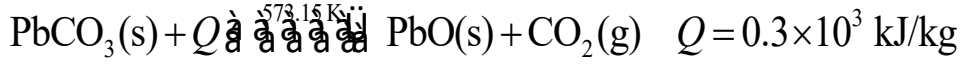

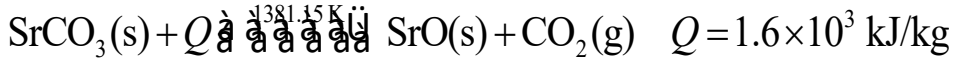

The $\mathrm{PbO} / \mathrm{PbCO}_{3}$ system is mainly used to form a chemical heat pump with the $\mathrm{CaO} / \mathrm{CaCO}_{3}$ system [48]. The decomposition of $\mathrm{PbCO}_{3}$ can be further divided into three sub-processes, which are completed at 573.15-603 $\mathrm{K}$, 623.15-703 K and 713.15-723 K, respectively, while $\mathrm{PbO}$ can react with $\mathrm{CO}_{2}$ under $0.4 \mathrm{~atm}$ at $573 \mathrm{~K}$ to release heat. As for the $\mathrm{SrO} / \mathrm{SrCO}_{3}$ system, it is suitable for heat storage applications above $1273 \mathrm{~K}$.

\subsubsection{Oxides in redox reactions}

In redox reactions, $\mathrm{O}_{2}$ is used as the gas reactant, making it possible to use air directly as a reaction gas as well as a HTF for heat discharging. However, redox reactions also have limitations, such as cycle instability and low heat storage density.

\subsubsection{1 $\mathrm{CoO} / \mathrm{Co}_{3} \mathrm{O}_{4}$}

The reversible chemical reaction is:

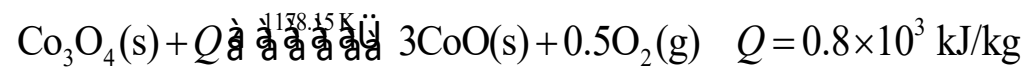

Wong et al. [49] experimentally verified that $\mathrm{CoO} / \mathrm{Co}_{3} \mathrm{O}_{4}$ had good kinetic properties. Agrafiotis et al. [50] obtained that the $\mathrm{CoO} / \mathrm{Co}_{3} \mathrm{O}_{4}$ should be operated between $1073 \mathrm{~K}$ and $1273 \mathrm{~K}$. Pagkoura et al. [51] found that adding cerium oxide could increase the reaction rate. However, $\mathrm{CoO}$ is considered as a carcinogen with a relatively high price.

\subsubsection{2 $\mathrm{Mn}_{3} \mathrm{O}_{4} / \mathrm{Mn}_{2} \mathrm{O}_{3}$}

The reversible chemical reaction is:

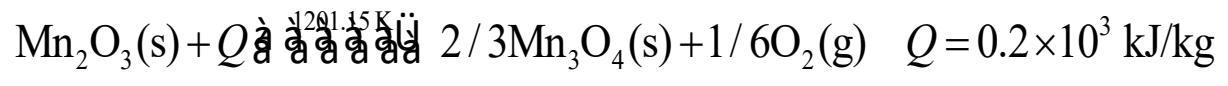


Although the reaction heat of $\mathrm{Mn}_{3} \mathrm{O}_{4} / \mathrm{Mn}_{2} \mathrm{O}_{3}$ is much smaller than that of $\mathrm{CoO} / \mathrm{Co}_{3} \mathrm{O}_{4}$, they are less toxic and much cheaper. In addition, there exists a hysteresis effect during the heat charging and discharging processes for $\mathrm{Mn}_{3} \mathrm{O}_{4} / \mathrm{Mn}_{2} \mathrm{O}_{3}$. It was found that adding iron to $\mathrm{Mn}_{2} \mathrm{O}_{3}$ could reduce the hysteresis effect, but the decomposition temperature would rise to $1323 \mathrm{~K}$, which was more likely to cause sintering [52]. Carrillo et al. [53] further added $20 \% \mathrm{~mol} \mathrm{Fe}$ and $5 \% \mathrm{~mol} \mathrm{Cu}$ and reduced the temperature difference between decomposition and oxidation from $225 \mathrm{~K}$ to $81 \mathrm{~K}$.

\section{Technical challenges in latent heat storage}

Inorganic salts usually suffer from a low thermal conductivity of around $0.5 \mathrm{~W} /(\mathrm{m} \cdot \mathrm{K})$, which makes it difficult to achieve a flexible heat transfer rate; however, this is not a problem for metals and their alloys. Common issues that metals and inorganic salts face are stability and corrosion.

\subsection{Heat transfer enhancement}

Heat transfer enhancement measures or solutions for inorganic salt PCMs can be divided into those that act at the material level, the component level and the system level.

\subsubsection{Challenges and opportunities at the material level}

\subsubsection{Incorporating highly thermal conductive particles}

Common highly thermal conductive particles consist of metallic particles, ceramic particles, carbon particles and so on. Metallic particles (e.g., Al, Cu and Mg) usually have high thermal conductivities, but settlement in inorganic salts caused by the density difference is easy to happen. Allowing for the density difference, Tian et al. [54] designed Mg particledoped eutectic ternary carbonate salts whose thermal conductivities are 19.6-45.1\% higher than that of the pure salt.

However, metallic particles may be hampered by oxidative degradation in molten salts at high temperatures, especially in nitrates, so oxide particles (e.g., $\mathrm{SiO}_{2}, \mathrm{CuO}, \mathrm{MgO}, \mathrm{Al}_{2} \mathrm{O}_{3}, \mathrm{ZnO}, \mathrm{Fe}_{2} \mathrm{O}_{3}$ ) are selected due to the excellent corrosion resistance and thermal stability. Shin and Banerjee [55] added $1 \mathrm{wt} \% \mathrm{SiO}_{2}$ nanoparticles into a binary carbonate eutectics and enhanced the thermal conductivity by $36-47 \%$ at $423-573 \mathrm{~K}$, which was considered to be caused by the interconnected substructures of higher density eutectic materials. Myers et al. [56] blended $\mathrm{CuO}$ nanoparticles in $\mathrm{NaNO}_{3}, \mathrm{KNO}_{3}$ and their eutectics, respectively. When the volume ratio of $\mathrm{CuO}$ particles was approximately $2 \%$, thermal conductivity increased significantly for both $\mathrm{KNO}_{3}$ and eutectics, which, however, increased only under $423 \mathrm{~K}$ for $\mathrm{NaNO}_{3}$. Wei et al. [57] doped $\mathrm{MgO}$ particles in Solar Salt and a ternary carbonate eutectics and showed that heat transfer performance of these two salts was both significantly enhanced with the addition of $\mathrm{MgO}$ particles. Saranprabhu et al. [58] added MgO nanoparticles to Solar Salt and obtained the highest thermal conductivity enhancement of $17.5 \%$ with $0.25 \mathrm{wt} \% \mathrm{MgO}$, which might be resulted from the reduced thermal resistance caused by the clustered nature of $\mathrm{MgO}$ nanoparticles. Han et al. [59] studied the effect of $\mathrm{Al}_{2} \mathrm{O}_{3}$ nanoparticle sizes on the thermophysical properties of Solar Salt. Thermal conductivity increased for all nanoparticles sizes at $413 \mathrm{~K}$ and $433 \mathrm{~K}$, but increased only for 300-nm and 1000-nm nanoparticles at $453 \mathrm{~K}$. Zhang et al. [60] measured the thermal conductivities of a ternary carbonate improved by three nano- $\mathrm{Al}_{2} \mathrm{O}_{3}$ samples at $298 \mathrm{~K}$ and found thermal conductivity was improved by $23.3 \%, 28.5 \%$ and $30.9 \%$, respectively. Zhang et al. [61] further modified the same ternary carbonate by $0.2-2.0 \mathrm{wt} \% \mathrm{~T}-\mathrm{ZnOw}$. The ternary salt containing $1.4 \mathrm{wt} \% \mathrm{~T}-\mathrm{ZnOw}$ had the highest thermal conductivity of $4.483 \mathrm{~W} /(\mathrm{m} \cdot \mathrm{K})$. Awad et al. [62] investigated the effect of $\mathrm{Fe}_{2} \mathrm{O}_{3}$ and $\mathrm{CuO}$ nanoparticles on the thermal conductivity of Solar Salt up to $773 \mathrm{~K}$. The results showed that $\mathrm{CuO}$ concentration from $0.5 \mathrm{wt} \%$ to $1.5 \mathrm{wt} \%$ had a negative effect on the thermal conductivity, while $\mathrm{Fe}_{2} \mathrm{O}_{3}$ nanoparticles increased the thermal conductivity except the case of $1 \mathrm{wt} \%$. 
Beyond oxide particles, high-thermal-conductivity ceramic particles (e.g., SiC) are also dispersed in inorganic salts to enhance heat transfer. Ueki et al. [63] increased the thermal conductivity of a ternary nitrate salt by mixing SiC nanoparticles and noted that the Brownian motion of nanoparticles did not significantly influence the thermal conductivity. Jiang et al. [64] added SiC nanoparticles to form-stable $\mathrm{K}_{2} \mathrm{CO}_{3} / \mathrm{Na}_{2} \mathrm{CO}_{3}-\mathrm{MgO}$ composite PCMs. An addition of $10 \mathrm{wt} \% \mathrm{SiC}$ particles enhanced the overall thermal conductivity from $1.94 \mathrm{~W} /(\mathrm{m} \cdot \mathrm{K})$ to $2.28 \mathrm{~W} /(\mathrm{m} \cdot \mathrm{K})$. Deng et al. [65] prepared a novel composite by doping minor amount of $\mathrm{SiC}$ into $\mathrm{Na}_{2} \mathrm{CO}_{3}-\mathrm{K}_{2} \mathrm{CO}_{3}$ eutectics and revealed that $\mathrm{SiC}$ could increase phase change enthalpy and decrease thermal conductivity, which, however, was different from the previous results.

Carbon materials have very high thermal conductivities, as well as relatively low densities and high corrosion resistance. Pincemin et al. [66] dispersed graphite flakes and expanded graphite powders in Solar Salt and showed that at $20 \mathrm{wt} \%$ graphite, a large particle size was favourable to create a conductive network, while at $10 \mathrm{wt} \%$ graphite, a larger particle size led to a decreased thermal conductivity. Lachheb et al. [67] adopted cold uniaxial compression method to prepare $\mathrm{LiNO}_{3} /$ graphite composites containing 0-20 wt\% graphite. The thermal conductivity increased with the mass fraction of graphite, but graphite particles suffer from relatively poor dispersibility due to surface tension. Ge et al. [68] introduced a micro-structured composite material to solve the incompatibility between molten salts and carbon particles. A $10 \mathrm{wt} \%$ carbon increased the thermal conductivity over $4.3 \mathrm{~W} /(\mathrm{m} \cdot \mathrm{K})$.

Carbon nanotubes and graphene have also been investigated as additives due to their large external surfaces, good thermal conductivities and high mechanical stability. Ye et al. [69] added multi-walled carbon nanotubes (MWCNTs) to $\mathrm{Na}_{2} \mathrm{CO}_{3} / \mathrm{MgO}$ composites and demonstrated the uniform dispersion of MWCNTs. The thermal conductivity was found to increase with the weight fraction of MWCNTs and the testing temperature. Hamdy et al. [70] mixed Solar Salt with 0.1-1.5 wt $\%$ MWCNTs and enhanced the thermal conductivity by 21.9-50.9\%. Wu et al. [71] prepared Solar Salt/MWCNTs composites with smaller MWCNT amounts by Hamdy's method and showed that $0.3 \mathrm{wt} \%$ MWCNTs could increase the thermal conductivity by a factor of 3. The improvement might be attributed to the uniform dispersion of MWCNTs and tiny thermally conductive channels between molten salts and MWCNTs. Different from MWCNTs, graphene has a unique two-dimensional planar structure. Dayou et al. [72] used CVD method to grow graphene on Mg0 surface in salts for thermal conductivity enhancement and achieved an increase in thermal conductivity from $0.693 \mathrm{~W} /(\mathrm{m} \cdot \mathrm{K})$ to 1.338 $\mathrm{W} /(\mathrm{m} \cdot \mathrm{K})$. Tao et al. [73] compared the effect of single-walled carbon nanotubes (SWCNTs), MWCNT, graphene and C60 on the thermal conductivity of $\mathrm{Li}_{2} \mathrm{CO}_{3}-\mathrm{K}_{2} \mathrm{CO}_{3}$ eutectics. The enhancement degree was largest with SWCNT, followed by MWCNT and graphene, while with $\mathrm{C} 60$ as additives, thermal conductivity was weakened. Table 4 summarizes the effect of thermal conductive particles on the thermal conductivity of inorganic salts.

\subsubsection{Embedding highly thermal conductive porous media}

A porous medium is a kind of material that contains a solid matrix with interconnected or disconnected pores, which can be saturated by PCMs to realize heat storage. High thermal conductivity of the matrix and large specific surface areas inside porous media are beneficial in enhancing heat transfer through the material.

When the pores are small enough, for example, at nano- or micro-scale, PCMs can maintain their original shape without any leakage during phase change owing to capillary forces, which makes form-stable composite PCMs possible. Usually, porous ceramics and expanded graphite (EG) are adopted. Guo and Wang [74] prepared a form-stable $\mathrm{NaNO}_{3} / \mathrm{SiO}_{2}$ composite PCM by a sol-gel procedure and determined the maximal weight ratio of $\mathrm{NaNO}_{3}$ to be $60 \%$. Jiang et al. [75] developed a form-stable nitrate/calcium silicate composite PCM by cold compression and sintering, and measured thermal conductivity to be $1.177 \mathrm{~W} /(\mathrm{m} \cdot \mathrm{K})$. Li et al. [76] characterized a form-stable $\mathrm{NaNO}_{3} /$ expanded perlite composite PCM and found the thermal conductivity was not high enough and decreased with the mass ratio of expanded perlite. From the previous studies, it is concluded that the heat transfer enhancement is still limited for ceramic form-stable composite PCMs due to the relatively low thermal conductivities of ceramic materials. 
Table 4. Effect of highly thermal conductive particles on the thermal conductivity of inorganic salts Salts Composite salts

\begin{tabular}{|c|c|c|c|c|c|c|}
\hline \multicolumn{2}{|l|}{ Salts } & \multicolumn{3}{|c|}{ Additives } & \multirow{2}{*}{$\begin{array}{c}\text { Composite salts } \\
\text { Thermal conductivity } \\
\mathrm{W} /(\mathrm{m} \cdot \mathrm{K})\end{array}$} & \multirow[b]{2}{*}{ Refs. } \\
\hline Material & $\begin{array}{l}\text { Thermal conductivity } \\
\qquad \mathrm{W} /(\mathrm{m} \cdot \mathrm{K})\end{array}$ & Material & Size & Amount & & \\
\hline $32.2 \% \mathrm{Li}_{2} \mathrm{CO}_{3}-33.2 \% \mathrm{Na}_{2} \mathrm{CO}_{3}-34.5 \% \mathrm{~K}_{2} \mathrm{CO}_{3}, \mathrm{wt} \%$ & 1.328 & $\mathrm{Mg}$ & 100-200 meshes & 0.1 wt $\%$ & 1.590 & {$[54]$} \\
\hline \multirow{3}{*}{$62 \% \mathrm{Li}_{2} \mathrm{CO}_{3}-38 \% \mathrm{~K}_{2} \mathrm{CO}_{3}, \mathrm{wt} \%$} & $0.455(423 \mathrm{~K})$ & \multirow{3}{*}{$\mathrm{SiO}_{2}$} & \multirow{3}{*}{$10-30 \mathrm{~nm}$} & \multirow{3}{*}{$1 \mathrm{wt} \%$} & $0.668(423 \mathrm{~K})$ & \multirow{3}{*}[55]{} \\
\hline & $0.498(498 \mathrm{~K})$ & & & & $0.678(498 \mathrm{~K})$ & \\
\hline & $0.493(573 \mathrm{~K})$ & & & & $0.677(573 \mathrm{~K})$ & \\
\hline \multirow{4}{*}{ Solar Salt } & \multirow{4}{*}{0.779} & \multirow{4}{*}{$\mathrm{MgO}$} & \multirow{4}{*}{--} & $0.25 \mathrm{wt} \%$ & 0.883 & \multirow{4}{*}[58]{} \\
\hline & & & & $0.5 \mathrm{wt} \%$ & 0.853 & \\
\hline & & & & $1 \mathrm{wt} \%$ & 0.858 & \\
\hline & & & & $2 \mathrm{wt} \%$ & 0.872 & \\
\hline \multirow{3}{*}{$32.1 \% \mathrm{Li}_{2} \mathrm{CO}_{3}-33.4 \% \mathrm{Na}_{2} \mathrm{CO}_{3}-34.5 \% \mathrm{~K}_{2} \mathrm{CO}_{3}, \mathrm{wt} \%$} & \multirow{3}{*}{$1.674(298 \mathrm{~K})$} & \multirow{3}{*}{$\mathrm{Al}_{2} \mathrm{O}_{3}$} & $20 \mathrm{~nm}$ & $1.0 \mathrm{wt} \%$ & $2.064(298 \mathrm{~K})$ & \multirow{3}{*}[60]{} \\
\hline & & & $50 \mathrm{~nm}$ & $1.0 \mathrm{wt} \%$ & $2.148(298 \mathrm{~K})$ & \\
\hline & & & $80 \mathrm{~nm}$ & $0.8 \mathrm{wt} \%$ & $2.191(298 \mathrm{~K})$ & \\
\hline \multirow{6}{*}{$32.1 \% \mathrm{Li}_{2} \mathrm{CO}_{3}-33.4 \% \mathrm{Na}_{2} \mathrm{CO}_{3}-34.5 \% \mathrm{~K}_{2} \mathrm{CO}_{3}, \mathrm{wt} \%$} & \multirow{6}{*}{1.674} & \multirow{6}{*}{$\mathrm{T}-\mathrm{ZnOw}$} & \multirow{6}{*}{--} & $0.2 \mathrm{wt} \%$ & 2.063 & \multirow{6}{*}[61]{} \\
\hline & & & & $0.4 w \mathrm{w} \%$ & 2.641 & \\
\hline & & & & $0.8 w \mathrm{t} \%$ & 3.363 & \\
\hline & & & & $1.0 \mathrm{wt} \%$ & 3.892 & \\
\hline & & & & $1.4 \mathrm{wt} \%$ & 4.483 & \\
\hline & & & & $2.0 \mathrm{wt} \%$ & 4.363 & \\
\hline \multirow{8}{*}{ Solar Salt } & $0.790(298 \mathrm{~K})$ & \multirow{7}{*}{$\mathrm{Fe}_{2} \mathrm{O}_{3}$} & & & 1.020 & \\
\hline & $0.687(373 \mathrm{~K})$ & & & & 0.823 & \\
\hline & $0.359(473 \mathrm{~K})$ & & & & 0.524 & \\
\hline & $0.589(523 \mathrm{~K})$ & & $20-40 \mathrm{~nm}$ & $0.5 \mathrm{wt} \%$ & 0.830 & \\
\hline & $0.558(573 \mathrm{~K})$ & & & & 0.870 & {$[62]$} \\
\hline & $0.649(673 \mathrm{~K})$ & & & & 0.927 & {$[0<]$} \\
\hline & $0.742(723 \mathrm{~K})$ & & & & 1.076 & \\
\hline & $0.790(298 \mathrm{~K})$ & & & & 0.828 & \\
\hline Solar Salt & $0.589(523 \mathrm{~K})$ & $\mathrm{Fe}_{2} \mathrm{O}_{3}$ & $20-40 \mathrm{~nm}$ & $1 \mathrm{wt} \%$ & 0.566 & [62] \\
\hline
\end{tabular}




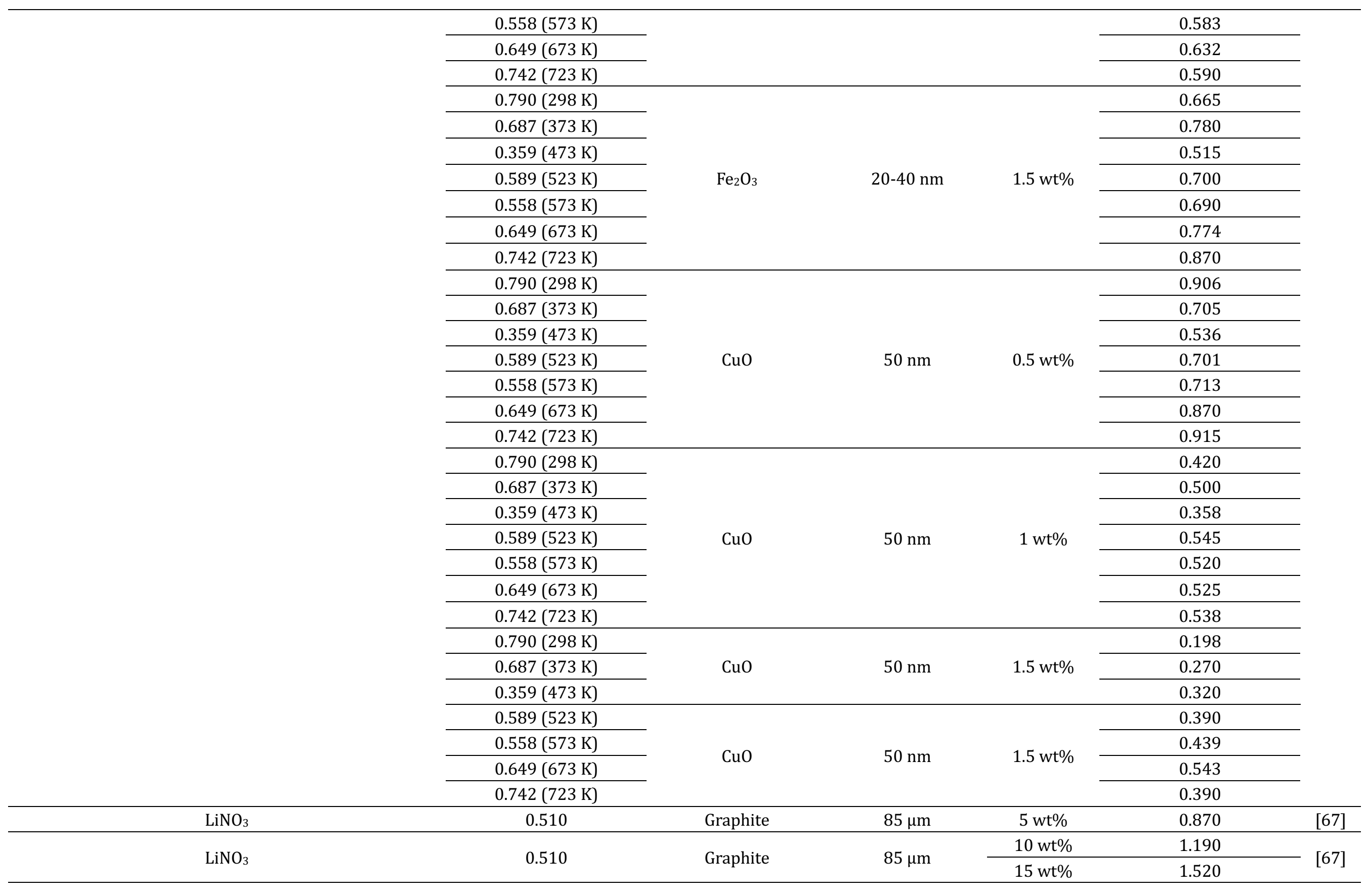




\begin{tabular}{|c|c|c|c|c|c|c|}
\hline & & & & $20 \mathrm{wt} \%$ & 1.860 & \\
\hline \multirow{12}{*}{$\mathrm{Na}_{2} \mathrm{CO}_{3} / \mathrm{MgO}$} & $0.750(313 \mathrm{~K})$ & \multirow{3}{*}{ MWCNT } & \multirow{3}{*}{$\begin{array}{l}l=10 \mu \mathrm{m} \\
d=11 \mathrm{~nm}\end{array}$} & \multirow{3}{*}{$0.1 \mathrm{wt} \%$} & 0.901 & \multirow{12}{*}{ [69] } \\
\hline & $0.825(348 \mathrm{~K})$ & & & & 1.025 & \\
\hline & $0.881(393 \mathrm{~K})$ & & & & 1.139 & \\
\hline & $0.750(313 \mathrm{~K})$ & \multirow{3}{*}{ MWCNT } & \multirow{3}{*}{$\begin{array}{l}l=10 \mu \mathrm{m} \\
d=11 \mathrm{~nm}\end{array}$} & \multirow{3}{*}{$0.2 \mathrm{wt} \%$} & 0.976 & \\
\hline & $0.825(348 \mathrm{~K})$ & & & & 1.131 & \\
\hline & $0.881(393 \mathrm{~K})$ & & & & 1.284 & \\
\hline & $0.750(313 \mathrm{~K})$ & \multirow{3}{*}{ MWCNT } & \multirow{3}{*}{$\begin{array}{l}l=10 \mu \mathrm{m} \\
d=11 \mathrm{~nm}\end{array}$} & \multirow{3}{*}{$0.3 \mathrm{wt} \%$} & 1.048 & \\
\hline & $0.825(348 \mathrm{~K})$ & & & & 1.196 & \\
\hline & $0.881(393 \mathrm{~K})$ & & & & 1.354 & \\
\hline & $0.750(313 \mathrm{~K})$ & \multirow{3}{*}{ MWCNT } & \multirow{3}{*}{$\begin{array}{l}l=10 \mu \mathrm{m} \\
d=11 \mathrm{~nm}\end{array}$} & \multirow{3}{*}{0.5 wt $\%$} & 1.127 & \\
\hline & $0.825(348 \mathrm{~K})$ & & & & 1.295 & \\
\hline & $0.881(393 \mathrm{~K})$ & & & & 1.489 & \\
\hline \multirow{2}{*}{ Solar Salt } & \multirow{2}{*}{$0.411(573 \mathrm{~K})$} & \multirow{2}{*}{ MWCNT } & \multirow{2}{*}{$\begin{array}{c}l=3-15 \mu \mathrm{m} \\
d=12-15 \mathrm{~nm}\end{array}$} & $0.3 \mathrm{wt} \%$ & 1.615 & \multirow{2}{*}{ [71] } \\
\hline & & & & $0.4 \mathrm{wt} \%$ & 0.780 & \\
\hline \multirow[t]{2}{*}{$49 \% \mathrm{Na}_{2} \mathrm{CO}_{3}-51 \% \mathrm{Li}_{2} \mathrm{CO}_{3}, \mathrm{wt} \%$} & \multirow[t]{2}{*}{0.693} & MgO+graphene & -- & -- & 1.243 & \multirow[t]{2}{*}{ [72] } \\
\hline & & graphene $/ \mathrm{Cu}+\mathrm{MgO}$ & -- & -- & 1.338 & \\
\hline
\end{tabular}


Different from porous ceramics, EG exhibits a worm-like microstructure with a high thermal conductivity of $160 \mathrm{~W} /(\mathrm{m} \cdot \mathrm{K})$, making it suitable as a supporting material in form-stable composites. Preparation methods for EG based composites include solution impregnation, melting infiltration, cold compression and physical mixing. Do Couto Aktay et al. [77] heterogeneously infiltrated and compressed two nitrite salts with EG. A significant increase in thermal conductivity was observed. Steinmann and Tamme [78] compressed Solar Salt with EG and also found the EG mass fraction influenced the effective thermal conductivity significantly. Acem et al. [79] proposed uniaxial compression and isostatic compression to prepare EG based composites. 15-20 wt\% EG led to apparent thermal conductivities close to $20 \mathrm{~W} /(\mathrm{m} \cdot \mathrm{K})$; uni-axial compression made composites highly orthotropic, while isostatic compression caused composites to show isotropic thermal behaviours. Xiao et al. [80] tested the apparent thermal conductivity of Solar Salt/EG mixtures in original powder state and measured the apparent thermal conductivity of Solar Salt/5-10 wt\% EG mixtures to increase by about 10-40\%. Xiao et al. [81] dispersed EG in Solar Salt and found a linear relation between thermal conductivity and EG mass ratio. Zhong et al. [82] added about $20 \mathrm{wt} \% \mathrm{EG}$ to $\mathrm{LiNO}_{3}-\mathrm{KCl}, \mathrm{LiNO}_{3}-\mathrm{NaNO}_{3}$ and $\mathrm{LiNO}_{3}-\mathrm{NaCl}$ and increased the thermal conductivity by 5.0 times, 6.9 times and 4.9 times, respectively. Huang et al. [83] prepared a $\mathrm{LiNO}_{3}-\mathrm{KCl} / \mathrm{EG}$ composite $\mathrm{PCM}$ and obtained with $20 \mathrm{wt} \% \mathrm{EG}$, thermal conductivity increased with the apparent density. Tian et al. [84] designed a ternary eutectic $\mathrm{NaCl}-\mathrm{CaCl}_{2}-\mathrm{MgCl}_{2} / \mathrm{EG}$ composite with $0.5-5 \mathrm{wt} \% \mathrm{EG}$ and increased the thermal conductivity by 34.8477.51\%. Li et al. [85] dispersed EG into $40 \mathrm{wt} \% \mathrm{LiNO}_{3}-60 \mathrm{wt} \% \mathrm{KNO}_{3}$. The thermal conductivity was 3-16 times larger than that of the binary nitrate and the thermal conductivity was close to that of the pure EG at $30 \mathrm{wt} \% \mathrm{EG}$. Liu et al. [86] explored a eutectic $\mathrm{MgCl}_{2}-\mathrm{KCl} / \mathrm{EG}$ composite and showed that thermal conductivity was measured to be $4.922 \mathrm{~W} /(\mathrm{m} \cdot \mathrm{K})$, which was 12 times that of eutectic salts. Xu et al. [87] prepared a $\mathrm{LiNO}_{3}-\mathrm{KCl}_{-} \mathrm{NaNO}_{3} / \mathrm{EG}$ composite. The thermal conductivity could be enhanced after adding EG and a linear relationship existed between thermal conductivity and compress density. Ren et al. [88] prepared a $\mathrm{Ca}\left(\mathrm{NO}_{3}\right)_{2}-\mathrm{NaNO}_{3} / \mathrm{EG}$ composite. There was no cracking with $7 \mathrm{wt} \% \mathrm{EG}$ and the thermal conductivity could be significantly increased by about 7.3 times. Table 5 summarizes the thermal conductivity of some form-stable composite PCMs. 
Table 5. The thermal conductivity of some form-stable composite PCMs

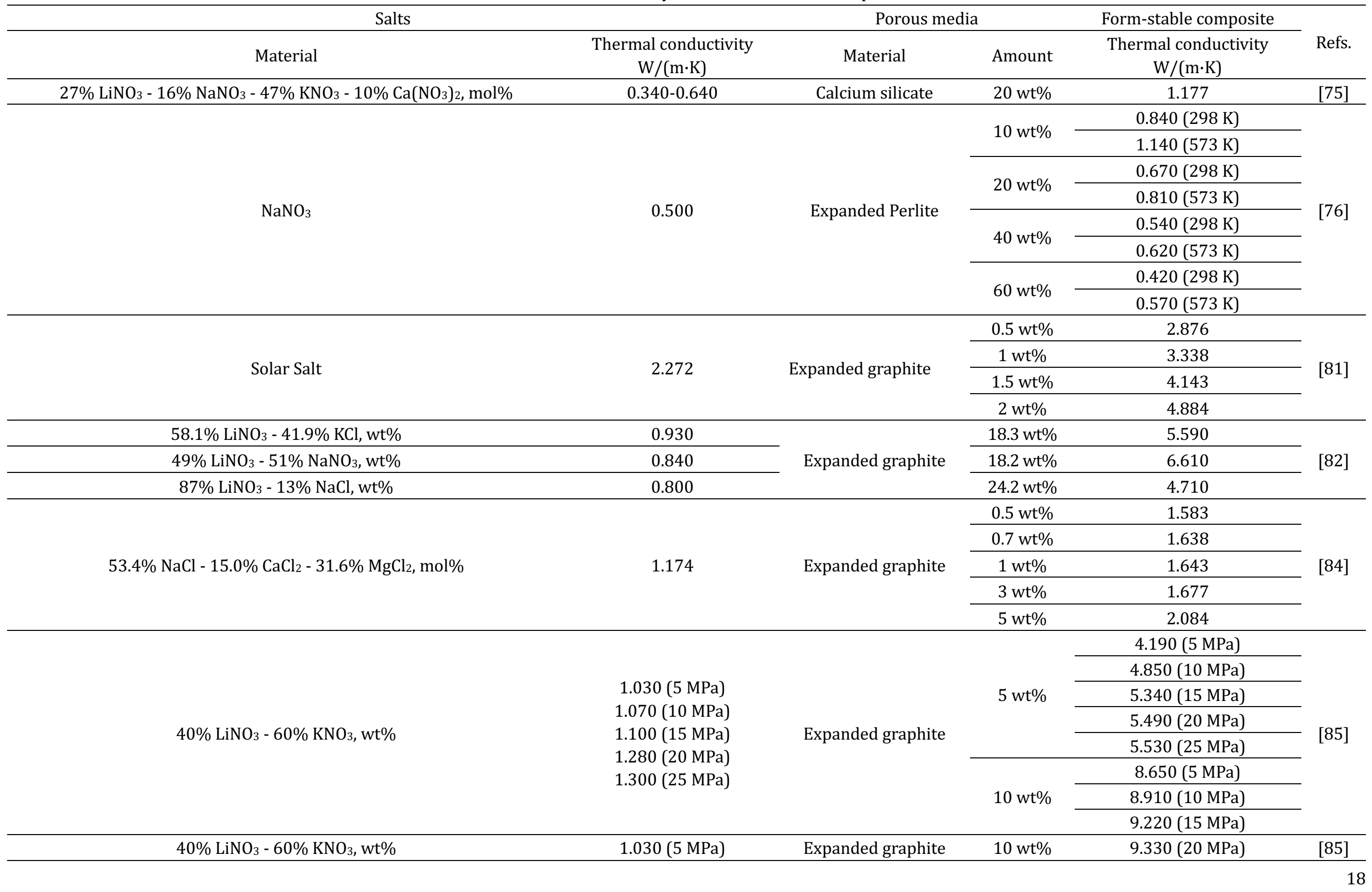




\begin{tabular}{|c|c|}
\hline & $9.530(25 \mathrm{MPa})$ \\
\hline \multirow{5}{*}{$15 \mathrm{wt} \%$} & $10.360(5 \mathrm{MPa})$ \\
\hline & $11.280(10 \mathrm{MPa})$ \\
\hline & $12.410(15 \mathrm{MPa})$ \\
\hline & $12.760(20 \mathrm{MPa})$ \\
\hline & $13.040(25 \mathrm{MPa})$ \\
\hline \multirow{5}{*}{$20 \mathrm{wt} \%$} & $14.390(5 \mathrm{MPa})$ \\
\hline & $14.650(10 \mathrm{MPa})$ \\
\hline & $15.120(15 \mathrm{MPa})$ \\
\hline & $15.360(20 \mathrm{MPa})$ \\
\hline & $15.620(25 \mathrm{MPa})$ \\
\hline \multirow{5}{*}{$30 \mathrm{wt} \%$} & $15.420(5 \mathrm{MPa})$ \\
\hline & $15.770(10 \mathrm{MPa})$ \\
\hline & $16.290(15 \mathrm{MPa})$ \\
\hline & $16.630(20 \mathrm{MPa})$ \\
\hline & $16.730(25 \mathrm{MPa})$ \\
\hline
\end{tabular}


Although EG can increase the thermal conductivity of inorganic salts, thermal conductivity anisotropy exists due to the discontinuous layered structures of EG, as shown in Figure 5 (a). Moreover, the density difference between supporting materials and PCMs in form-stable composite PCMs may result in phase segregation after several cycles, as shown in Figure 5 (b). Open-cell foam materials with connected and fixed skeletons are preferred and considered to be the promising supporting materials, such as metal foams and carbon foams.
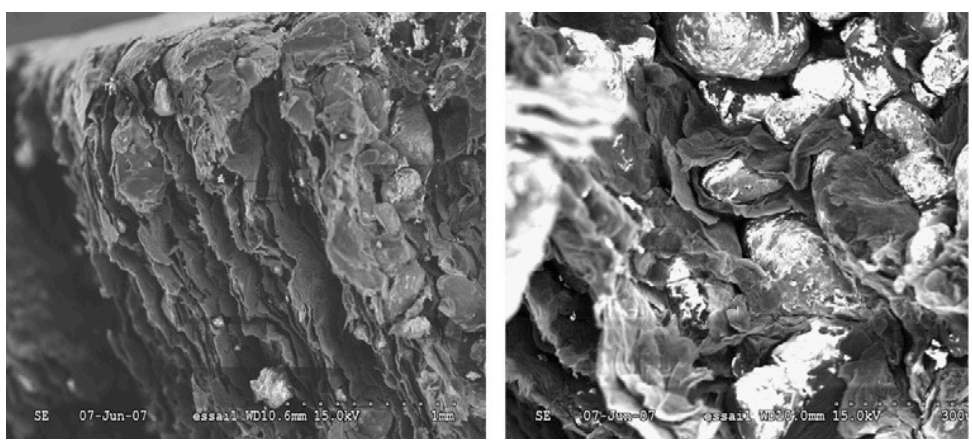

(a) SEM images of salt/EG composites by uni-axial cold-compression [89]

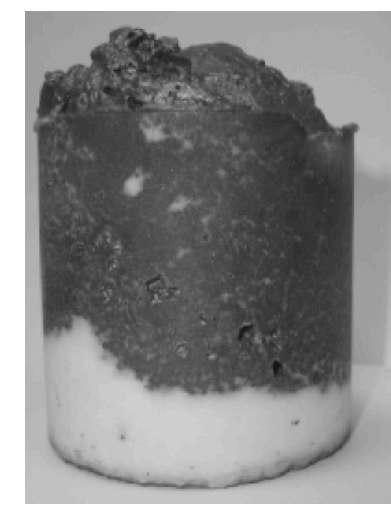

(b) Inhomogeneous $\mathrm{NaNO}_{3} / \mathrm{EG}$ composite [90]

Figure 5. Morphology and structure of specific salt/EG composite PCMs

Open-cell metal foams are porous media high porosities, with high thermal conductivities, large specific surface areas, attractive stiffness/strength properties and ultra-low weight. Common metal foams include copper, aluminium or nickel foams, and so on. Numerical simulations are widely used in this research area in order to understand the flow, heat transfer and solid-liquid phase change in metal foams using local thermal equilibrium and non-equilibrium models on the Representative Elementary Volume (REV) scale. Gao et al. [91] and Chen et al. [92] proposed a thermal LatticeBoltzmann model to simulate the melting process with natural convection in metal foams on the REV and pore scale, respectively. Zhao et al. [93] established a phase field model to investigate the undercooling effect during solid-liquid phase change in metal foams. In addition, the solid-liquid phase change behaviour in microcellular metal foams [94] and metal foams with varying porosity [95] have also been investigated. As for experimental studies, Zhao and Wu [96] compared the effect of metal foams and EG on the melting of $\mathrm{NaNO}_{3}$. Heat transfer could be significantly enhanced by both metal foams and EG, but the overall performance of metal foams was superior to that of EG. Zhang et al. [97] pointed out that natural convection in molten salts was dominant during the melting process, especially at high temperatures, which, however, was weakened by metal foams; the solidification process was enhanced by metal foams.

Metal foams can be corroded by molten salts at high temperatures, but graphite foams have good corrosion resistance to molten salts. Lafdi et al. [98] first studied the application of graphite foams in PCMs at high temperatures for space and terrestrial applications. Kim et al. [99] used a $\mathrm{MgCl}_{2} /$ graphite foam combination in a CSP plant and reduced the 
heat transfer pipe number. Zhao et al. [100] considered the effect of graphite foams on the LHS for CSP plants and showed that graphite foams could significantly improve the heat transfer as well as the exergy efficiency. Singh et al. [101] compared the effect of graphite foams with two porosities infiltrated with $\mathrm{MgCl}_{2}$. Thermal conductivities of $\mathrm{MgCl}_{2} /$ graphite foam composites were higher than those of $\mathrm{MgCl}_{2}$ alone and increased with the density of graphite foams.

\subsubsection{Micro/nano-encapsulation}

As micro/nano-encapsulated PCMs, their decreased diameter and increased specific surface areas make the thermal resistance significantly reduced. So far, micro/nano-encapsulated PCMs have been widely used in lowtemperature applications, but encapsulated PCMs for medium and high temperature are still limited. Li et al. [102] prepared novel microcapsules using $\mathrm{NaNO}_{3}$ as the core and perhydropolysilazane (PHPS) as the shell, which had $85 \mathrm{wt} \% \mathrm{NaNO}_{3}$. The melting temperature almost had no changes and the supercooling only had a small increase of $2.69 \mathrm{~K}$. Wu et al. [103] prepared microencapsulated $\mathrm{Na}_{2} \mathrm{SO}_{4}$ composites with $300-\mathrm{nm} \mathrm{SiO}_{2}$ shell via sol-gel technique. The silica mass fraction was optimized at $5.4 \%$ and the thermal conductivity at $600-800 \mathrm{~K}$ increased by 20.8-31.1\%. Zhang et al. [104] succeeded in using silica shells to micro-encapsulate $\mathrm{KNO}_{3}$ at an encapsulation ratio of $95.2 \%$ by a water-limited sol-gel process. Zhang et al. [105] further micro-encapsulated eutectic $\mathrm{Li}_{2} \mathrm{CO}_{3}$ $\mathrm{Na}_{2} \mathrm{CO}_{3}$ in silica shells and showed an enhanced heat capacity of $134.4 \%$ compared to solar salt.

\subsubsection{Challenges and opportunities at the component level}

\subsubsection{Using fins or enhanced heat transfer tubes}

Typically, beyond material limitations (Section 3.1.1), heat transfer can be limited also at the component level due to the asymmetric phase change processes in LHS, which has been confirmed experimentally and computationally [106]. Adding fins is a traditional way to enhance the heat transfer on the PCM side. Common fins consist of longitudinal fins, annular fins, pin fins and so on. Steinmann and Tamme [78] combined foils made of exfoliated graphite with PCMs to form a sandwich structure. Laing et al. [107] further compared the sandwich structures made from graphite foils and aluminium, and found that graphite was preferred up to $523 \mathrm{~K}$ and aluminium fins could be used at a higher temperature. Tao and He [108] introduced a local enhanced fin-tube to improve the melting uniformity caused by natural convection. Though the local fins could improve the uniformity, fin parameters should be appropriately selected. Ma et al. [109] added annular fins to a high-temperature LHS considering thermal stress and obtained a more uniform temperature distribution. The average charging/discharging power increased by 6.89.1\% and the overall system efficiency increased from $34.4 \%$ to $44.1 \%$.

However, in previous studies, the selection of fin parameters (e.g., number, size, location) mainly relies on engineering experience and lacks theoretical guidance, making it difficult to obtain optimal fin structures. Recently, optimization methods begin to be applied to the fin design in LHS. Alayil and Balaji [110] used a hybrid artificial neural network coupled genetic algorithm to obtain the optimum cross-plate fin parameters for a PCM-based heat sink. Sciacovelli et al. [111] optimized tree-shape fins to enhance the performance of LHS through CFD modelling and the response surface method, as shown in Figure 6 (a). An increase of 24\% in system efficiency was achieved. Also of importance in these systems, is the fact that the optimal fin design depends on the operating time. Sciacovelli and Verda [112] further proposed Y-shape fins with a tilt angle to maximize the performance of LHS based on entropy generation. Such fins allowed to achieve a twofold increase in the solidification rate and increase the thermodynamic efficiency by $13 \%$. However, the above optimizations are still limited to low dimensions. 


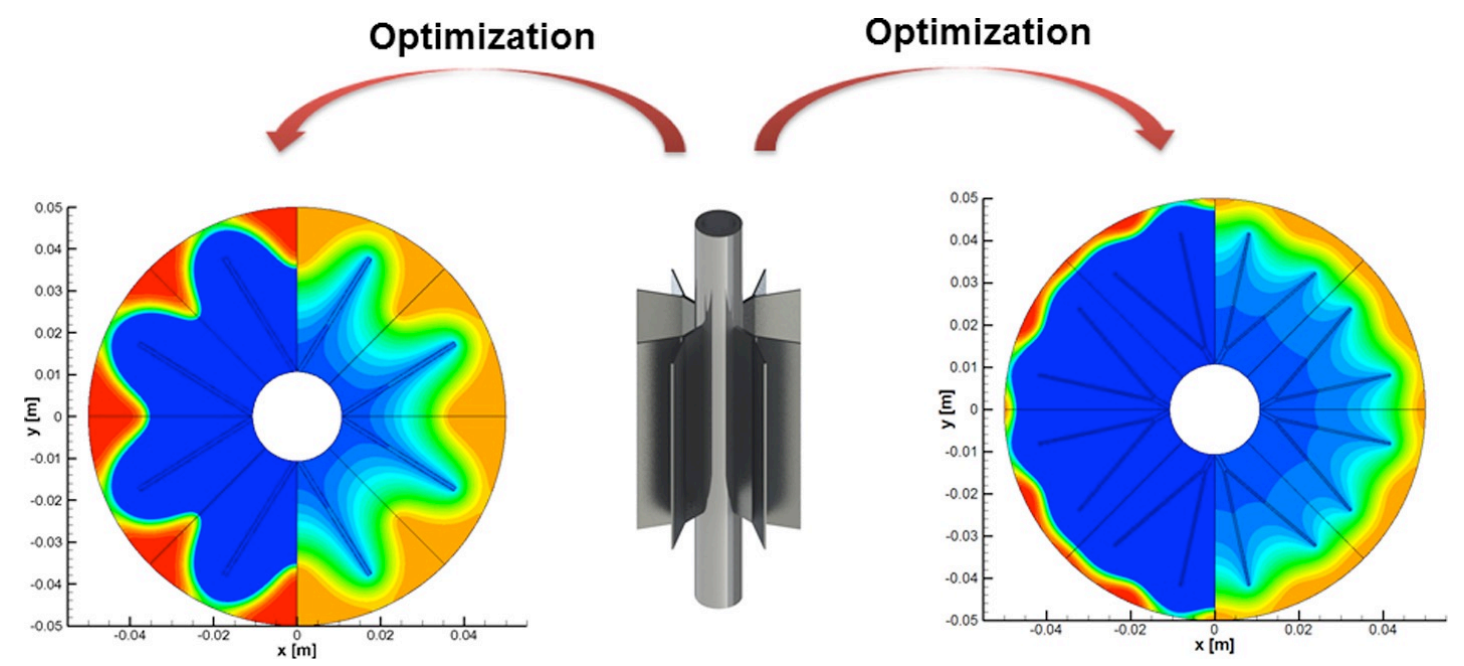

(a) Response surface method [111]

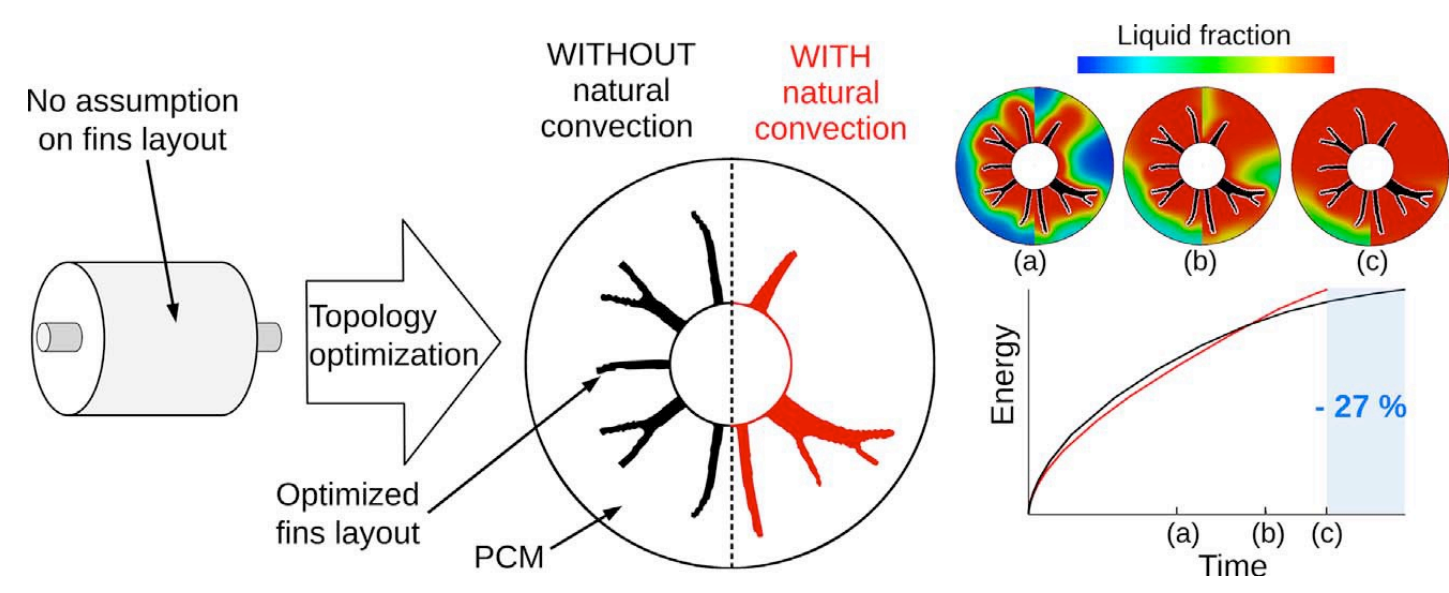

(b) Topology optimization considering natural convection [113]
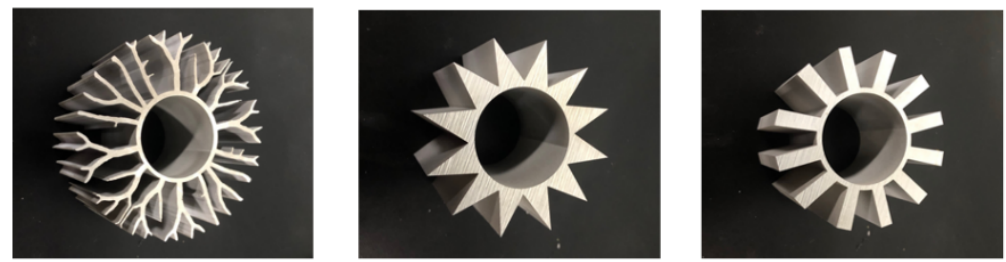

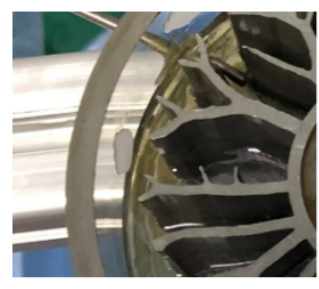

Optimized fin

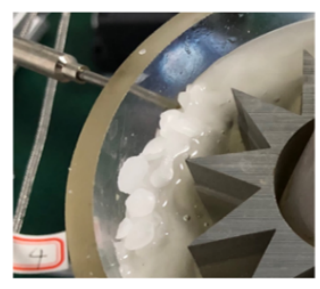

Triangular fin

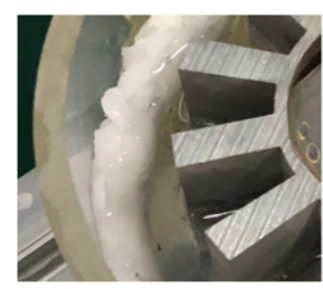

Rectangular fin

(c) Experimental validation of topology optimization [114]

Figure 6. Optimal fin design, and corresponding temperature and liquid fraction distributions

Topology optimization makes it possible to perform high degree-of-freedom optimization and has been extended from mechanics to heat transfer problems. Pizzolato et al. [115] used topology optimization to design the fins in shell-and-tube LHS. The optimized fins formed branched shapes, which yielded design features that could not be revealed with alternative design routes. Pizzolato et al. [113] further took natural convection into 
consideration and found that the optimized layout for melting was fundamentally different from the one neglecting fluid flows, as shown in Figure 6 (b). Also, Pizzolato et al. [116] demonstrated the manufacturability of topology-optimized fins by 3D printing. Zhao et al. [114] discussed the effect of numerical factors in topology optimization on the fin distribution in LHS, compared the optimized fins with the regular fins by experiment and demonstrated the effectiveness of topology optimization, as shown in Figure 6 (c).

In some situations (e.g., for the solar dish thermal generation system with air or gas mixture as the HTF), heat transfer on the HTF side is also poor. Tao et al. [117] introduced enhanced tubes and compared the effect of dimpled tube, cone-finned tube and helically finned tube on the performance of LHS. All the three kinds of enhanced tubes could improve the PCM melting rate. Although the HTF pressure drop for the enhanced tubes was larger than that of the smooth tube, the largest pressure drop was still much lower than the working pressure.

\subsubsection{Macro-encapsulation}

Similar to micro/nano-encapsulation, macro-encapsulation can also reduce the thermal resistance, but the volume expansion of PCMs may cause the pressure inside capsules to rise and lead the shell to crack. Steinmann and Tamme [78] manufactured cylindrical capsules filled with eutectic $\mathrm{NaNO}_{3} / \mathrm{KNO}_{3}$. While the pressure rise was moderate below melting temperature, the pressure increased significantly after melting if the initial gas volume was smaller than $20 \%$. Pitié et al. [118] used thick-shell model to estimate the inner pressure of the shell and concluded that the particles could melt without cracking the shell only under specific conditions. Zheng et al. [119] used cylindrical steel shells to encapsulate $\mathrm{NaNO}_{3}$ and eutectic $\mathrm{NaCl}-\mathrm{MgCl}_{2}$, and showed that a volume change of PCMs might lead to capsulation failures. Several methods have been proposed to solve the possible shell crack problem, for example, reserving or creating spaces for volume expansion of PCMs inside capsules. However, reserving or creating spaces inside capsules would introduce the thermal resistance between PCMs and shells. Elmozughi et al. [120] analysed a stainless-steel capsule considering a 20\% void and buoyancy-driven convection, and found that melting and solidification took longer time. Archibold et al. [121] simulated a melting process enclosed in a spherical shell where air compression was considered and found that increasing the Grashof number from $1.32 \times 10^{4}$ to $2.06 \times 10^{5}$ enhanced heat transfer. When the Grashof number was $9.09 \times 10^{4}$, the PCM melted faster when the Stefan number increased from 0.077 to 0.097. Solomon et al. [122] studied the effect of central void, random void and top-localized void on the heat transfer. The melting time with a central void was the shortest, $22 \%$ faster than with a random void distribution and 39\% faster than a top-localized void distribution.

\subsubsection{Adding heat pipes or intermediate heat transfer media}

Heat pipes are a kind of high-thermal conductive device through evaporation and condensation of working fluid occurring at the two ends. For medium/high-temperature applications, the available working fluid includes Therminol VP-1, diphenyl, naphthalene and potassium.

Thermal network models are widely used in studies on heat pipes. Shabgard et al. [123] investigate the effect of adding heat pipes to a high-temperature LHS system and demonstrated that heat pipes enhanced thermal performance in terms of dimensionless heat pipe effectiveness. Nithyanandam and Pitchumani [124] carried out parametric studies to assess the influence of geometric and operational parameters of heat pipes on the system performance, and determined the optimum system design for maximizing transferred energy, effectiveness and energy transfer rates. Robak et al. [125] conducted an economic evaluation of a LHS system with thermosyphons for large-scale CSP application and suggested that LHS with embedded thermosyphons was economically competitive with current SHS systems.

At the heat pipe ends, fins can also be adopted to promote heat transfer on the PCM side. Jung and Boo [126] developed an analytical model for predicting the transient behaviour of a LHS in which circular fins were attached to 
the heat pipes. Khalifa et al. [127] conducted numerical and experimental investigations to quantify the advantages of axially finned heat pipes rather than bare heat pipes in a LHS, and showed that the energy extracted increased by $86 \%$ and the heat pipes effectiveness increased by $24 \%$. Tiari et al. [128] investigated the thermal characteristics of a finned heat pipe-assisted LHS. An increase in fin length resulted in more uniform temperature distribution, while fin number did not have a significant effect. Almsater et al. [129] first incorporated the evaporation and condensation correlations of the working fluid to analyse the effect of axially finned heat pipes on LHS systems. The system performance was enhanced significantly by adding axial fins and including the evaporation and condensation.

\subsubsection{Challenges and opportunities at the system level}

\subsubsection{Cascaded latent heat storage}

Cascaded latent heat storage (CLHS) is an efficient and economical way to store thermal energy where multiple PCMs are arranged according to melting temperatures. As shown in Figure 7, in CLHS, the temperature difference between HTFs and PCMs along the HTF flow direction can be maintained, thus a uniform heat transfer rate is obtained. The idea of multiple PCMs was first proposed and later studied through numerical simulation [130] and experimental methods [131], which demonstrated a higher heat transfer rate against single PCM. So far, a large amount of theoretical and numerical studies on CLHS have been performed in terms of energy analysis. Cui et al. [132] proposed a solar receiver consisting of three PCMs to solve the incomplete melting problem and found that multiple PCMs could not only enhance the energy transfer rate, but also decrease the fluctuation of gas exit temperature. Michels and Pitz-Paal [133] investigated a CLHS using inorganic salts as PCMs in parabolic trough power plants and confirmed the enhanced performance of a CLHS with respect to the total amount of PCMs that melted and solidified. Seeniraj and Laksshmi Narasimhan [134] studied the performance enhancement of a LHS unit employing multiple PCMs and fins, and showed an appreciable enhancement in the melting rate and a nearly uniform HTF exit temperature. Li et al. [135] developed a shell-and-tube LHS model filled with three PCMs and found that lower-melting temperature PCMs melted fastest and the melting time decreased with inlet temperatures. Shamsi et al. [136] optimized the PCM types, placement and quantity in the operation of an encapsulated CLHS for CSP plants, which showed an improvement in system performance compared to the best case of a single PCM store.

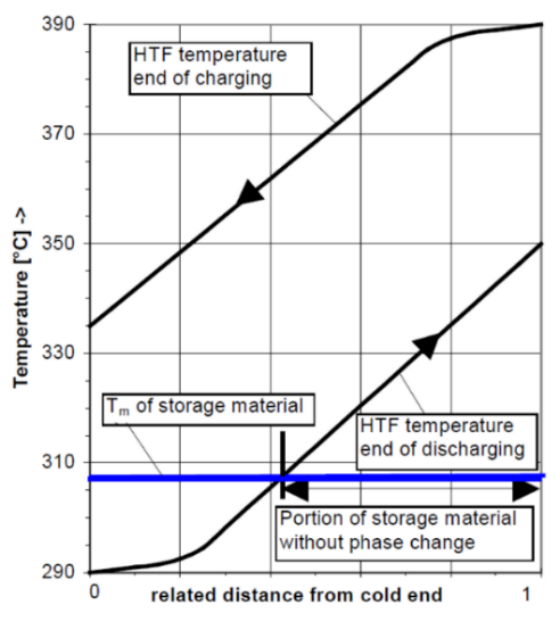

Single stage

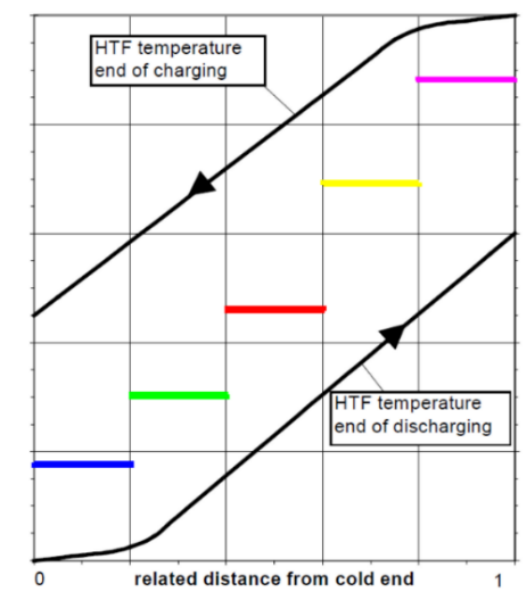

Cascaded stage

Figure 7. Schematic diagram of single-stage LHS system and CLHS system [137]

However, due to the irreversibility of heat storage process, it is necessary to take the quality or usefulness of thermal energy into consideration. Lim et al. [138] carried out an exergy optimization of LHS with two and infinite 
stages, and obtained the optimal distributions of melting points. Aceves et al. [139] also used exergy analysis to study the optimization of PCM distribution with infinite stages. However, the melting temperatures of PCMs for infinite stages are considered continuous, which is not practical. Gong and Mujumdar [140] performed an exergy optimization on CLHS with two, three and five stages in combined charging/ discharging processes. Xu and Zhao [141] obtained the analytical solution to the cases of arbitrary stage numbers and discrete melting temperatures based on exergy optimization. Nevertheless, the assumptions made in the theoretical optimization are divorced from the actual situations (e.g., heat transfer and sensible heat inside PCMs are ignored), so simulations and experiments are necessary. Shabgard et al. [142] compared the heat transfer in cascaded and non-cascaded LHS equipped with heat pipes and found that a CLHS recovered 10\% more exergy than the best non-cascaded LHS. Li et al. [143] analysed the overall exergetic efficiency of a two-stage LHS and showed that the overall exergetic efficiency could be improved by 19.053.8\% compared to a single-stage LHS. Tian and Zhao [144] conducted an energy and exergy analysis on the metal foam enhanced CLHS. Heat and exergy exchange rates of CLHS were both improved by metal foams, but exergy efficiency could not be significantly improved by metal foams. Solomon and Oztekin [145] conducted a second law analysis of an encapsulated PCM-based CLHS, and showed that systems with multiple PCMs outperformed the single PCM-based systems and the PCM numbers would have a greater impact with a longer system.

From the perspective of the second law of thermodynamics, exergy and entropy generation are related to each other and widely adopted in heat-work conversion approaches. Entropy generation minimization theory has been extended to heat transfer analysis, but there still exist paradoxes. Guo et al. [146] proposed "entransy" in terms of an analogy between heat and electrical conduction to solve this problem. Some authors claim that if TES is aimed at heat transfer purpose rather than heat-work conversion, entransy analysis is more suitable than exergy analysis and entropy generation analysis [147], although this approach in general is disputed. In any case, Tao et al. [148] studied the two-stage LHS based on entransy theory and carried out a preliminary optimization. Xu and Zhao [149] further performed an optimization for CLHS and obtained the analytical solutions to optimal temperatures for arbitrary stages.

So far, CLHS has been extensively studied through theoretical optimization and numerical simulation from the view of thermodynamics laws or entransy theory, but experimental results are still limited, especially at medium and high temperatures. Figure 8 shows some representative lab-scale experimental CLHS systems. Michels and PitzPaal [133] carried out experimental studies in the charging and discharging process of a CLHS where $\mathrm{KNO}_{3}$, $\mathrm{KNO}_{3} / \mathrm{KCl}$ and $\mathrm{NaNO}_{3}$ were adopted. The results showed that a CLHS could reach a higher utilization of its theoretical possible storage capacity when operated in the periodically balanced state. Yuan et al. [150] establish a three-stage CLHS with carbonate composites whose melting temperatures were $772.85 \mathrm{~K}, 757.05 \mathrm{~K}$ and $695 \mathrm{~K}$, respectively. The non-thoroughly melting was solved. Furthermore, the overall heat storage quantity, heat release quantity, average charging powers, average discharging power of the CLHS were 39.5\%, 35.7\%, 38.4\% and $27.0 \%$ higher than those of the non-CLHS, respectively. Zhao et al. [151] established an experimental CLHS filled with three nitrate composites whose melting temperature were $398.58 \mathrm{~K}, 497.42 \mathrm{~K}$ and $579.36 \mathrm{~K}$, and analysed the charging performance based on energy, exergy and entransy, respectively. The solid-liquid phase change in the three stages did not take place simultaneously due to the poor heat transfer inside tanks. More stages and higher HTF inlet temperatures could improve energy storage efficiency, exergy storage efficiency and entransy storage efficiency. 


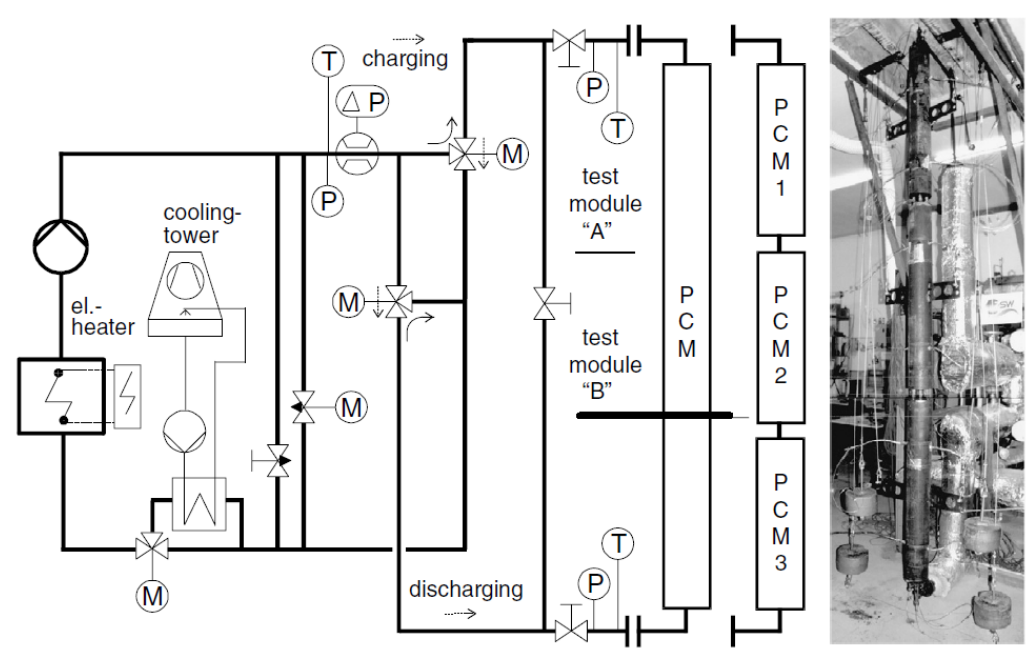

(a) Michels and Pitz-Paal's CLHS system [133]

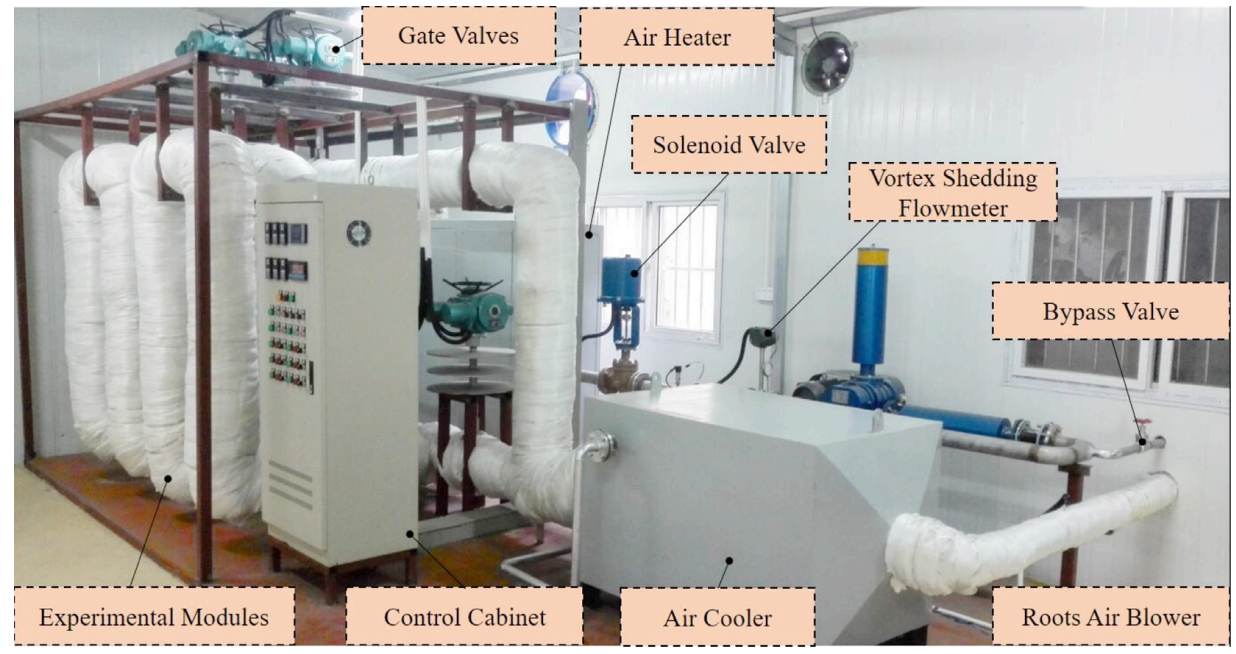

(b) Yuan et al.'s CLHS system [150]

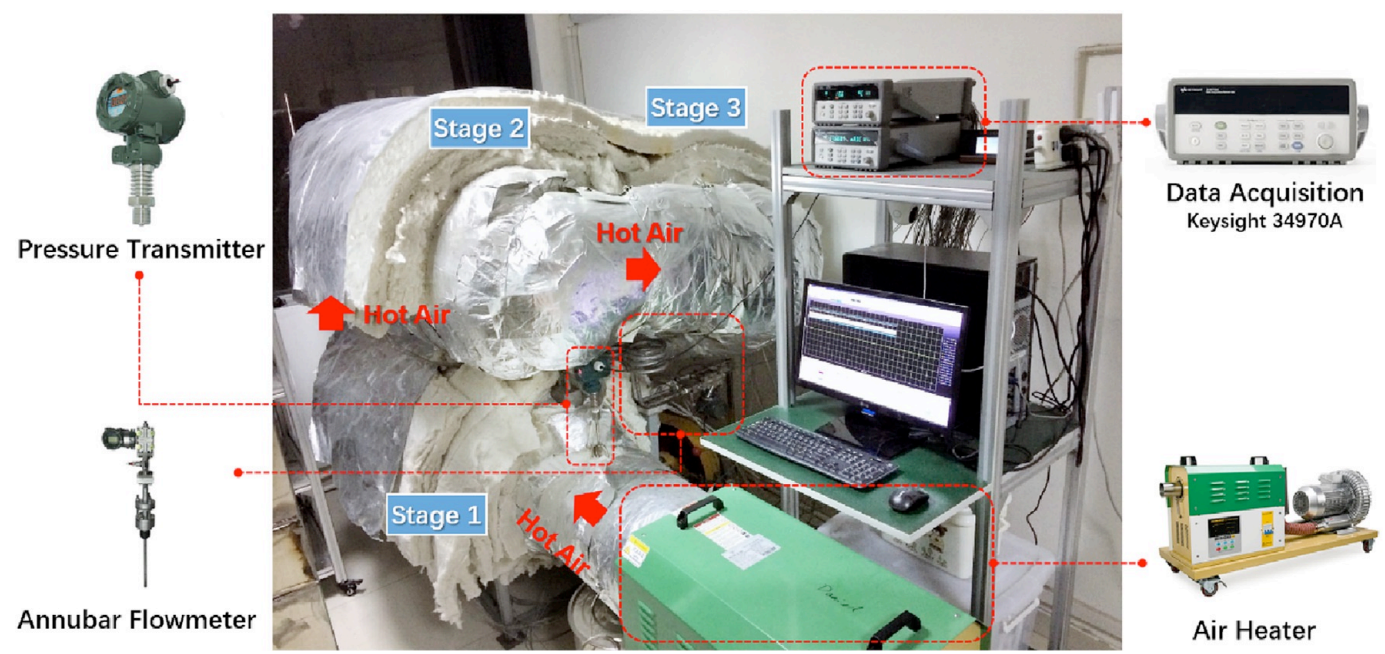

(c) Zhao et al.'s CLHS system [151]

Figure 8. Representative lab-scale experimental CLHS systems

\subsubsection{Packed-bed latent heat storage}

Macro-encapsulated PCMs are usually packed randomly in a packed-bed LHS and used as the storage media. At medium/high-temperatures, air or molten salt is often used as HTF. Due to its simplicity and low cost, packed-bed 
LHS is popular for medium/high-temperature applications and its research can be mainly classified into numerical simulations and experimental studies. Numerical models can be mainly divided into single-phase model, Schumman's model, concentric-dispersion model and continuous solid-phase model. Single-phase model where solid and fluid phases are considered as unique is useful to analyse packed beds filled with high-thermal conductive capsules, so it is not popular in the situations where inorganic salts are adopted.

Schumman's model assumed that only convection between solid and fluid phases, and heat losses to the environment were integrated, while heat conduction inside particles and fluids, and heat exchange between particles were neglected. Hence, Schumman's model should be modified if applied to a packed-bed LHS when Biot number is large. Tumilowicz et al. [152] applied a modified lumped capacitance method to Schumman's model to consider the cases where Biot number was large and introduced an effective convective heat transfer coefficient.

Concentric-dispersion model assumes a thermal gradient inside the solid particles and no inter-particle heat transfer, hence the temperature gradient at the particle surfaces would only be due to the heat transfer between fluid and particles. Bindra et al. [153] conducted an exergy analysis on a packed-bed LHS, and found that higher axial dispersion and higher ambient losses led to a lower exergy efficiency. Peng et al. [154] established a packed-bed LHS model considering radial heat transfer and wall heat losses, and indicated that decreasing the capsule size and fluid velocity, or increasing the storage height, would increase the charge efficiency. Wu et al. [155] investigated the temperature response and phase change process within capsules of a packed-bed LHS. The outlet temperature showed a quasi-isothermal period and increased with melting temperatures, leading to a higher effective discharging efficiency. Galione et al. [156] built a multi-layer storage tank model with solid filler materials in the middle and encapsulated PCMs at the ends. The multi-layered solid-PCM approach prevented the thermocline degradation and led to higher efficiency. Zhao et al. [157] further carried out a cost analysis on a similar multi-layer solid-PCM thermocline TES for CSP plants and found that such a TES was more cost-competitive. Wu et al. [158] and Elfeky et al. [159] compared the performance between cascaded and non-cascaded packed-bed LHS. The results showed that cascaded systems had a faster charging and discharging rate and a higher energy/exergy efficiency.

Continuous solid-phase model is considered as a continuous porous medium, including heat conduction in the axial and radial directions of both solid and fluid phases. Though it is usually discretized in one dimension, it is still possible to model the porosity variation along the radial direction and determine the radial flow distribution using extended Brinkman equations. Bellan et al. [160] analysed the heat transfer characteristics in a two-dimensional packed-bed LHS. Stefan number played a vital role in the total heat storage capacity due to sensible heat, and the properties of capsule shells significantly influenced the system performance, especially when the thermal conductivity of shells was low. Zanganeh et al. [161] analysed the outflow temperature of a packed-bed TES with rocks in the middle and PCMs on the top for CSP application. A PCM volume of only 1.33\% of the total storage volume was sufficient to keep the outflow temperature during discharging stable.

Compared to numerical simulations, experimental studies on packed-bed LHS at medium- and high temperatures are limited. Li et al. [162] established a high-temperature packed-bed LHS where a ternary carbonate was selected with melting point and latent heat being $668 \mathrm{~K}$ and $174.7 \mathrm{~kJ} / \mathrm{kg}$, respectively. The convective heat transfer resistance between capsules and HTF was identified as the main factor, which could be improved by controlling the flow rate. Li et al. [163] further proposed a two-layer packed-bed LHS with variable capsule diameters along the flow direction. The optimal capsule diameter was 20-30 $\mathrm{mm}$. The charging/discharging rate of the two-stage system was shown to be up to $12.4 \%$ higher than that of an equivalent single-stage system. 


\subsection{Cycling and thermal stability}

\subsubsection{Cycling stability}

In melting and solidification cycles, microstructures and compositions of metals and metallic compounds may change due to the varying interactions between microscope particles, especially for the composite PCMs, which in most cases will cause a decrease in heat storage performance.

\subsubsection{Metals and their alloys}

In terms of metals and their alloys, research on cycling stability has mainly focused on alloys, especially binary and ternary alloys. As for binary alloys, Al-Si alloys have attracted attention as high-temperature PCMs due to their abundance and suitable melting temperature. Li et al. [164] studied the cycling stability of Al - $17 \mathrm{wt} \% \mathrm{Si}$ alloys and found that the melting temperature and latent heat increased after 1200 cycles, which was attributed to the changes in grain size and shape of Si. Gokon et al. [165] performed cycling stability tests for four hypereutectic Al-Si alloys, particularly Al - $25 \mathrm{wt} \% \mathrm{Si}$ alloys. The temperature profiles were almost the same with little evidence of oxidation up to 20 cycles. Wang et al. [166] found that the melting temperature, latent heat, specific heat and thermal conductivity of Al - $12.6 \mathrm{wt} \%$ Si alloys (eutectic) showed almost no change after 1000 cycles. Zhao et al. [167] studied the cycling stability of hypoeutectic, eutectic and hypereutectic Al-Si alloys, respectively. Melting temperatures all remained stable after 100 cycles, but a small variation in the latent heat was only found for eutectic Al-Si alloys and $\mathrm{Al}-20 \mathrm{wt} \% \mathrm{Si}$ alloys. Thermal conductivity changed after 100 cycles except eutectic alloys.

Beyond Al-Si alloys, the cycling stability of other binary alloys is also studied by various investigators. BlancoRodríguez et al. [168] carried out a life-cycle analysis of up to 20 cycles for eutectic Mg-Zn alloys and showed no appreciable mass changes of $0.04 \%$. Sugo et al. [169] compared the cycling stability of two miscible-gap binary alloys, $\mathrm{Al}-\mathrm{Sn}$ alloys and Fe-Cu alloys. For Al-Sn alloys, no significant changes in the onset temperature of melting/solidification and energy capacity were observed, while for Fe-Cu alloys, a shift in the heating curve was caused due to the effect of confinement. Liu et al. [170] designed Ag-Bi nanocomposites with Bi nanoparticles embedded in an Ag matrix and confirmed the silver matrix successfully prevented nanoparticle coalescence during 100 cycles. Gokon et al. [171] studied the cycling properties of three hypereutectic $\mathrm{Cu}-\mathrm{Si}$ alloys, particular $\mathrm{Cu}-20 \mathrm{wt} \% \mathrm{Si}$ alloys. The temperature profiles were similar after 2, 10 and 20 cycles, showing little evidence of segregation and enrichment.

As for ternary alloys, cycling stability test mainly focuses on Al-Mg-Zn ternary alloys. Sun et al. [172] studied the thermal repeatability of $\mathrm{Al}-34 \mathrm{wt} \% \mathrm{Mg}-6 \mathrm{wt} \% \mathrm{Zn}$ eutectic alloys with respect to 1000 cycles. The change in melting temperature was in the range of 3.06-5.3 $\mathrm{K}$ and the latent heat decreased by $10.98 \%$, which might be due to the degradation of chemical structures. Risueño et al. [173] investigated the cycling stability of $5.1 \mathrm{~mol} \% \mathrm{Al}-70$ mol\% Mg - $24.9 \mathrm{~mol} \% \mathrm{Zn}$ alloys and $6 \mathrm{~mol} \% \mathrm{Al}-8.2 \mathrm{~mol} \% \mathrm{Mg}-85.8 \mathrm{~mol} \% \mathrm{Zn}$ alloys in 100 and 700 cycles. The heat of fusion and melting temperatures were almost constant for the two ternary alloys up to 100 cycles and only for the first alloys up to 700 cycles. Risueño et al. [174] further evaluated the cycling stability of $8.7 \mathrm{~mol} \% \mathrm{Al}-7.3 \mathrm{~mol} \%$ Mg - 84 mol\% Zn alloys, 11.3 mol\% Al - 88.7 mol\% Zn alloys, 7.8 mol\% Mg - 92.2 mol\% Zn alloys, 72 mol\% Mg - 28 mol\% $\mathrm{Zn}$ alloys and $5.1 \mathrm{~mol} \% \mathrm{Al}-70 \mathrm{~mol} \% \mathrm{Mg}-24.9 \mathrm{~mol} \% \mathrm{Zn}$ alloys. In 100-cycle and 500-cycle tests, no obvious variations of onset melting temperatures and heat of fusion were observed.

\subsubsection{Inorganic salts and their eutectics}

Research on the cycling stability of inorganic salts involves nitrates, carbonates and chlorides. Laing et al. [107] tested a proto-type LHS filled with $\mathrm{NaNO}_{3}$ under 172-cycle operation and proved no changes in the melting temperature. Maldonado et al. [175] investigated the thermophysical properties of Solar Salt after 10 and 50 cycles. 
Its phase change enthalpy hardly varied and chemical structures were the same. Zhao et al. [32] prepared two binary $\mathrm{Ca}\left(\mathrm{NO}_{3}\right)_{2}-\mathrm{NaNO}_{3}$ salts and performed a 26 -cycle test. The weight losses of these two samples were only $0.20 \%$ and $0.42 \%$ after 26 cycles, respectively. The DSC curves had high reproducibility in the heating process, but not in the cooling process of $20 \mathrm{~mol} \% \mathrm{Ca}\left(\mathrm{NO}_{3}\right)_{2}-80 \mathrm{~mol} \% \mathrm{NaNO}_{3}$. Zhou and Eames [176] investigated the stability of $46 \mathrm{~mol} \%$ $\mathrm{NaNO}_{3}-54 \mathrm{~mol} \% \mathrm{LiNO}_{3}$ and $40 \mathrm{~mol} \% \mathrm{NaNO}_{3}-60 \mathrm{~mol} \% \mathrm{LiNO}_{3}$ for 51 cycles. Though large weight losses exist in the first cycle for both mixtures due to their hydroscopic properties, the weight losses were only $0.28 \%$ and $0.33 \%$, respectively, for the next 50 cycles. Additives are also added to improve the cycling stability of nitrate salts. Peng et al. [177] added $5 \%$ additive of chlorides into a $\mathrm{NaNO}_{3}-\mathrm{KNO}_{3}-\mathrm{NaNO}_{2}$ mixture and showed that loss of latent heat for the ternary nitrate salt decreased from $28.7 \%$ to $15 \%$ after 14 cycles. $\mathrm{Li}$ and Wu [178] discussed the effect of $\mathrm{CsNO}_{3}$ on the cycling stability of $68 \mathrm{wt} \% \mathrm{KNO}_{3}-18 \mathrm{wt} \% \mathrm{LiNO}_{3}-14 \mathrm{wt} \% \mathrm{Ca}\left(\mathrm{NO}_{3}\right)_{2}$. The stability and fusion heat of the composite after 800 cycles were both improved when adding $0.2-0.38 \mathrm{wt} \% \mathrm{CsNO}_{3}$.

Cycling stability tests have also performed on carbonate salts and chloride salts. Petri et al. [179] experimentally studied the cycling stability of $\mathrm{LiKCO}_{3}$ at 753-808 $\mathrm{K}$ for 5650 hours and 129 cycles. Jiang et al. [180] conducted a 500-cycle test for the $\mathrm{Na}_{2} \mathrm{CO}_{3}-\mathrm{Li}_{2} \mathrm{CO}_{3}$ eutectics and showed little changes in the thermal properties. Shin et al. [181] tested $32 \mathrm{wt} \% \mathrm{Li}_{2} \mathrm{CO}_{3}-35 \mathrm{wt} \% \mathrm{~K}_{2} \mathrm{CO}_{3}-33 \mathrm{wt} \% \mathrm{Na}_{2} \mathrm{CO}_{3}$ and found that it exhibited a distinct melting temperature without phase separation or sub-cooling over 50 cycles. Liu et al. [182] conducted cycling stability tests up to 40 and 100 cycles for $28.5 \mathrm{wt} \% \mathrm{Li}_{2} \mathrm{CO}_{3}-71.5 \mathrm{wt} \% \mathrm{~K}_{2} \mathrm{CO}_{3}, 35 \mathrm{wt} \% \mathrm{Li}_{2} \mathrm{CO}_{3}-65 \mathrm{wt} \%$ $\mathrm{K}_{2} \mathrm{CO}_{3}, 64 \mathrm{wt} \% \mathrm{MgCl}_{2}-36 \mathrm{wt} \% \mathrm{KCl}, 52 \mathrm{wt} \% \mathrm{MgCl}_{2}-48 \mathrm{wt} \% \mathrm{NaCl}$ and $22 \mathrm{wt} \% \mathrm{Li}_{2} \mathrm{CO}_{3}-62 \mathrm{wt} \% \mathrm{~K}_{2} \mathrm{CO}_{3}-16 \mathrm{wt} \%$ $\mathrm{Na}_{2} \mathrm{CO}_{3}$, respectively. They reported that carbonate salts underwent a weakened sub-cooling phenomenon after several cycles, but the phase change became unnoticeable after 20 cycles for the ternary carbonate. After 40 cycles, $64 \mathrm{wt} \% \mathrm{MgCl}_{2}-36 \mathrm{wt} \% \mathrm{KCl}$ creeped out, while no noticeable change was observed for $52 \mathrm{wt} \% \mathrm{MgCl}_{2}-48 \mathrm{wt} \%$ $\mathrm{NaCl}$. Jiang et al. [183] found that the thermophysical properties of the $\mathrm{Na}_{2} \mathrm{CO}_{3}-\mathrm{NaCl}$ eutectics, as well as the phase identification/morphology varied slightly after 100, 200 and 300 cycles. Liu et al. [184] extended the stability testing on $\mathrm{Na}_{2} \mathrm{CO}_{3}-\mathrm{NaCl}$ eutectics to 1000 cycles and found that the thermophysical properties did not vary notably.

\subsubsection{Metallic and metallic compound composite materials}

Medium/high-temperature composite PCMs, such as micro/nano-particle doped PCMs, form-stable PCMs and encapsulated PCMs, usually suffer from large differences in the physical and chemical properties between PCMs and additives, which may lead to a failure in structure stability after several melting and solidification cycles.

In micro/nano-particle doped PCMs, particles tend to aggregate into large particles due to surface effect, Brownian motion, van der Waals force and hydrogen bonding, and settle down in the PCMs. Myers et al. [56] determined any potential degradation of $\mathrm{CuO}$ nanoparticle enhanced $\mathrm{KNO}_{3}, \mathrm{NaNO}_{3}$ and Solar Salt after melting. The infrared spectra appeared to change little after melting, but pre-melt and post-melt spectra for Solar Salt are a little different due to the formation of a new structure. Zhang et al. [61] compared the cycling stability of $\mathrm{Li}_{2} \mathrm{CO}_{3}-\mathrm{Na}_{2} \mathrm{CO}_{3}-\mathrm{K}_{2} \mathrm{CO}_{3}$ with and without T-ZnOw particles. No significant changes in melting point, specific heat and thermal conductivity were found after 30 cycles. As for enthalpy, ternary carbonates/T-ZnOw had a lower degree of decay than ternary carbonates after 30 cycles.

In form-stable composite PCMs, the porous media (e.g., ceramics and EG) are not fixed so that structures may change after several cycles due to volume changes and density differences. As for ceramic form-stable composite PCMs, Jalalzadeh-Azar et al. [185] examined the cycling stability of $\mathrm{Na}_{2} \mathrm{SO}_{4} / \mathrm{SiO}_{2}$ form-stable composite PCM pellets in a packedbed LHS for 20 cycles, but found poor cycling stability of the pellets. Guo and Wang [186] further extended the test of $\mathrm{Na}_{2} \mathrm{SO}_{4} / \mathrm{SiO}_{2}$ form-stable composite PCMs to 100 cycles. No PCM leakage existed, but the latent heat decreased due to the possible crystal structure changes of $\mathrm{Na}_{2} \mathrm{SO}_{4}$. Li et al. [187] studied the cycling stability of $\mathrm{NaNO}_{3} / \mathrm{expanded}$ vermiculite form-stable composite PCMs for 700 cycles and found a mass change of 5.1\%. Jiang et al. [188] compared the cycling stability of three eutectic $\mathrm{Na}_{2} \mathrm{SO}_{4}-\mathrm{NaCl} /$ ceramic composites. Both $\alpha$-alumina and mullite made the 
composites keep original with a negligible weight loss after 20 cycles, but the $\mathrm{Na}_{2} \mathrm{SO}_{4}-\mathrm{NaCl} /$ diatomite composite cracked after 20 cycles. Leng et al. [189] investigated the cycling stability of eutectic $\mathrm{NaCl}-\mathrm{KCl} /$ diatomite form-stable composites. During 1000 cycles, the melting temperature was consistent, while the volume density and the latent heat gradually decreased and stabilized. Ge et al. [68] tested the cycling stability of a form-stable composite PCM consisting of eutectic $\mathrm{Li}_{2} \mathrm{CO}_{3}-\mathrm{Na}_{2} \mathrm{CO}_{3}, \mathrm{MgO}$ and graphite flakes. The composite maintained its original shape with negligible mass changes, and no significant changes in melting temperature and latent heat were seen over 28 cycles. Ge et al. [190] further extended the test to 300 cycles and confirmed no significate changes during melting. Li et al. [191] found that for the above composite PCM, salt migration, particle breakage and particle redistribution caused by the thermal cycling could lead to more homogenous distribution of ingredients. Jiang et al. [64] prepared a composite PCM consisting of eutectic $\mathrm{K}_{2} \mathrm{CO}_{3}$ $\mathrm{Na}_{2} \mathrm{CO}_{3}, \mathrm{MgO}$ and $\mathrm{SiC}$, and showed a uniform distribution and high chemical compatibility of different components after 100 cycles. As for EG form-stable composite PCMs, Zhao et al. [192] measured salt loss of an ENG-TSA added $\mathrm{KNO}_{3}$ $\mathrm{NaNO}_{3}$ mixture after 20 cycles. The mass loss of salts increased with the density or the nitrate mass fraction due to the smaller space for expansion. Zhong et al. [82] conducted a 100 -cycle test for $\mathrm{LiNO}_{3}-\mathrm{KCl} / \mathrm{EG}, \mathrm{LiNO}_{3}-\mathrm{NaNO}_{3} / \mathrm{EG}$ and $\mathrm{LiNO}_{3}-$ $\mathrm{NaCl} / \mathrm{EG}$. The melting temperatures remained stable and the latent heat became slightly lower. Huang et al. [193] obtained the endothermic and exothermic curves of $\mathrm{LiNO}_{3}$-KCl/EG composite PCMs after 10, 50, 100 and 500 cycles. The temperature vs. time curves were almost identical, which indicated good cycling stability.

In encapsulated PCMs, the pressure inside the capsulation shell would increase due to the volume expansion of PCMs when melting, which may lead to the shell cracks. So far, cycling stability studies on encapsulated PCMs are mainly about micro/macro-capsulated metallic PCMs. As for micro-encapsulated metallic PCMs, Maruoka and Akiyama [194] prepared an encapsulated PCM adopting Pb pellets as the core and Ni film as shells, and showed that the Ni layer should be thick enough for 50-cycle tests. Zhang et al. [195] encapsulated Cu balls with $\mathrm{Cr} / \mathrm{Ni}$ layers and tested the samples for 1000 cycles. Though the previously uniform $\mathrm{Cr}$ layer cracked, a continuous gap was formed, and no crack or leakage was found. Nomura et al. [196] micro-encapsulated Al-Si alloys with $\alpha-\mathrm{Al}_{2} \mathrm{O}_{3}$ shells and performed cycling tests up to 10 cycles. The melting temperature and latent heat were almost unchanged, and micro-encapsulated PCMs kept the original structure without leakage. Nomura et al. [197] extended the test to 300 cycles and confirmed excellent durability. Similarly, He et al. [198] investigated the structural and phase-change characteristics of micro-encapsulated Al-Si alloys with $\mathrm{Al}_{2} \mathrm{O}_{3}$ shells, and pointed out that the accumulative cracked ratio exceeded $20 \%$ after 20 cycles and the cracks would cause serious thermal stress problems. As for macro-encapsulated metallic PCMs, Zhao et al. [199] used Zn as the core and stainless steel or $\mathrm{Ni}$ as shells. The repeatability was under $1 \%$ with solid steel shells, while a noticeable discrepancy was found with Ni shells due to Zn-Ni alloying reaction. Fukahori et al. [200] used an alumina cup with an alumina cap to encapsulate Al-Si alloys and performed cycling tests up to 100 cycles. The temperature history profiles were similar and no PCM leakage or capsule breakage was observed. As for encapsulated inorganic salt PCMs, Li et al. [201] carried out a cycling test on microcapsules using $\mathrm{NaNO}_{3}$ as the core and perhydropolysilazane as the shell. After 80 cycles, the latent heat reduced by 3.6\%, the melting point decreased by $1 \mathrm{~K}$ and the supercooling degree fluctuated within $2 \mathrm{~K}$.

\subsubsection{Thermal stability}

When the temperature rises beyond a certain degree, PCMs may suffer from changes in composition or structure, or even decompose, especially inorganic salts and inorganic salt based composite materials. This section concerns such thermal stability issues of these types of salts.

\subsubsection{Inorganic salts}

In inorganic salts, nitrate salts and carbonate salts usually have lower decomposition temperatures. For nitrate salts, Bauer et al. [202] examined the thermal stability of $\mathrm{NaNO}_{3}$ and found that $\mathrm{NaNO}_{3}$ was stable up to $623 \mathrm{~K}$ with a little 
nitrite forming. Zhou and Eames [176] investigated the thermal stability of $46 \mathrm{~mol} \% \mathrm{NaNO}_{3}-54 \mathrm{~mol} \% \mathrm{LiNO}_{3}$ and 40 mol\% $\mathrm{NaNO}_{3}-60 \mathrm{~mol} \% \mathrm{LiNO}_{3}$, and indicated that they started to decompose at $773 \mathrm{~K}$. Olivares and Edwards [203] compared the thermal stability of $\mathrm{KNO}_{3}-\mathrm{NaNO}_{3}-\mathrm{LiNO}_{3}$ eutectics in different atmospheres. $\mathrm{NO}$ was detected at $598 \mathrm{~K}$ in argon, $698 \mathrm{~K}$ in nitrogen, $748 \mathrm{~K}$ in air and $813 \mathrm{~K}$ in oxygen. $\mathrm{Li}$ and $\mathrm{Wu}$ [178] added 0-0.06 wt\% $\mathrm{CsNO}_{3}$ to improve the thermal stability of $68 \mathrm{wt} \% \mathrm{KNO}_{3}-18 \mathrm{wt} \% \mathrm{LiNO}_{3}-14 \mathrm{wt} \% \mathrm{Ca}\left(\mathrm{NO}_{3}\right)_{2}$. The modified nitrate salts showed good stability when stored at $673 \mathrm{~K}$ for 72 days and suffered instability at the beginning as stored at $773 \mathrm{~K}$. Peng et al. [177] tested the effect of $5 \%$ chloride additives on the thermal stability of a $\mathrm{NaNO}_{3}-\mathrm{KNO}_{3}-\mathrm{NaNO}_{2}$ composite, and found the weight loss decreased from $1.48 \%$ to $1.4 \%$ at $773 \mathrm{~K}$ and from $19.12 \%$ to $0.5 \%$ at $823 \mathrm{~K}$, respectively. Maldonado et al. [175] performed a thermal gravimetric analysis on Solar Salt and found that its weight loss was below $3 \%$ at $773 \mathrm{~K}$.

For carbonate salts, Olivares et al. [204] investigated the thermal stability of $\mathrm{Li}_{2} \mathrm{CO}_{3}-\mathrm{Na}_{2} \mathrm{CO}_{3}-\mathrm{K}_{2} \mathrm{CO}_{3}$ eutectics up to $1273 \mathrm{~K}$ in argon, air and $\mathrm{CO}_{2}$. In $\mathrm{CO}_{2}$, the carbonate salt was stable up to at least $1273 \mathrm{~K}$, while, in argon and air, the salt began to decompose at 983-988 $\mathrm{K}$ and $803 \mathrm{~K}$, respectively. Jiang et al. [180] considered the thermal stability of $\mathrm{Na}_{2} \mathrm{CO}_{3}-\mathrm{Li}_{2} \mathrm{CO}_{3}$ eutectics. The $\mathrm{Na}_{2} \mathrm{CO}_{3}-\mathrm{Li}_{2} \mathrm{CO}_{3}$ eutectics showed good thermal and chemical stability in $\mathrm{CO}_{2}$ up to $873 \mathrm{~K}$, but there was a weight loss of $0.8 \%$ in $\mathrm{N}_{2}$.

Mixtures with different kinds of salts have also been evaluated. Jiang et al. [183] found that the $\mathrm{Na}_{2} \mathrm{CO}_{3}$ - $\mathrm{NaCl}$ eutectics were more stable in $\mathrm{CO}_{2}$ without weight losses up to $973 \mathrm{~K}$, while a weight loss of $0.51 \%$ around $913 \mathrm{~K}$ in $\mathrm{N}_{2}$ was detected. Jiang et al. [188] also found that the $\mathrm{Na}_{2} \mathrm{SO}_{4}-\mathrm{NaCl}$ eutectics were thermally stable up to $973 \mathrm{~K}$.

\subsubsection{Composite materials}

The thermal stability of composite PCMs based on inorganic salts was also investigated, covering micro/nanoparticle doped PCMs, form-stable PCMs and micro-encapsulated PCMs. As for micro/nano-particle doped PCMs, Tian et al. [54] blended Mg particles with $\mathrm{Li}_{2} \mathrm{CO}_{3}-\mathrm{Na}_{2} \mathrm{CO}_{3}-\mathrm{K}_{2} \mathrm{CO}_{3}$ eutectics. Compared with pure ternary carbonates, the upper temperature limit of thermal stability degraded slightly. Furthermore, the degradation increased with $\mathrm{Mg}$ loading. Xiong et al. [205] discussed the effect of $\mathrm{SiO}_{2}$ nanoparticles on the decomposition point of $\mathrm{NaBr}-\mathrm{KBr}$ $\mathrm{LiBr}-\mathrm{CaBr}_{2}$ eutectics. The decomposition point firstly increased and then reduced greatly with the $\mathrm{SiO}_{2}$ nanoparticle concentration. The particle size also had a great influence.

As for ceramic form-stable PCMs, Li et al. [187] used heat treatment to a $\mathrm{NaNO}_{3} /$ expanded vermiculite composite for $200 \mathrm{~h}$ and showed no obvious changes. Jiang et al. [188] assessed the thermal stability of three $\mathrm{Na}_{2} \mathrm{SO}_{4}-\mathrm{NaCl} / \mathrm{ceramic}$ composites. The composites with $\alpha$-alumina and mullite had good thermal stability without weight losses until $973 \mathrm{~K}$, but $\mathrm{Na}_{2} \mathrm{SO}_{4}-\mathrm{NaCl} /$ diatomite cracked. Jiang et al. [64] found that the decomposition temperatures of eutectic $\mathrm{K}_{2} \mathrm{CO}_{3}$ $\mathrm{Na}_{2} \mathrm{CO}_{3} / \mathrm{MgO}$ composites at heating rates of 5 and $10 \mathrm{~K} / \mathrm{min}$ were $1167 \mathrm{~K}$ and $1158 \mathrm{~K}$, respectively. Guo et al. [206] added nano-SiO $\mathrm{O}_{2}$ to eutectic $\mathrm{Na}_{2} \mathrm{CO}_{3}-\mathrm{K}_{2} \mathrm{CO}_{3} / \mathrm{MgO}$ form-stable PCMs and held at $1023 \mathrm{~K}$ for $168 \mathrm{~h}$. The doped nano-SiO $\mathrm{O}_{2}$ particles could restrain salt losses and improve the stability in structure and thermal properties. As for EG form-stable PCMs, Huang et al. [193] studied the thermal stability of $\mathrm{LiNO}_{3}-\mathrm{KCl} / \mathrm{EG}$ composites in air. Though the decomposition of the composites began at $588 \mathrm{~K}$, the composites could stay thermal-stable up to $673 \mathrm{~K}$. Xu et al. [87] carried out a leakage test on eutectic $\mathrm{LiNO}_{3}-\mathrm{KCl}-\mathrm{NaNO}_{3} / \mathrm{EG}$ composites by heating at $493 \mathrm{~K}$ for $1 \mathrm{~h}$ and found leakage stopped with more than $25 \mathrm{wt} \% \mathrm{EG}$.

As for micro-encapsulated PCMs, Li et al. [201] heated microcapsules using $\mathrm{NaNO}_{3}$ as the core and perhydropolysilazane as the shell for $5 \mathrm{~h}$ at $623 \mathrm{~K}, 723 \mathrm{~K}, 773 \mathrm{~K}$, and $823 \mathrm{~K}$, and found that the microcapsules were relatively stable until $773 \mathrm{~K}$.

\subsection{Corrosion}

In general, the chemical reactivity of liquid PCMs increases with temperature, especially metals and inorganic salts. In order to realize safe and long-term heat storage at medium and high temperatures, it is essential to find suitable capsulation materials for specific PCMs. 


\subsubsection{Metals and their alloys}

Jacob and Bruno [207] summarized shell materials containing PCMs at high temperatures and pointed out that the majority of high-temperature PCMs are encapsulated by steel-based metallic shells. However, liquid metals have a highly corrosive nature and react easily with other metals at high temperatures. Sun et al. [172] studied the compatibility between $\mathrm{Al}-34 \mathrm{wt} \% \mathrm{Mg}-6 \mathrm{wt} \% \mathrm{Zn}$ alloys and ss304L/C20 steels. The corrosion rates reported in this work were $0.0829 \mathrm{mg} /$ day for ss $304 \mathrm{~L}$ and $0.0953 \mathrm{mg} /$ day for C20 steels.

Compared to metals, ceramics are more suitable to encapsulate metallic PCMs due to the excellent corrosion resistance. Fukahori et al. [208] conducted a corrosion analysis of $\mathrm{Al}_{2} \mathrm{O}_{3}, \mathrm{AlN}, \mathrm{Si}_{3} \mathrm{~N}_{4}, \mathrm{SiC}$ and $\mathrm{SiO}_{2}$ in molten $\mathrm{Al}$-Si alloys at $1273 \mathrm{~K}$ for $100 \mathrm{~h}$. $\mathrm{Al}_{2} \mathrm{O}_{3}, \mathrm{AlN}$ and $\mathrm{Si}_{3} \mathrm{~N}_{4}$ had high corrosion resistance to $\mathrm{Al}-\mathrm{Si}$ alloys. Weak corrosion was detected between $\mathrm{Al}-25 \mathrm{wt} \% \mathrm{Si}$ and $\mathrm{SiC}$, while $\mathrm{SiO}_{2}$ was corroded in all the samples. Xu et al. [209] studied the compatibility of three recycled ceramics with $99 \mathrm{wt} \% \mathrm{Al}, \mathrm{Al}-5 \mathrm{wt} \% \mathrm{Si}$ and $\mathrm{Al}-12 \mathrm{wt} \%$ Si at $1273 \mathrm{~K}$ for $100 \mathrm{~h}$. Cofalit showed chemical stability in $99 \mathrm{wt} \%$ $\mathrm{Al}$ and instability in the other two alloys. Blast furnace slag presented good chemical stability towards the two Al-Si alloys. Coal fly ashes sintered ceramics were highly interactive towards all the three alloys. Zhao et al. [167] further investigated the corrosive property of hypoeutectic, eutectic and hypereutectic Al-Si alloys with six kinds of ceramics at $1173 \mathrm{~K}$ for 120 h. Two conclusions different with Fukahori et al.'s results were obtained: (1) $\mathrm{Si}_{3} \mathrm{~N}_{4}$ reacted with molten Al-Si alloys; (2) reactions between $\mathrm{Al}-\mathrm{Si}$ alloys and $\mathrm{SiC}$ existed with intensity decreasing with the mass ratio of $\mathrm{Si}$ in $\mathrm{Al}-\mathrm{Si}$ alloys.

\subsubsection{Inorganic salts and their eutectics}

Jacob and Bruno [207] pointed out that most high-temperature PCMs could be capsulated by steel-based metallic shells, but the corrosive nature further varied depending on the type of inorganic salts. As for nitrate salts, the corrosion of Solar Salt is extensively studied. Good and Bradshaw [210] evaluated the effect of impurities in Solar Salt on the corrosivity to ss304, ss316 and A36 carbon steel. Corrosion rates were insensitive to the impurity contents and acceptable for engineering applications. Fernández et al. [211] tested the corrosion of ss304, ss430

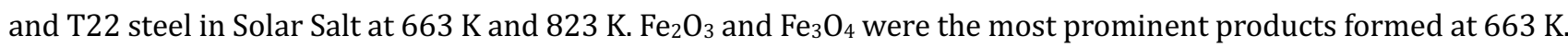
At $823 \mathrm{~K}$, stainless steels revealed a better corrosion resistance than T22 steel due to the formation of $\mathrm{FeCr}_{2} \mathrm{O}_{4}$ protective spinels. Fernández et al. [212] also studied the corrosion behaviour of stainless steel OC-4 in Solar Salt at $663 \mathrm{~K}$ and found no attack occurred in $2000 \mathrm{~h}$. Fernández et al. [213] further investigated the corrosion behaviour of ss347 in a nano-fluid made of Solar Salt and $1 \mathrm{wt} \% \mathrm{Al}_{2} \mathrm{O}_{3}$ or $\mathrm{SiO}_{2}$ nanoparticles. Higher chloride content of Solar Salt led to a higher corrosion rate, but the nanoparticles did not increase the corrosion rate. Nieto-Maestre et al. [214] compared the corrosion behaviour of $\mathrm{A} 516$ carbon steel and ss 347 in Solar Salt doped with $1 \mathrm{wt} \% \mathrm{Al}_{2} \mathrm{O}_{3}$ nanoparticles. For A516 carbon steel, the corrosion layer grew at $94.8 \mu \mathrm{m} / \mathrm{yr}$ and $\mathrm{Al}_{2} \mathrm{O}_{3}$ nanoparticles had a protective influence, while for ss347 the corrosion layer was practically negligible. Beyond Solar Salt, Zhu et al. [215] studied the corrosion of ss316 in molten Hitec salts at $723 \mathrm{~K}, 873 \mathrm{~K}$ and $953 \mathrm{~K}$. A good corrosion resistance was shown at $723 \mathrm{~K}$, but the corrosion density increased 4 times as the temperature rose from $873 \mathrm{~K}$ to $953 \mathrm{~K}$.

As for chloride salts, Shankar et al. [216] exposed Ni-based alloys 600, 625, 690 and $800 \mathrm{H}$ to molten LiCl-KCl eutectics at 673-873 K for $2 \mathrm{~h}$. Ni-based alloys 600 and 690 offered better corrosion resistance compared to Ni-based alloys 625 and 800H. Vignarooban et al. [217] estimated the corrosion rates for Hastelloys C-276, C-22 and N in molten $\mathrm{NaCl}-\mathrm{KCl}-\mathrm{ZnCl}_{2}$ eutectics at $523 \mathrm{~K}$ and $773 \mathrm{~K}$. Hastelloys C-276 and C-22 showed reasonably good corrosion resistance up to $773 \mathrm{~K}$, while Hastelloy $\mathrm{N}$ showed a corrosion rate higher than $150 \mu \mathrm{m} / \mathrm{yr}$ at $773 \mathrm{~K}$. Hofmeister et al. [218] investigated the corrosion properties of a low-carbon stainless steel X2CrNi18-9 and a high-carbon stainless steel X6CrNiTi18-10 in molten LiCl-KCl-CsCl salts at 673-873 K. A Ni-based superalloy CMSX-4 was also tested at $1073 \mathrm{~K}$. X2CrNi18-9 revealed severe intergranular corrosion for all testing conditions, whereas X6CrNiTi18-10 was protected against intergranular corrosion by $\mathrm{Cr}_{2} \mathrm{O}_{3}$ layers up to $773 \mathrm{~K}$. CMSX-4 revealed limited corrosion after exposure to the 
molten salt for $3 \mathrm{~h}$. Gomez-Vidal and Tirawat [219] evaluated the corrosion of ss347, ss310 and Ni-based alloys (800H and 625 ) in $34.4 \mathrm{wt} \% \mathrm{NaCl}-65.6 \mathrm{wt} \% \mathrm{LiCl}$ eutectics at $923-973 \mathrm{~K}$. ss347 suffered from the highest corrosion rate of $7.49 \pm 0.32 \mathrm{~mm} / \mathrm{yr}$. Sun et al. [220] studied the effect of alloying elements on the corrosion of Ni-based alloys in NaCl$\mathrm{KCl}-\mathrm{MgCl}_{2}$ at 873-1073 $\mathrm{K}$ and indicated that the elements $\mathrm{Cr}$, Mo and $\mathrm{W}$ could affect the alloy corrosion.

Corrosion studies on carbonate salts have focused mainly on $\mathrm{Li}_{2} \mathrm{CO}_{3}-\mathrm{Na}_{2} \mathrm{CO}_{3}-\mathrm{K}_{2} \mathrm{CO}_{3}$ eutectics. de Miguel et al. [221] studied the corrosion behaviour of $\mathrm{HR} 3 \mathrm{C}$ steel in $\mathrm{Li}_{2} \mathrm{CO}_{3}-\mathrm{Na}_{2} \mathrm{CO}_{3}-\mathrm{K}_{2} \mathrm{CO}_{3}$ eutectics at $973 \mathrm{~K}$ and found that $\mathrm{LiFeO}_{2}$, $\mathrm{LiCrO}_{2}$, $\mathrm{NiO}$ and $\mathrm{FeCr}_{2} \mathrm{O}_{4}$ were arranged in different layers as main corrosion products. Encinas-Sánchez et al. [222] further compared the corrosion behaviour of $\mathrm{HR} 3 \mathrm{C}$ steel in $\mathrm{Li}_{2} \mathrm{CO}_{3}-\mathrm{Na}_{2} \mathrm{CO}_{3}-\mathrm{K}_{2} \mathrm{CO}_{3}$ eutectics at $973 \mathrm{~K}$ and $1073 \mathrm{~K}$ for $2000 \mathrm{~h}$. The continuous transition from the rhombohedral to the cubic phase of $\mathrm{LiFeO}_{2}$ oxide layer was accelerated as the test temperature increased. Gallardo-González et al. [223] determined the corrosion rate of ss 316 in $\mathrm{Li}_{2} \mathrm{CO}_{3}-\mathrm{Na}_{2} \mathrm{CO}_{3}-\mathrm{K}_{2} \mathrm{CO}_{3}$ at $873 \mathrm{~K}$ and measured the corrosion rate to be 1.03-2.07 mm/yr. Fernández et al. [224] exposed two austenitic alloys, OC4 and HR224, to $\mathrm{Li}_{2} \mathrm{CO}_{3}-\mathrm{K}_{2} \mathrm{CO}_{3}-\mathrm{Na}_{2} \mathrm{CO}_{3}$ eutectics at $923 \mathrm{~K}$ for $1000 \mathrm{~h}$. Two layers composed of $\mathrm{NiO}, \mathrm{Al}_{2} \mathrm{O}_{3}$ and $\mathrm{Fe}_{2} \mathrm{O}_{3}$ were produced on OC4s, while HR224 showed a more complex structure with three layers composed of $\mathrm{NiO} \mathrm{NiFe}_{2} \mathrm{O}_{4}$ and $\mathrm{CrFe}_{2} \mathrm{O}_{4}$.

Turning to fluoride salts, Misra and Whittenberger [225] compared the corrosion propensity of commercial alloys in $\mathrm{LiF}-19.5 \mathrm{wt} \% \mathrm{CaF}_{2}$ at $1070 \mathrm{~K}$ and $\mathrm{NaF}-27 \mathrm{wt} \% \mathrm{CaF}_{2}-36 \mathrm{wt} \% \mathrm{MgF}_{2}$ at $1203 \mathrm{~K}$, showing that fluorides must be substantially free of $\mathrm{H}_{2} \mathrm{O}$ to prevent corrosion. Whittenberger and Misra [226] conducted compatibility studies to determine suitable containment alloys for $\mathrm{NaF}-22 \mathrm{wt} \% \mathrm{CaF}_{2}-13 \mathrm{wt} \% \mathrm{MgF}_{2}, \mathrm{NaF}-32 \mathrm{wt} \% \mathrm{CaF}_{2}$ and $\mathrm{NaF}-23 \mathrm{wt} \%$ $\mathrm{MgF}_{2}$. None of the commercially available high-temperature alloys appeared to offer adequate corrosion resistance over a long lifetime, however, mild steel, pure nickel and Nb-1Zr proved useful. Patel et al. [227] studied the corrosion property of Nimonic 80A, Inconel 718 and Inconel C-276 at $953 \mathrm{~K}$ in $46.5 \mathrm{~mol} \% \mathrm{LiF}$ - $11.5 \mathrm{~mol} \% \mathrm{NaF}$ - $42 \mathrm{~mol} \% \mathrm{KF}$. The latter two alloys showed better corrosion resistance, while Nimonic $80 \mathrm{~A}$ exhibited relatively low corrosion resistance.

As for sulfate salts, Fu et al. [228] studied the corrosion behaviour of $\mathrm{HR} 3 \mathrm{C}$ steel in molten $\mathrm{Na}_{2} \mathrm{SO}_{4}-\mathrm{K}_{2} \mathrm{SO}_{4}$ and the impacts of applied stresses at $973 \mathrm{~K}$ and $1023 \mathrm{~K}$. The corrosion resistance of HR3C to the molten salts was strongly related to the formation of outer oxide layers. The stress generally led to a larger $\mathrm{Cr}$ amount in the oxide layer. When the stress increased, the influence became stronger with some $\mathrm{Cr}_{x} \mathrm{Ni}_{\mathrm{y}}$ appearing at the surface of specimens.

Amongst the mixtures of different kinds of salts, $\mathrm{NaCl}-\mathrm{Na}_{2} \mathrm{CO}_{3}$ eutectics and $\mathrm{NaCl}-\mathrm{Na}_{2} \mathrm{SO}_{4}$ eutectics are investigated in the field of corrosion. Liu et al. [184] investigated the corrosion behaviour of ss316 in $\mathrm{NaCl}-\mathrm{Na}_{2} \mathrm{CO}_{3}$ eutectics and found that the corrosion rate of ss316 increased linearly and thereafter stabilized at $70 \mathrm{mg} / \mathrm{cm}^{2}$. Sarvghad et al [229] compared ss316, duplex ss2205 and carbon steel 1008 for compatibility with $\mathrm{NaCl}-\mathrm{Na}_{2} \mathrm{CO}_{3}$ eutectics at $973 \mathrm{~K}$. Oxidation was the primary attack, and ss 316 exhibited the lowest corrosion current density due to the film formed on the surface. Sarvghad et al. [230] examined the compatibility of Inconel 601 with $\mathrm{NaCl}-\mathrm{Na}_{2} \mathrm{CO}_{3}$ eutectics and NaCl$\mathrm{Na}_{2} \mathrm{SO}_{4}$ eutectics at $973 \mathrm{~K}$. NaCl-Na2 $\mathrm{CO}_{3}$ eutectics were found 3.2 times more aggressive than $\mathrm{NaCl}-\mathrm{Na}_{2} \mathrm{SO}_{4}$ eutectics. Sarvghad et al. [231] further confirmed $\mathrm{NaCl}-\mathrm{Na}_{2} \mathrm{CO}_{3}$ eutectics were more aggressive to ss316, too.

Recently, 100\% recycled ceramics elaborated by melting and subsequent crystallization of inertized asbestos containing wastes (IACWs), municipal solid waste incinerator fly ash, coal fly ash (CFA) and steel slags tend to be popular due to the good thermo-physical properties and high thermo-mechanical strength up to $1273 \mathrm{~K}$. Guillot et al. [232] tested the corrosion compatibility between IACWs and molten salts at 473-1273 K. Compared with sulphates, phosphates, carbonates, the nitrates showed good compatibility. Calvet et al. [233] immersed Cofalit ceramic samples in Solar Salt and $\mathrm{NaNO}_{3}-\mathrm{KNO}_{3}-\mathrm{Ca}\left(\mathrm{NO}_{3}\right)_{2}$ salts for $500 \mathrm{~h}$ at $773 \mathrm{~K}$. No corrosion layer was observed on the sample surface tested in Solar Salt, while a 10- $\mu \mathrm{m}$ thick layer of calcium silicate formed on the sample surface tested in the ternary salt. Motte et al. [234] tested the thermo-chemical compatibility of IACW, CFA, electric arc furnace (EAF) steel slag, blast furnace (BF) steel slags and converter steel slags with Solar Salt for $500 \mathrm{~h}$ at $773 \mathrm{~K}$. IACW, CFA and laboratory BF steel slags could be used in direct contact with Solar Salt. Industrial BF steel slags were slightly modified, but still seemed compatible. Converter steel slags and EAF steel slags were not appropriate in a direct molten salt storage configuration. 


\section{Technical challenges in thermochemical heat storage}

Like LHS, THS also has challenges in heat transfer and cycling stability. In addition, the mechanical properties of THS materials and the design of THS systems are also issues that need to be studied.

\subsection{Heat transfer}

In THS, heat transfer exists between the HTF and the reaction bed, as well as inside the reaction bed. However, the whole heat transfer rate is usually limited by the poor convection heat transfer on the HTF side and the low thermal conduction inside the THS material powders. For example, the thermal conductivity of $\mathrm{Mg}(\mathrm{OH})_{2}$ powders was about $0.2 \mathrm{~W} /(\mathrm{m} \cdot \mathrm{K})$. Kanzawa and Arai [235] found that when heating the $\mathrm{Ca}(\mathrm{OH})_{2}$ powders from one side, only the $\mathrm{Ca}(\mathrm{OH})_{2}$ powders near the heating surface were heated and decomposed due to the low thermal conductivity. Kim et al. [236] pointed out that, in a $\mathrm{MgO} / \mathrm{H}_{2} \mathrm{O}$ packed-bed reactor, the low thermal conductivity of the reactants increased the reaction time and decreased the heat output. Effective heat transfer enhancement measures are necessary for THS systems.

The compacted composite material is an option to improve the heat transfer performance of THS systems. Shkatulov et al. [45] mixed EG with $\mathrm{Mg}(\mathrm{OH})_{2}$ to enhance the thermal conductivity, which could be further improved by compacting the mixtures. Kim et al. [236] adopted EG in $\mathrm{Mg}(\mathrm{OH})_{2}$ to increase the thermal conductivity and reactivity during dehydration and hydration. Zamengo et al. [237] succeeded in increasing the thermal conductivity of bulk $\mathrm{Mg}(\mathrm{OH})_{2}$ from $0.1-0.3 \mathrm{~W} /(\mathrm{m} \cdot \mathrm{K})$ to $1.9 \mathrm{~W} /(\mathrm{m} \cdot \mathrm{K})$ by compressing the mixtures of reactants and EG. Chaise et al. [47] mixed $\mathrm{MgH}_{2}$ with EG and found that the thermal conductivity increased from $0.48 \mathrm{~W} /(\mathrm{m} \cdot \mathrm{K})$ to $4.2 \mathrm{~W} /(\mathrm{m} \cdot \mathrm{K})$ and $1 \mathrm{~W} /(\mathrm{m} \cdot \mathrm{K})$ in the radial and axial directions, respectively. Rodríguez Sánchez et al. [238] found that a higher thermal conductivity up to $19.5 \mathrm{~W} /(\mathrm{m} \cdot \mathrm{K})$ was obtained via compacting EG/metal hydrides.

Another compromise approach to enhance heat transfer is to add the heat transfer components to reactor beds, for example, fins and metal foams. Metallic fins have been widely used to enhance heat transfer inside packed-bed reactors, as shown in Figure 9 (a). Azpiazu et al. [239] compared the performance of packed beds with and without copper fins. In the packed bed without copper fins, $\mathrm{Ca}(\mathrm{OH})_{2}$ powders with a thickness of more than $1.5 \mathrm{~cm}$ could not be completely decomposed, because it was difficult to transfer heat through the powders and reach the decomposition temperature. In the packed bed with copper fins, $\mathrm{Ca}(\mathrm{OH})_{2}$ powders were completely decomposed. However, anisotropy in heat transfer may be caused, making the effective thermal conductivity in the direction of fins one to two orders of magnitude higher than that in the direction perpendicular to fins. Embedding metal foams into the packed bed is an effective way to achieve uniform heat transfer enhancement. Metal foams could increase the thermal conductivity of hydride powders from $0.2 \mathrm{~W} /(\mathrm{m} \cdot \mathrm{K})$ to $8 \mathrm{~W} /(\mathrm{m} \cdot \mathrm{K})$ [240]. Laurencelle and Goyette [241] demonstrated that the heat storage/release time of the packed-bed reactors could be significantly reduced after embedding metal foams. As shown in Figure 9 (b), metal foams should be welded to the heat exchanger to reduce the contact thermal resistance.

The above two methods reduce the storage density per unit volume, but it can be solved by the direct THS system. Generally, the low thermal conductivity of reactant powders is caused by the gaps between particles. In a direct THS system, HTF flows through the bed, bringing the heat required for the reaction or taking away the heat generated by the reaction. HTF can also act as the gaseous reactants. In such a way, heat conduction between particles is avoided, thus enhancing the whole heat transfer. However, it is worth noting that pressure losses due to flow resistance exist in the direct THS concept, which is a crucial issue for the operation.

It should be emphasized that the chemical reaction of THS requires a suitable reaction temperature, so heat transfer must match the chemical reaction, which is different from the LHS systems and increases the complexity of THS systems. 


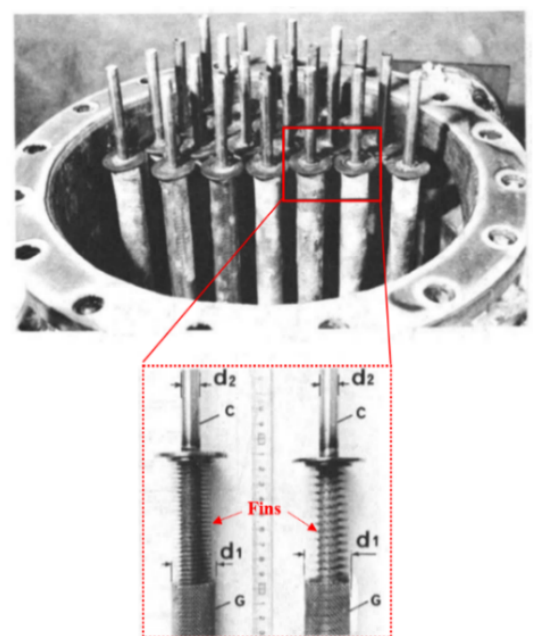

(a) Packed-bed reactor with spiral fins [242]

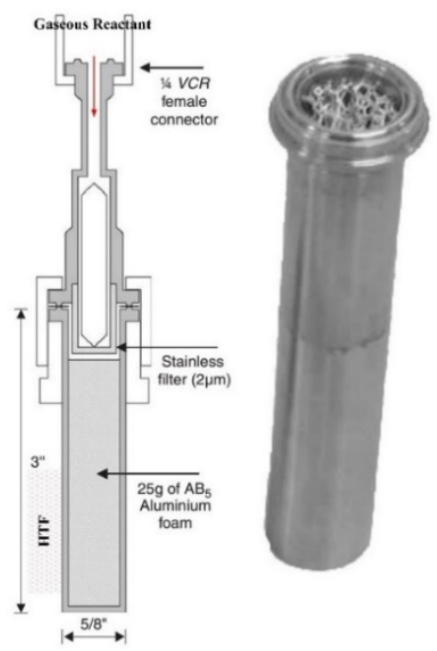

(b) Packed-bed reactor with metal foams [243]

Figure 9. Packed-bed reactor types

\subsection{Cycling stability}

The performance of THS systems may gradually decrease to an unacceptable level due to agglomeration, sintering, impurities, or by-product reactions, so cycling stability is an important factor that should be examined. The reaction rate and the extent of reaction are usually used as the criteria, because they are related with dynamic performance and heat capacity, respectively.

\subsubsection{Metallic oxide/hydroxide reactions}

Ervin [244] completed 500 and 211 cycles on $\mathrm{Mg}(\mathrm{OH})_{2}$ and $\mathrm{Ca}(\mathrm{OH})_{2}$, respectively. For $\mathrm{Mg}(\mathrm{OH})_{2}$, the capacity to lose and absorb water started at approximately 95\%, then dropped to 60-70\% within 40 cycles, and stabilized at this level for 500 cycles. No detectable changes were observed in the rates of hydration or dehydration. $\mathrm{Ca}(\mathrm{OH})_{2}$ showed better stability with the extent of reaction being about 95\% during 211 cycles. However, its reaction rate gradually decreased and then stabilized after 190 cycles. Schaube et al. [37] tested the cycling stability of $10 \mathrm{mg}$ samples for $\mathrm{CaO} / \mathrm{Ca}(\mathrm{OH})_{2}$ conversion and Schaube et al. [245] further examined $60 \mathrm{~g}$ samples. Sakellariou et al. [246] used $\mathrm{Ca}\left(\mathrm{NO}_{3}\right)_{2} \cdot 4 \mathrm{H}_{2} \mathrm{O}$ and $\mathrm{Ca}\left(\mathrm{CH}_{3} \mathrm{COO}\right)_{2} \cdot \mathrm{H}_{2} \mathrm{O}$ as $\mathrm{CaO}$ precursors for the preparation of synthetic CaO-based materials (stated as ex-CaN and ex-CaA, respectively) and carried out the cycling tests of ex-CaN and ex-CaA materials. The hydration activity was maintained up to a total cycle number of 10 and the ex-CaN materials showed measurably higher activity. Sakellariou et al. [247] further prepared CaO-based bodies using kaolinite as a binder. The combination of natural limestone and $25 \mathrm{wt} \%$ kaolinite made mechanically strong materials and no significant decrease in hydration capacity was found after 20 cycles. Dai et al. [248] developed a $\mathrm{Ca}(\mathrm{OH})_{2} / \mathrm{CaO}$ system, and found heat storage density and output temperature were high with no obvious degradation until 20 cycles. However, agglomeration was found which caused a decrease in permeability.

Kato et al. [249] compared the cycling stability of ultrafine $\mathrm{MgO}$ powders, common $\mathrm{Mg}(\mathrm{OH})_{2}$ and $\mathrm{Mg}\left(\mathrm{OC}_{2} \mathrm{H}_{5}\right)_{2}$. $\mathrm{The}$ ultrafine $\mathrm{MgO}$ powders showed high durability with the degree of reaction stabilizing after 5 cycles. The degree of reaction of common $\mathrm{Mg}(\mathrm{OH})_{2}$ continued to decrease until 15-20 cycles and stabilized at $20 \%$. The conversion of $\mathrm{Mg}\left(\mathrm{OC}_{2} \mathrm{H}_{5}\right)_{2}$ was less than $10 \%$ after 8 cycles. The impurities and growing particle sizes were the main reasons. Gravogl et al. [250] used $\mathrm{Mg}(\mathrm{OH})_{2}, \mathrm{MgCO}_{3}$ and $\mathrm{MgC}_{2} \mathrm{O}_{4} \cdot 2 \mathrm{H}_{2} \mathrm{O}$ as precursor materials to produce $\mathrm{MgO}$. Changed in the morphology of MgO particles resulted in different hydration behaviour and cycling stability. The $\mathrm{MgO}$ made from $\mathrm{MgC}_{2} \mathrm{O}_{4} \cdot 2 \mathrm{H}_{2} \mathrm{O}$ could be completely rehydrated in the first cycle and the conversion was slightly less than $50 \%$ after 5 cycles. Piperopoulos et al. [251] investigated the effect of cationic surfactant-cetyl trimethyl ammonium bromide (CTAB) on the structural and physical 
properties during the precipitation of $\mathrm{Mg}(\mathrm{OH})_{2} . \mathrm{Mg}(\mathrm{OH})_{2}$ containing $2.0 \mathrm{mM}$ CTBA had the highest volumetric stored/released heat capacity and the dehydration/hydration conversion remained at $72.7 \%$ after 8 cycles.

\subsubsection{Metal/metal hydride reactions}

Vigeholm et al. [252] considered commercially available Mg powders and found that the powders sintered into an extremely porous agglomerate after 20 cycles. Pedersen et al. [253] performed 515-cycle tests on Mg powders with a particle size of $50 \mu \mathrm{m}$. A moderate loss of hydrogen storage capacity was observed. The cycle number affected the time of maximum hydrogen absorption, but had no noticeable effect on the desorption process. Reiser et al. [254] tested on the reversibility of a Mg-based system for more than 1000 reaction cycles and showed good cycling stability.

\subsubsection{Oxide/carbonate reactions}

Barker [255] found the decomposition and synthesis of $\mathrm{CaCO}_{3}$ powders with mean particle size $10 \mu \mathrm{m}$ were not wholly reversible and suggested particle size should be less than $44 \mathrm{~nm}$ to improve the reversibility. Barker [256] further confirmed that reactivity of $93 \%$ could be achieved by using $\mathrm{CaCO}_{3}$ powders with mean particle size $10 \mathrm{~nm}$ and the reversibility did not decrease after many cycles. Aihara et al. [257] also confirmed that the reaction rate increased as the average diameter of reactant particles decreased. The addition of $\mathrm{CaTiO}_{3}$ prevented the sintering of reactive particles and improve the reaction reversibility. Criado et al. [258] recommended $\mathrm{Ca}(\mathrm{OH})_{2}$ as a by-product in the carbonation of $\mathrm{CaO}$, because hydroxylation of $\mathrm{CaO}$ was not influenced by cycling up to 20 cycles. BenitezGuerrero et al. [259] compared the cycling performance of $\mathrm{CaO}$ powders calcined from limestone, chalk and marble. During 20 cycles, deactivation was more significant for marble, followed by chalk and then limestone. Obermeier et al. [260] chose $\mathrm{Ca}\left(\mathrm{NO}_{3}\right)_{2} \cdot 4 \mathrm{H}_{2} \mathrm{O}$ and $\mathrm{Ca}\left(\mathrm{CH}_{3} \mathrm{COO}\right)_{2} \cdot \mathrm{H}_{2} \mathrm{O}$ as Ca-precursors to prepare CaO-based materials, and improved the reaction stability after 20 cycles. Furthermore, $\mathrm{Al}\left(\mathrm{NO}_{3}\right)_{2} \cdot 9 \mathrm{H}_{2} \mathrm{O}$ was used to synthesize Al-modified CaO-based compositions, which presented a deactivation of only $10 \%$ when the $\mathrm{Ca} / \mathrm{Al}$ molar ratio was 95:5.

Kato et al. [261] compared repeated $\mathrm{PbO} / \mathrm{PbCO}_{3}$ and $\mathrm{CaO} / \mathrm{CaCO}_{3}$ reactions. The reactivity of $\mathrm{PbO} / \mathrm{PbCO}_{3}$ systems was stable after 4 cycles, while a continuous decrease in the reaction amount during repetition was observed for $\mathrm{CaO} / \mathrm{CaCO}_{3}$ systems. Rhodes et al. [262] used $\mathrm{SrZrO}_{3}$ and yttria-stabilized strontium zirconate (SrYSZ) as inert support materials for the $\mathrm{SrCO}_{3} / \mathrm{SrO}$ system. The $\mathrm{SrO} / \mathrm{SrYSZ}$ exhibited better reaction performance and 40 wt $\%$ SrO/SrYSZ showed good energy storage stability decreasing from $1450 \mathrm{MJ} / \mathrm{m}^{3}$ to $1260 \mathrm{MJ} / \mathrm{m}^{3}$ during 45 cycles.

\subsubsection{Redox reactions}

Agrafiotis et al. [263] combined a $\mathrm{Co}_{3} \mathrm{O}_{4} / \mathrm{CoO}$ system with porous ceramics in an integrated thermochemical reactor/heat exchanger concept. The foam material maintained structural integrity and stoichiometric redox performance simultaneously for 30 cycles. In addition, Karagiannakis et al. [264] prepared $\mathrm{Co}_{3} \mathrm{O}_{4}$ honeycomb structures with internal extrusion and coating for the same purpose. No redox performance degradation was observed over 116 cycles.

Carrillo et al. [265] verified that $\mathrm{Mn}_{3} \mathrm{O}_{4} / \mathrm{Mn}_{2} \mathrm{O}_{3}$ could achieve a 30-cycle reversible reaction, but the cycling performance was greatly affected by particle size. Though smaller particles led to lower exothermic reaction temperature, they were easier to sinter. Carrillo et al. [53] further performed a 30-cycle test to verify the cycling stability of $\mathrm{Mn}_{2} \mathrm{O}_{3} / \mathrm{Mn}_{3} \mathrm{O}_{4}$ co-doped with $\mathrm{Cu}$ and $\mathrm{Fe}$. The samples doped with $1 \mathrm{~mol} \% \mathrm{Cu}$ presented fairly stable redox cycles, while those containing $5 \mathrm{~mol} \% \mathrm{Cu}$ showed a remarkable change in their cycling stability. Table 6 summarizes the cycling stability performance of some THS materials. 
Table 6. Cycling stability tests on THS materials

\begin{tabular}{|c|c|c|c|c|}
\hline Materials & Cycles & Reaction rates & Reaction extent & Refs. \\
\hline \multirow{4}{*}{$\mathrm{CaO} / \mathrm{Ca}(\mathrm{OH})_{2}$} & 211 & Gradual decrease up to $\sim 190$ cycles & Remained at $95 \%$ up to 211 cycles & {$[244]$} \\
\hline & 100 & -- & $\begin{array}{l}\text { In the first four cycles, } 96 \% \text { of } \mathrm{CaO} \text { can be rehydrated because of impurity; complete conversion was } \\
\text { maintained from the } 4^{\text {th }} \text { cycle and over the next } 96 \text { cycles }\end{array}$ & [37] \\
\hline & 25 & $\begin{array}{l}\text { Slight reduction at the start but } \\
\text { stabilized after } 10 \text { cycles }\end{array}$ & Fluctuated without reduction after 25 cycles and mean value approached $100 \%$ & [245] \\
\hline & 10 & $\begin{array}{l}\text { No noticeable decrease in dehydration } \\
\text { and hydration rates }\end{array}$ & No noticeable decrease in the extent of dehydration and hydration & [266] \\
\hline \multirow[b]{2}{*}{$\mathrm{MgO} / \mathrm{Mg}(\mathrm{OH})_{2}$} & 500 & $\begin{array}{l}\text { No noticeable decrease in dehydration } \\
\text { and hydration rate }\end{array}$ & Decreased from $95 \%$ to $60 \%-70 \%$ in the first 40 cycles and became stable thereafter & {$[244]$} \\
\hline & 25 & $\begin{array}{l}\text { For ultrafine } \mathrm{Mg}(\mathrm{OH})_{2} \text {, a gradual decrease } \\
\text { was observed up to } 5 \text { cycles, but stable } \\
\text { thereafter }\end{array}$ & $\begin{array}{l}\text { For ultrafine } \mathrm{Mg}(\mathrm{OH})_{2} \text {, a drop from } 60 \% \text { to } 50 \% \text { was observed in the first } 5 \text { cycles and stable thereafter; } \\
\text { for common } \mathrm{Mg}(\mathrm{OH})_{2} \text {, a drop from } 60 \% \text { to } 20 \% \text { was observed over } 24 \text { cycles; with Mg ethoxide as the } \\
\text { precursor, a drop from } 28 \% \text { to }<10 \% \text { was observed over } 10 \text { cycles }\end{array}$ & [249] \\
\hline \multirow{3}{*}{$\mathrm{CaO} / \mathrm{CaCO}_{3}$} & 7 & -- & Decreased from $\sim 70 \%$ to about $35 \%$ over 7 cycles and expected to decrease in further cycles & [261] \\
\hline & 40 & $\begin{array}{l}\text { Carbonation rate decreased over } 40 \\
\text { cycles }\end{array}$ & Carbonation $(24 \mathrm{~h})$ was nearly completed after 40 cycles & [256] \\
\hline & 30 & $\begin{array}{l}\text { Carbonation rate approached a stable } \\
\text { state after } 10 \text { cycles }\end{array}$ & The extent of decarbonation and carbonation was maintained for 30 cycles & [255] \\
\hline $\mathrm{PbO} / \mathrm{PbCO}_{3}$ & 6 & -- & Decreased from $19 \%$ to $8 \%$ in initial 4 cycles and was maintained in the next two cycles & [261] \\
\hline $\mathrm{BaO} / \mathrm{BaO}_{2}$ & 20 & -- & $\begin{array}{l}\text { Started from } 100 \% \text { in the first cycle to } 30 \%-40 \% \text { in } 20 \text { th cycle and was expected to decrease in the } \\
\text { further repetitive cycles }\end{array}$ & [267] \\
\hline \multirow[b]{2}{*}{$\mathrm{Mg} / \mathrm{MgH}_{2}$} & 30 & -- & $\begin{array}{l}\text { No reduction in absorption capacity after } 30 \text { cycles, but the desorption extent varied slightly with the } \\
\text { different commercial materials }\end{array}$ & {$[252]$} \\
\hline & 515 & $\begin{array}{l}\text { Rate of both absorption and desorption } \\
\text { did not vary noticeably as a function of } \\
\text { cycle number }\end{array}$ & Decreased gradually throughout the entire cycling tests from $80 \%$ to approximately $60 \%$ & [253] \\
\hline $\begin{array}{c}\mathrm{Mg} / \mathrm{MgH}_{2} \\
\text { (Ni-doped) }\end{array}$ & 800 & -- & $\begin{array}{l}\text { Increased in the first } 100-300 \text { cycles; nearly } 80 \% \text { hydriding efficiency was maintained after } \\
\text { stabilization }\end{array}$ & \multirow{4}{*}{ [254] } \\
\hline $\begin{array}{c}\mathrm{Mg}- \\
\mathrm{Ni} / \mathrm{Mg}_{2} \mathrm{NiH}_{4}\end{array}$ & 1100 & -- & $\begin{array}{l}\text { Approximately } 83 \% \text { hydriding efficiency was maintained throughout } 1100 \text { cycles except for several } \\
\text { fluctuations }\end{array}$ & \\
\hline $\begin{array}{c}\mathrm{Mg}- \\
\mathrm{Fe} / \mathrm{Mg}_{2} \mathrm{FeH}_{6}\end{array}$ & 550 & -- & $\begin{array}{l}\text { Hydriding extent increased from } 70 \% \text { to } 90 \% \text { in the initial } 50 \text { cycles and had an excellent cyclic } \\
\text { stability in the remaining } 500 \text { cycles }\end{array}$ & \\
\hline $\begin{array}{c}\mathrm{Mg}- \\
\mathrm{Co} / \mathrm{Mg}_{2} \mathrm{CoH}_{5}\end{array}$ & 1000 & -- & $\begin{array}{l}\text { Hydriding extent fluctuated within the range of 70\%-78\% throughout the entire } 1000 \text { cycles without } \\
\text { noticeable decrease }\end{array}$ & \\
\hline
\end{tabular}




\subsection{Mechanical properties}

In thermochemical reactors, particles or pellets made of THS materials are usually in direct contact with flowing gases (e.g., steam, air). The prerequisite for developing this technology is to minimize entrainment of the material by gases to maintain the mechanical integrity of materials.

Pagkoura et al. [51] mixed cobalt oxide with ceria, zirconia, alumina, iron oxide, silicon carbide and manganese oxide, and investigated their thermo-mechanical properties. Most composite pellets experienced varying degrees of deformation, while the pellets made from mixtures of cobalt oxide with $10 \mathrm{wt} \%$ alumina or $23 \mathrm{wt} \%$ mill-scale iron oxide showed good thermo-mechanical stability. Criado et al. [268] used sodium silicate as a binder of CaO particles for $\mathrm{CaO} / \mathrm{Ca}(\mathrm{OH})_{2}$ reversible reactions, which led to the formation of $\mathrm{Ca}$ silicates. The materials containing $\mathrm{CaCO}_{3}$ with a particle size of 36-63 $\mu \mathrm{m}$ and a molar $\mathrm{Ca} / \mathrm{Si}$ ratio of 4.8-6.2 calcined in air at $1123 \mathrm{~K}$ showed a high molar hydration conversion of 0.6-0.7 and crushing strength values greater than $2 \mathrm{~N}$ after 200 cycles. Figure 10 and Figure 11 show the crushing strength of composite materials within 200 cycles and the formation process of composite materials. Furthermore, Criado et al. [269] found that the growth of $\mathrm{Ca}(\mathrm{OH})_{2}$ grains during hydration caused the fracture of calcium silicate and led to a decrease in mechanical strength. A preparation process was proposed to improve the situation and required the exposure to around $1153 \mathrm{~K}$ in pure $\mathrm{CO}_{2}$ before calcination, as shown in Figure 12 . After 100 cycles, the crushing strength could be maintained at $28 \mathrm{~N}, 4$ times higher than the previous materials.

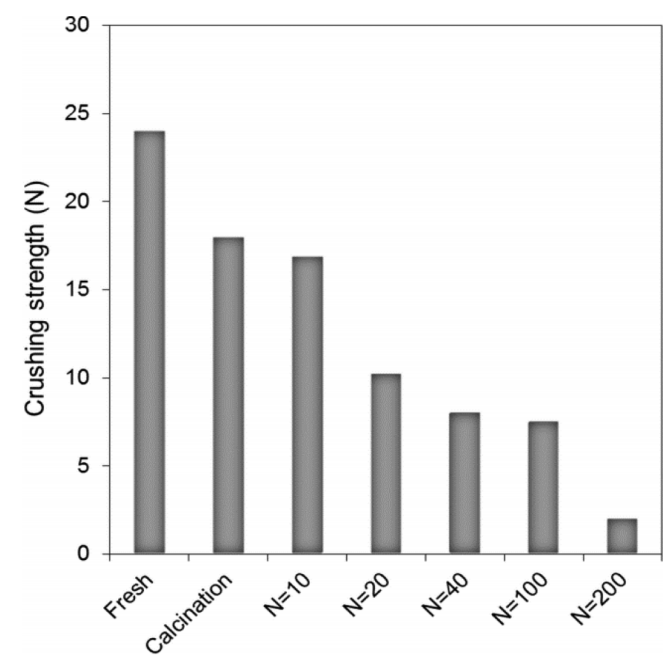

Figure 10. Crushing strength of composite materials within 200 cycles [268]

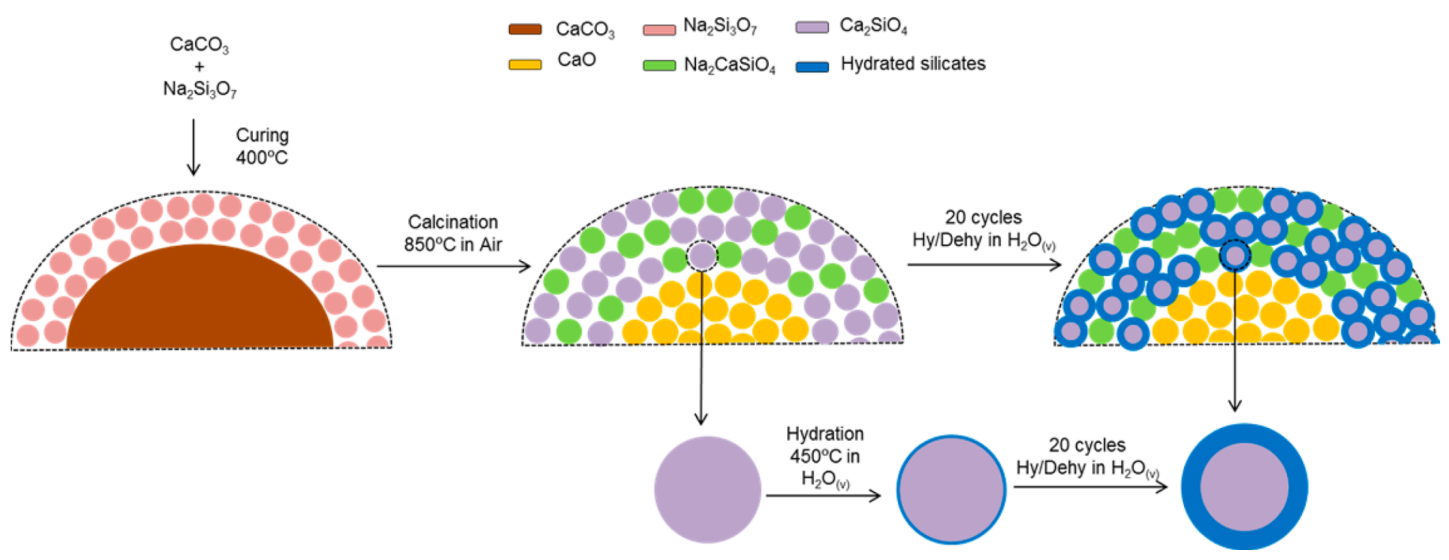

Figure 11. Formation process of composite materials [268] 


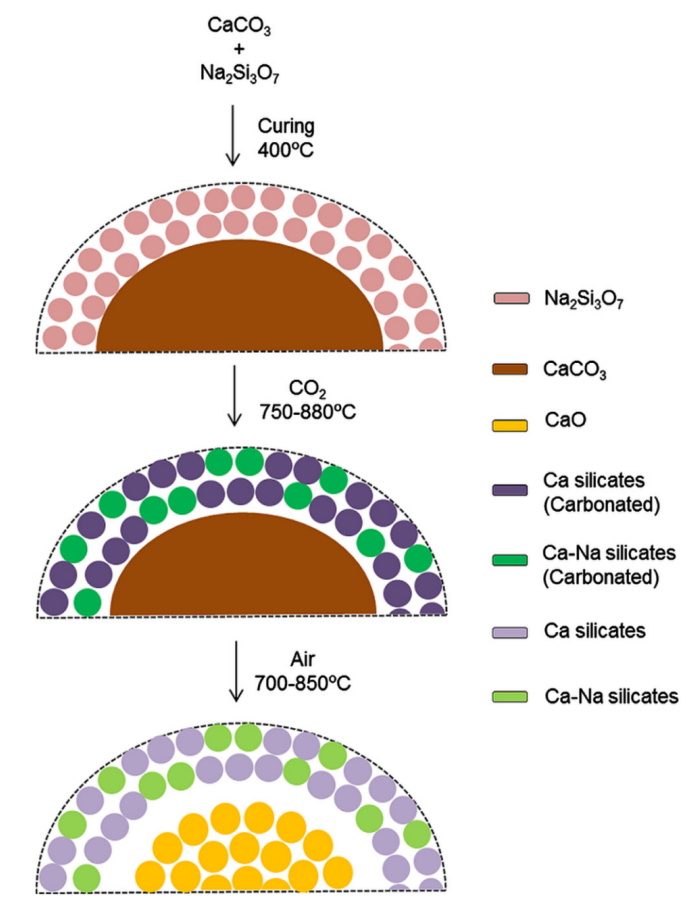

Figure 12. Formation mechanism of composite materials after two high-temperature steps: silicate formation under pure $\mathrm{CO}_{2}$ and then calcination in air [269]

Afflerbach et al. [270] developed a semi-permeable ceramic shell to enhance the mechanical properties of $\mathrm{Ca}(\mathrm{OH})_{2}$ particles, with the semi-permeable structure also ensuring the required steam transport. The crushing strength reached $86.7 \mathrm{~N}$ and then remained at $82.6 \mathrm{~N}$ after 10 cycles. Sakellariou et al. [247] chose kaolinite as a binder to develop nearly spherical structured $\mathrm{CaO}$ particles. Particles with 25 wt\% kaolinite were optimal in achieving a balance between mechanical strength and reaction performance. The crushing strength remained over $30 \mathrm{~N}$ after 20 cycles. Preisner et al. [271] added $20 \mathrm{wt} \% \mathrm{TiO}_{2}, \mathrm{ZrO}_{2}$, or $\mathrm{CeO}_{2}$ as supportive materials to $\left(\mathrm{Mn}_{0.7} \mathrm{Fe}_{0.3}\right)_{2} \mathrm{O}_{3}$ to improve mechanical strength. The additives improved the mechanical properties of manganeseiron-oxide particles, and $\mathrm{ZrO}_{2}$ had the highest resistance towards attrition.

Current measures for improving the mechanical properties of THS materials involve mainly constructing supporting structures or adding binders. However, for THS materials, supporting materials or binders are impurities and reduce the heat storage density. Therefore, finding more effective supporting structures or binders to reduce their proportion in composite materials is the next step in future research.

\subsection{Thermochemical reactors and heat storage systems}

The thermochemical reactor is the key issue to achieve the maximum conversion of reactants and increase reactor power of THS systems. Generally, the thermochemical reactor can be divided into the packed-bed reactor and the continuous reactor.

\subsubsection{Packed-bed reactor}

In a typical packed-bed reactor, solid reactants/products are placed in a fixed bed and HTF does not contact with THS materials. Packed-bed reactors can be incorporated into existing industrial systems by introducing HTF into the packed-bed reactors. However, they have disadvantages of discontinuous operation and low heat/mass transfer rates. 


\subsubsection{Performance of packed-bed reactors}

In practical thermochemical reactors, there is a coupling between chemical reactions and heat transfer; chemical reactions affect the temperature field by absorbing/releasing heat, which in turn affects chemical reactions. In addition, mass transfer is also linked to chemical reactions, especially in packed-bed reactors. Therefore, when analysing the performance of thermochemical reactors, the coupling of chemical reactions and heat/mass transfer should be considered.

The heat output/input power is essential for packed-bed reactors. Schmidt et al. [272] obtained the discharging power of a $\mathrm{CaO} / \mathrm{Ca}(\mathrm{OH})_{2}$ packed-bed reactor. In peak power mode, maximum power of $325 \mathrm{~kW}$ th $/ \mathrm{t}-\mathrm{Ca}(\mathrm{OH})_{2}$ was reached and the air outlet temperature was maintained above $723 \mathrm{~K}$ for $35 \mathrm{~min}$. In nominal power mode, heat was released at $150 \mathrm{~kW}$ th $/ \mathrm{t}-\mathrm{Ca}(\mathrm{OH})_{2}$ for an extended period and the air outlet temperature was maintained above $723 \mathrm{~K}$ for $75 \mathrm{~min}$. Yan and Zhao [273] investigated the dehydration/hydration performance of a packed-bed reactor filled with pure $\mathrm{Ca}(\mathrm{OH})_{2}$ and Li-doped $\mathrm{Ca}(\mathrm{OH})_{2}$ under various temperatures and pressures. Li-doped $\mathrm{Ca}(\mathrm{OH})_{2}$ could store heat at a lower temperature than pure $\mathrm{Ca}(\mathrm{OH})_{2}$ as illustrated in Figure 13 (a). Figure 13 (b) showed that air inside powders could impede the reaction, because air took up the channels inside the powders so that the gaseous reactants could hardly contact with the particles. Wokon et al. [274] tested approximately $500 \mathrm{~g}$ of granular manganese-iron oxide with a mean particle size of $2.13 \mathrm{~mm}$ in a $54.3 \mathrm{~mm}$-diameter tube. The charging time was reduced when the air flow rate and the air inlet temperature were augmented.

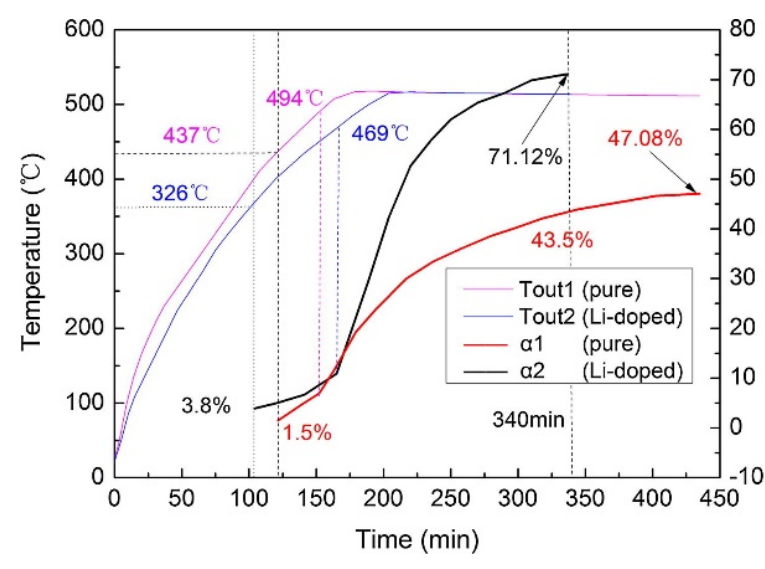

(a) Dehydration process (pure or Li-dopted)

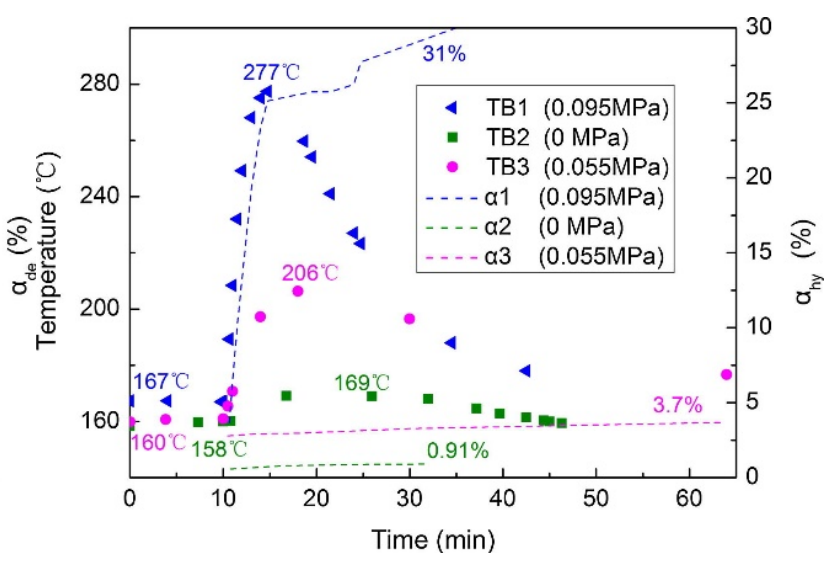

(b) Hydration process (vacuum or non-vacuum)

Figure 13. Dehydration/hydration performance of a packed-bed reactor under various operation conditions [273]

The poor heat conduction inside the THS materials is a constraint for the heat input/output power. Kim et al. [236] found that the thermal conductivity of reactants was low in packed-bed $\mathrm{MgO} / \mathrm{Mg}(\mathrm{OH})_{2}$ reactors, which prolonged reaction time and reduced heat input/output rates. Pan and Zhao [275] found that the low thermal conductivity of packed-bed reactors was induced by the thermal resistance of air among the particles. To solve this problem, Schaube et al. [276] proposed a direct-type reactor, where HTF flowed through the particles and exchanged heat with them. The direct-type reactor performed better than the indirect-type reactor in terms of heat transfer, while it came with other problems, such as pressure losses.

In addition to heat input/output power, energy storage density is also essential for thermochemical reactors, which is measured by stored heat per unit volume. Zamengo et al. [277] estimated that the heat storage density could reach $747 \mathrm{MJ} / \mathrm{m}^{3}$ for packed-bed reactors packed with compact $\mathrm{Mg}(\mathrm{OH})_{2}$ blocks and $502 \mathrm{MJ} / \mathrm{m}^{3}$ for packedbed reactors filled with $\mathrm{Mg}(\mathrm{OH})_{2}$ pellets. However, energy storage density only considers the space of the reactor bed and does not consider the space occupied by heat exchangers and gas storage tanks. The evaluation of heat storage density may need further research considering the space required by the entire system. 


\subsubsection{Packed-bed thermochemical heat storage systems}

The packed-bed thermochemical reactor and gas storage apparatus form a complete packed-bed THS system. If the gaseous reactants used in the system can be liquefied at room temperature, a simple liquid tank with heat exchangers can be used as a gas storage apparatus, as shown in Figure 14 (a). Operation conditions of these packed-bed systems can be adjusted by changing the gas pressure determined by the liquid temperature in the tank. During heat storage, the liquid is cooled to reduce gas pressure and material $\mathrm{AB}$ is heated, causing the material $\mathrm{AB}$ to decomposition. During heat release, liquid is heated to increase the gas pressure and facilitate the synthesis of material A and B. However, some gaseous reactants, such as $\mathrm{CO}_{2}$, are not easily liquefied at room temperature, which should be stored in a gas tank connected to multiple compressors, as shown in Figure 14 (b). The compressor works during the heat storage process and stops during the heat release. The compressor-gas tank mode can be substituted by the use of two reaction pairs with the same gaseous reactant, as illustrated in Figure 14 (c). The decomposition temperature and energy density of material CB are lower than those of material $\mathrm{AB}$, thus the left tank can generate large amounts of heat despite that some low-temperature energy is consumed by the right tank during heat release. Based on this concept, Kato et al. [261] proposed a $\mathrm{CaO}-\mathrm{CO}_{2}-\mathrm{PbO}$ heat storage system, thus bypassing large high-pressure gas tanks and gas compressing equipment. The heat storage rate was limited by the carbonation of $\mathrm{PbO}$, which required a larger amount of $\mathrm{PbO}$ than $\mathrm{CaO}$. Kyaw et al. [278] compared the tworeactor mode with the compressor-gas tank mode. $\mathrm{CaO}_{-} \mathrm{CO}_{2}-\mathrm{MgO}$ system was effective for temperature upgradation around $1273 \mathrm{~K}$, and the $\mathrm{CaO}-\mathrm{CO}_{2}$-compressor system was very suitable for storing and delivering heat at the same temperature. In practical applications, packed-bed heat storage systems should also be vacuumed before the operation because air affects the flow of the gaseous reactant and suppresses the thermochemical reactions.

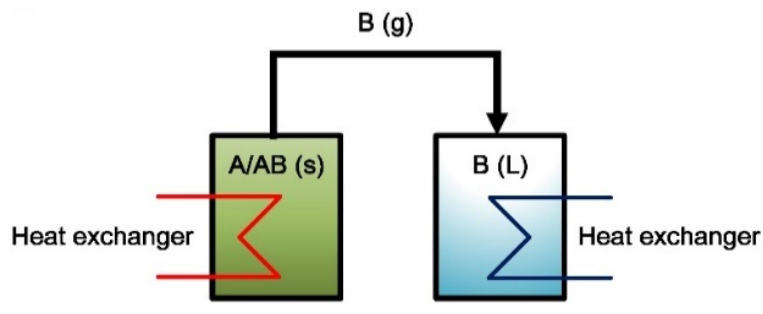

(a) The gaseous reactant stored as liquid

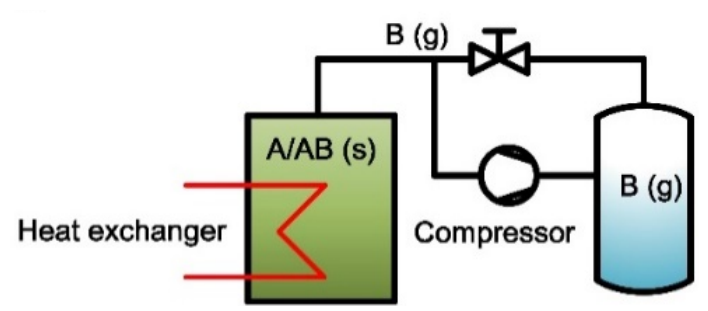

(b) The gaseous reactant stored by a compressor

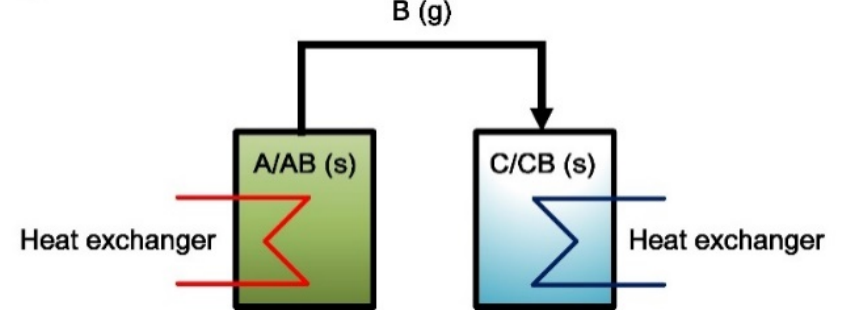

(c) The gaseous reactant stored by another chemical reaction

Figure 14. Packed-bed heat storage systems

\subsubsection{Continuous reactors}

In a continuous reactor, the reaction chamber is separate from the material storage tank, so the reactor can operate continuously during heat storage and release. Solid reactants are transferred from the storage tank into the reactor, and then once the reaction was completed, solid products are transferred to another storage tank, which makes working in steady-state and storing a large amount of heat through a relatively small reactor possible. However, continuous reactors mean material transportation, so mechanical parts are added and the cycle stability is also affected. 


\subsubsection{Performance of continuous reactors}

The prerequisite for continuous reactors is the transportation of solid materials, and an extruder is feasible for the transportation of materials. Figure 15 (a) shows an extruder reactor by combining an extruder with a heat exchange tube. The extruder makes good contact between solids and gas, which improves heat and mass transfer. A fluidizedbed reactor is another suitable choice for continuous operation, as shown in Figure 15 (b). The addition of inlets and outlets for solid materials makes this reactor different from conventional packed-bed reactors, and brings better heat and mass transfer. Zondag et al. [279] built and tested a $10 \mathrm{~kW} / 100 \mathrm{kWh}$ scale continuous fluidized bed where $270 \mathrm{~kg}$ of $\mathrm{Ca}(\mathrm{OH})_{2}$ mixed with $12 \mathrm{wt} \% \mathrm{Al}_{2} \mathrm{O}_{3}$ were filled in the storage tank. Schmidt et al. [280] designed a MW-scale fluidizedbed reactor characterized by a bubbling fluidized bed with continuous guided solid flows and immersed heat exchanger tubes. However, fluidized-bed reactors also have some disadvantages, such as more auxiliaries and more requirements for THS materials. Notably, it is challenging to find materials of suitable size and density that can be used in a fluidized bed. To overcome the drawback of the fluidized bed, a flow reactor is proposed. In a flow reactor shown in Figure 15 (c), the powders flow along the vertical plates by gravity. The heat transfer between reaction materials and HTF can be directed through plate heat exchangers or using gaseous reactants as media.

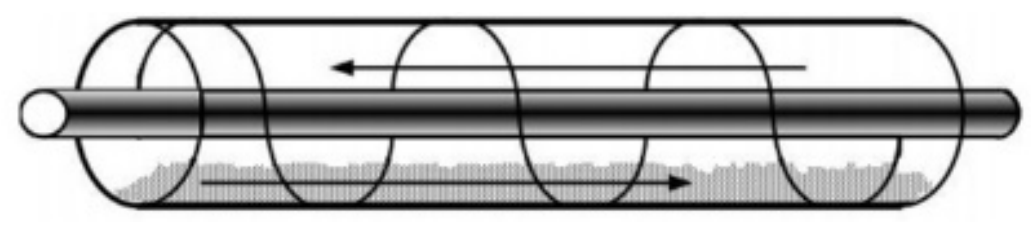

(a) Extruder reactor [279]

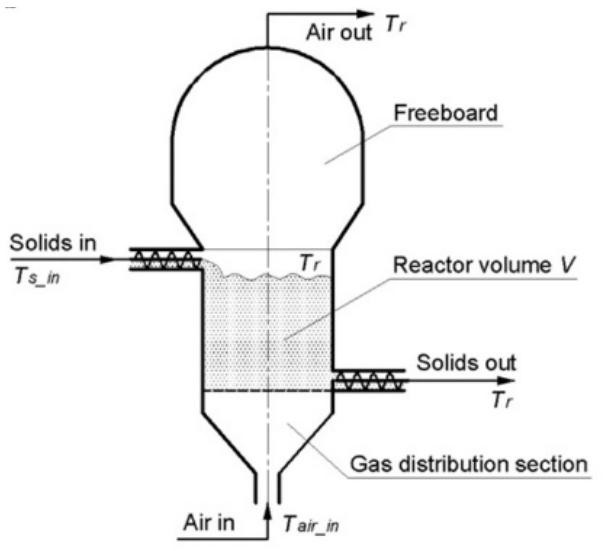

(b) Fluidized-bed reactor [279]

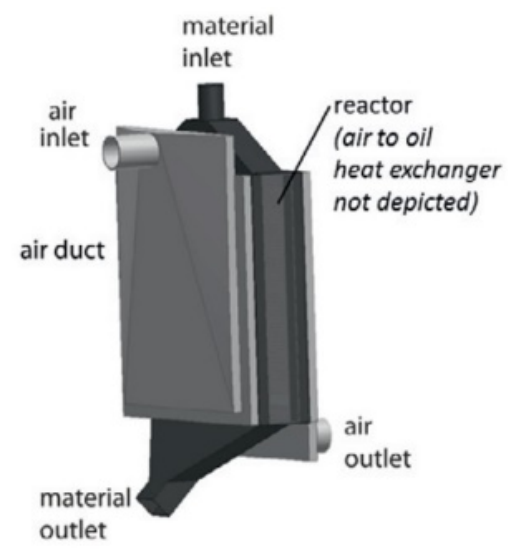

(c) Flow reactor [281]

Figure 15. Continuous reactor types 


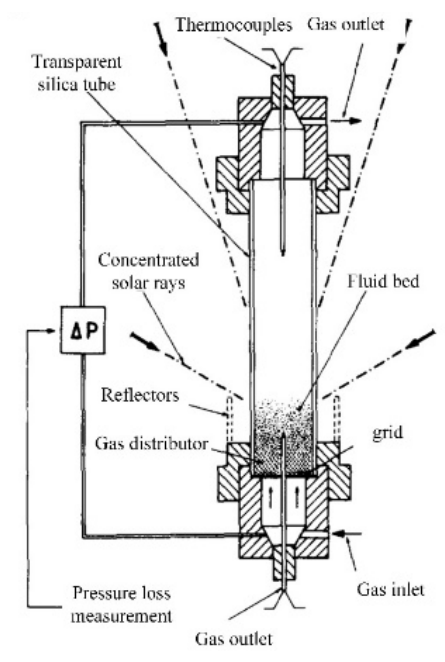

(a) Fluidized-bed reactor [284]

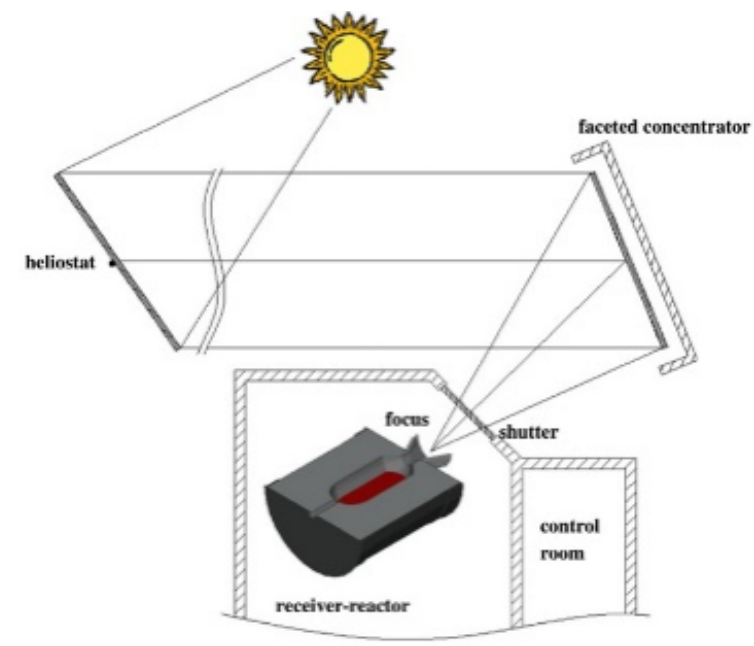

(b) Working principle of a rotary kiln [286]

Figure 16. Continuous reactors utilizing solar energy

The coupling between heat/mass transfer processes and chemical reactions in a continuous reactor is more complex than a packed-bed reactor. Farcot et al. [282] investigated a continuous reactor with a falling solid flow and a humid air crossflow, and found the presence of a sharp reaction front influenced by the air circulation in the porous bed. Flegkas et al. [283] modelled a $\mathrm{MgO} / \mathrm{Mg}(\mathrm{OH})_{2}$ fluidized-bed reactor with bundled-tube heat exchangers based on solid-state kinetics and fluidization hydrodynamics, combined with a K-L modelling approach, and showed that supplying steam during the heat release is the major drawback of the system.

From a heat source perspective, continuous reactors can directly utilize solar energy without any media. These reactors include fluidized-bed reactors and rotary kilns, as shown in Figure 16, which can work in a steady state at high temperatures. Flamant et al. [284] found that the thermal conversion efficiencies (from solar energy to chemical energy) of the fluidized bed and the rotary kiln were 0.35 and 0.1-0.3, respectively. Meier et al. [285] performed experiments on a $10-\mathrm{kW}$ solar rotary kiln reactor, which exhibited an efficiency of $20 \%$.

\subsubsection{Continuous thermochemical heat storage systems}

So far, continuous THS systems have not been fully investigated. Generally, continuous THS systems are more complex than packed-bed THS systems and include three independent loops for solids, gases and HTF, as shown in Figure 17 (a). The key to continuous operation is the loop for solid reactants. The main advantage of continuous systems is the dissociation between the thermal power and the storage capacity. The chamber where the reaction takes place is separate from the material storage tank. Meanwhile, materials A and AB should be stored in separate tanks. During heat storage, material AB is continuously introduced into the chamber to absorb heat and material A is transported from the reaction chamber to the storage tank. During heat release, material A is introduced into the chamber and reacts with material B to generate heat. Material AB is transported and stored in another storage tank.

Conventional THS systems are used to match the heat demand and supply in terms of time, so heat storage and release processes take place in the same place. However, the mismatch between heat demand and supply with respect to space is also common. In such cases, heat needs to be stored in one place, and then consumed in another place. The continuous reactor is also an alternative for this situation, as shown in Figure 17 (b). Material AB decomposes in an area where heat needs to be stored. Subsequently, product $A$ is transported to an area for heat release, where the reactor recovers material $\mathrm{AB}$ and produces thermal energy. 


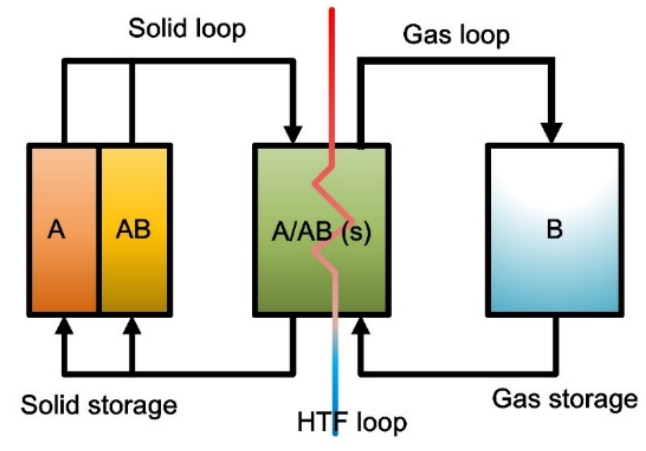

(a) Local heat storage system
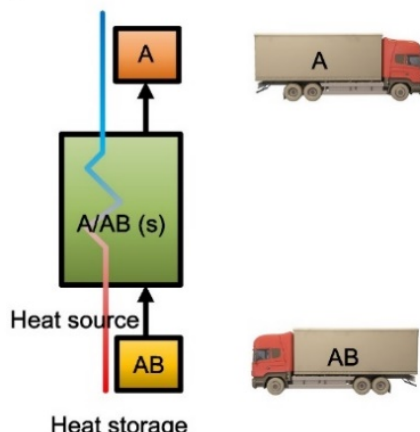

(b) Remote heat storage system

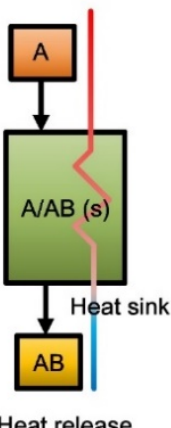

Heat release

Figure 17. Continuous heat storage systems

\section{Conclusions}

In this paper, the state-of-the-art progress in medium- and high-temperature latent and thermochemical heat storage using metals and metallic compounds as storage media was reviewed comprehensively from a technical perspective. In medium/high-temperature latent heat storage, inorganic salts and metals are often adopted as phase change materials. When inorganic salts are used, heat transfer enhancement is the key issue for thermal energy storage systems to achieve good performance, which can be divided as opportunities at three levels:

1) At the material level, particles with high thermal conductivities can be used to increase the heat conduction of inorganic salts with limited enhancement due to the non-connected heat transfer network, while highly thermal conductive porous media can harness internally connected structures to achieve greater heat transfer enhancement. A combination of both methods can lead to even better results, because it is easier to form a multi-scale and multi-dimensional heat transfer network. In any case, preparation techniques for micro/nanoencapsulated phase change materials suitable for medium/high-temperatures are still not mature.

2) At the component level, the design of heat transfer structures (e.g., fins, flow channels) is essential to achieving heat transfer enhancement. At present, the active structural optimization method represented by topology optimization can achieve high-degree-of-freedom structural optimization based on a specific optimization goal, and has been used successfully in the optimization of fin structures. An extension to the optimization of flow channels, or the combined optimization of fins and flow channels provides further possibilities for innovation in the design of storage tanks with the development of advanced processing technologies represented by 3-D printing and additive manufacturing. The research focus on macro-encapsulation is shifting from the matching of phase change materials to shell materials to how to solve the problem of preventing shell cracks based on the coupling of heat transfer and mechanics. Adding heat pipes or intermediate heat transfer media is still limited to simulation studies based on thermal network models.

3) At the system level, cascaded and packed-bed latent heat stores are two major methods for enabling heat transfer enhancement. The advantages of cascaded storage are increased heat transfer rates, reduced exergy losses, stabilized outlet temperatures and fast charging/discharging processes, which have been demonstrated via theoretical analyses, numerical simulation and experimental studies. For packed-bed latent heat storage, various numerical models have been proposed in the literature for different scenarios and applications, with the concentric-dispersion model currently being the most popular model. Relevant experimental studies are still limited. It is worth mentioning that as the energy demand diversifies towards the combined supply of cold, heat and electricity, storage systems only aimed for heat delivering need to be developed into multi-energy-vector storage systems. The integration of latent heat storage into large-scale 
electrical energy storage systems (e.g., pumped-thermal electricity storage) may be a promising solution for achieving such combined storage of cold, heat and electricity.

When the storage temperature rises above $100^{\circ} \mathrm{C}$, stability and corrosion problems tend to become more serious for phase change materials, especially for inorganic salts and metals. Stability considerations involve performance evaluation over multiple cycles and at extreme temperatures. In general, after a certain number of melting and solidification cycles, alloys and eutectic salts suffer from a degree of performance degradation (both with respect to their heat storage and heat transfer abilities) due to changes in their microstructural or chemical composition, while composite phase change materials face more severe performance degradation due to the large differences in the physical and chemical properties between phase change materials and additives, which needs further investigation, especially in long-term cycling stability tests under different working conditions. Current research on thermal stability mainly focuses on nitrate salts, carbonate salts and their composite salts. However, decomposition kinetics under different conditions and the effect of additives on their decomposition behaviour are also in need of further investigation.

Different corrosion-resistant materials can be employed for different types of phase change materials. Metals usually use ceramic materials as shells, while inorganic salts use stainless steel-based metal shells or ceramic shells. Our present knowledge of corrosion relies heavily on simple experimental testing and lacks indepth understanding of the corrosion mechanism, especially the dynamic corrosion behaviour of the shell materials immersed in phase change materials at different temperatures.

In medium/high-temperature thermochemical heat storage, metallic oxides/hydroxides reactions, metals/metal hydrides reactions, oxides/carbonates reactions and redox reactions can be used to realize reversible heat charging and discharging. In general, thermochemical heat storage materials take the form of powders, and the pores between the small particles in the stacked state lead to reduced heat transfer capabilities. Similar to latent heat storage, thermochemical storage can also benefit from heat transfer enhancement with similar approaches for achieving this. However, in terms of the detailed requirements from heat transfer enhancement, thermochemical storage differs significantly from latent storage in that the heat transfer process in thermochemical heat storage must be precisely matched to the chemical reaction and mass transfer processes. Too high or too low heat transfer may prevent the temperature from being at the optimal reaction temperature and cause the reaction to stop.

Many factors affect the cycling stability of thermochemical heat storage systems and introduce challenges to corresponding research beyond those of latent heat storage. At present, the cyclic stability of common thermochemical reactions has been tested, which confirms different degrees of degradation after cycles for thermochemical reactions of interest. However, the degradation mechanism in many cases is still not clear and needs further investigation.

Mechanical properties are also an important issue for thermochemical heat storage and relevant studies are still limited to a few materials, so an extension to further materials is recommended. Moreover, supporting materials or binders that are used to improve the mechanical property in thermochemical heat storage are impurities and reduce heat storage density, so more effective supporting structures or binders are a promising area of future research.

Finally, although packed-bed reactors and corresponding heat storage systems have been studied through numerical simulations and experimental studies, continuous reactors and corresponding heat storage systems are still at the prototype design stage. There is scope to pay more attention to continuous reactors and corresponding heat storage systems, especially since these have shown particular potential in the context of realizing seasonal and large-scale storage.

\section{Credit authorship contribution statement}

Dr. Yao Zhao: Conceptualisation, methodology, formal analysis, investigation, data curation, writing - original draft, project administration. Prof. Changying Zhao: Conceptualisation, methodology, funding acquisition, resources, supervision, writing - review and editing. Prof. Christos N. Markides: Conceptualisation, funding acquisition, supervision, writing review and editing. Dr. Hong Wang: Conceptualisation, resources. Mr. Wen Li: Conceptualisation, resources. 


\section{Declaration of competing interest}

The authors declare that there are no conflicts of interest.

\section{Acknowledgments}

This work was supported by the National Natural Science Foundation of China (Grant No. 51906150). It was also supported by the UK Engineering and Physical Sciences Research Council (EPSRC) [grant numbers EP/P004709/1, $\mathrm{EP} / \mathrm{R} 045518 / 1$, and EP/S032622/1].

\section{References}

[1] BP. BP Energy Outlook. 2019 ed. London: BP p.l.c; 2019.

[2] EIA. International Energy Outlook 2019. Washington DC: US Energy Information Administration; 2019.

[3] Ren21. Renewables 2020 Global Status Report. Paris: REN21 Secretariat; 2020.

[4] BP. Statistical Review of World Energy 2020. London: BP p.l.c; 2020.

[5] IEA. CO2 Emissions from Fuel Combustion 2019 Highlights. Paris: International Energy Agency; 2019.

[6] Markides CN. The role of pumped and waste heat technologies in a high-efficiency sustainable energy future for the UK. Applied Thermal Engineering. 2013;53:197-209.

[7] IRENA. Renewable Power Generation Costs in 2019. Abu Dhabi: International Renewable Energy Agency; 2020.

[8] DOE. Waste heat recovery: technology and opportunities in U.S. industry. Washington DC: U.S. Department of Energy; 2008.

[9] ERI. Survey report on utilization of industrial energy consumption. Beijing: Energy Research Institute, National Development and Reform Commission; 2012.

[10] Forman C, Muritala IK, Pardemann R, Meyer B. Estimating the global waste heat potential. Renewable and Sustainable Energy Reviews. 2016;57:1568-79.

[11] Ge Z, Li Y, Li D, Sun Z, Jin Y, Liu C, et al. Thermal energy storage: Challenges and the role of particle technology. Particuology. 2014;15:2-8.

[12] IEA-ETSAP, IRENA. Thermal Energy Storage-Technology Brief. 2013.

[13] Kuravi S, Trahan J, Goswami DY, Rahman MM, Stefanakos EK. Thermal energy storage technologies and systems for concentrating solar power plants. Progress in Energy and Combustion Science. 2013;39:285-319.

[14] Zhang H, Baeyens J, Cáceres G, Degrève J, Lv Y. Thermal energy storage: Recent developments and practical aspects. Progress in Energy and Combustion Science. 2016;53:1-40.

[15] Li Q Li C, Du Z, Jiang F, Ding Y. A review of performance investigation and enhancement of shell and tube thermal energy storage device containing molten salt based phase change materials for medium and high temperature applications. Applied Energy. 2019;255:113806.

[16] Carrillo AJ, Gonzalez-Aguilar J, Romero M, Coronado JM. Solar energy on demand: a review on high temperature thermochemical heat storage systems and materials. Chem Rev. 2019;119:4777-816.

[17] Fernández AI, Barreneche C, Belusko M, Segarra M, Bruno F, Cabeza LF. Considerations for the use of metal alloys as phase change materials for high temperature applications. Solar Energy Materials and Solar Cells. 2017;171:275-81.

[18] Birchenall CE, Riechman AF. Heat storage in eutectic alloys. Metallurgical Transactions A. 1980;11:1415-20.

[19] Farkas D, Birchenall CE. New eutectic alloys and their heats of transformation. Metallurgical Transactions A. 1985;16:323-8.

[20] Cherneeva L, Rodionova E, Martynova N. Use of alloys for heat storage. Izv V U Z Uchebn Energ. 1982;7:52-5.

[21] Achard P, Arefi S, Lecomte D, Mayer D. Study of heat storage at around $450{ }^{\circ} \mathrm{C}$ in aluminum-magnesium base 
alloys. 1981:98.

[22] Wang X, Liu J, Zhang Y, Di H, Jiang Y. Experimental research on a kind of novel high temperature phase change storage heater. Energy Conversion and Management. 2006;47:2211-22.

[23] Wang Z, Wang H, Li X, Wang D, Zhang Q, Chen G, et al. Aluminum and silicon based phase change materials for high capacity thermal energy storage. Applied Thermal Engineering. 2015;89:204-8.

[24] Li X, Wang H, Wang H, Kim S, Esfarjani K, Ren Z, et al. Metallic composites phase-change materials for hightemperature thermal energy storage. 7 th International Conference on Energy Sustainability. Minneapolis: ASME; 2013. [25] Wei G, Huang P, Xu C, Liu D, Ju X, Du X, et al. Thermophysical property measurements and thermal energy storage capacity analysis of aluminum alloys. Solar Energy. 2016;137:66-72.

[26] Rodríguez-Aseguinolaza J, Blanco-Rodríguez P, Risueño E, Tello MJ, Doppiu S. Thermodynamic study of the eutectic Mg49-Zn51 alloy used for thermal energy storage. Journal of Thermal Analysis and Calorimetry. 2014;117:93-9.

[27] Fang D, Sun Z, Li Y, Cheng X. Preparation, microstructure and thermal properties of MgBi alloys as phase change materials for thermal energy storage. Applied Thermal Engineering. 2016;92:187-93.

[28] Jankowski NR, McCluskey FP. A review of phase change materials for vehicle component thermal buffering. Applied Energy. 2014;113:1525-61.

[29] Bauer T, Laing D, Tamme R. Recent progress in alkali nitrate/nitrite developments for solar thermal power applications. In: Gaune-Escard M, Haarberg GM, editors. Molten Salts Chemistry and Technology. 1st ed. West Sussex: John Wiley \& Sons, Ltd; 2014. p. 543-53.

[30] Iverson BD, Broome ST, Kruizenga AM, Cordaro JG. Thermal and mechanical properties of nitrate thermal storage salts in the solid-phase. Solar Energy. 2012;86:2897-911.

[31] Roget F, Favotto C, Rogez J. Study of the KNO3-LiNO3 and KNO3-NaNO3-LiNO3 eutectics as phase change materials for thermal storage in a low-temperature solar power plant. Solar Energy. 2013;95:155-69.

[32] Zhao CY, Ji Y, Xu Z. Investigation of the Ca(NO3)2-NaNO3 mixture for latent heat storage. Solar Energy Materials and Solar Cells. 2015;140:281-8.

[33] Myers PD, Goswami DY. Thermal energy storage using chloride salts and their eutectics. Applied Thermal Engineering. 2016;109:889-900.

[34] Du L, Ding J, Tian H, Wang W, Wei X, Song M. Thermal properties and thermal stability of the ternary eutectic salt $\mathrm{NaCl}-\mathrm{CaCl} 2-\mathrm{MgCl} 2$ used in high-temperature thermal energy storage process. Applied Energy. 2017;204:1225-30.

[35] Ren N, Wu Y-t, Wang T, Ma C-f. Experimental study on optimized composition of mixed carbonate for phase change thermal storage in solar thermal power plant. Journal of Thermal Analysis and Calorimetry. 2011;104:1201-8.

[36] Misra AK. Fluoride salts as phase change materials for thermal energy storage in the temperature range 10001400 K. Journal of The Electrochemical Society. 1988;135:850-4.

[37] Schaube F, Koch L, Wörner A, Müller-Steinhagen H. A thermodynamic and kinetic study of the de- and rehydration of $\mathrm{Ca}(\mathrm{OH}) 2$ at high $\mathrm{H} 2 \mathrm{O}$ partial pressures for thermo-chemical heat storage. Thermochimica Acta. 2012;538:9-20.

[38] Criado YA, Alonso M, Abanades JC. Kinetics of the $\mathrm{CaO} / \mathrm{Ca}(\mathrm{OH}) 2$ hydration/dehydration reaction for thermochemical energy storage applications. Industrial \& Engineering Chemistry Research. 2014;53:12594-601.

[39] Murthy MS, Raghavendrachar P, Sriram SV. Thermal decomposition of doped calcium hydroxide for chemical energy storage. Solar Energy. 1986;36:53-62.

[40] Fujii I, Tsuchiya K, Shikakura Y, Murthy MS. Consideration on thermal decomposition of calcium hydroxide pellets for energy storage. Journal of Solar Energy Engineering. 1989;111:245-50.

[41] Kato Y, Yamashita N, Yoshizawa Y. Study of chemical heat pump with reaction system of magnesium oxide/water. activation of magnesium oxide hydration. Kagaku Kogaku Ronbunshu. 1993;19:1213-6.

[42] Kato Y, Yamashita N, Kobayashi K, Yoshizawa Y. Kinetic study of the hydration of magnesium oxide for a chemical heat pump. Applied Thermal Engineering. 1996;16:853-62. 
[43] Ryu J, Hirao N, Takahashi R, Kato Y. Dehydration behavior of metal-salt-added magnesium hydroxide as chemical heat storage media. Chemistry Letters. 2008;37:1140-1.

[44] Kato Y, Takahashi R, Sekiguchi T, Ryu J. Study on medium-temperature chemical heat storage using mixed hydroxides. International Journal of Refrigeration. 2009;32:661-6.

[45] Shkatulov A, Ryu J, Kato Y, Aristov Y. Composite material "Mg(OH)2/vermiculite": A promising new candidate for storage of middle temperature heat. Energy. 2012;44:1028-34.

[46] Bogdanović B, Ritter A, Spliethoff B. Active MgH2-Mg systems for reversible chemical energy storage. Angewandte Chemie International Edition in English. 1990;29:223-34.

[47] Chaise A, de Rango P, Marty P, Fruchart D. Experimental and numerical study of a magnesium hydride tank. International Journal of Hydrogen Energy. 2010;35:6311-22.

[48] Kato Y, Saku D, Harada N, Yoshizawa Y. Utilization of high temperature heat using a calcium oxide/lead oxide/carbon dioxide chemical heat pump. Journal of Chemical Engineering of Japan. 1997;30:1013-9.

[49] Wong B, Brown L, Schaube F, Tamme R, Sattler C. Oxide based thermochemical heat storage. SolarPACES, Perpignan, France. 2010:21-4.

[50] Agrafiotis C, Roeb M, Schmücker M, Sattler C. Exploitation of thermochemical cycles based on solid oxide redox systems for thermochemical storage of solar heat. Part 1: Testing of cobalt oxide-based powders. Solar Energy. 2014;102:189-211.

[51] Pagkoura C, Karagiannakis G, Zygogianni A, Lorentzou S, Kostoglou M, Konstandopoulos AG, et al. Cobalt oxide based structured bodies as redox thermochemical heat storage medium for future CSP plants. Solar Energy. 2014;108:146-63.

[52] Carrillo AJ, Serrano DP, Pizarro P, Coronado JM. Improving the thermochemical energy storage performance of the Mn2O3/Mn304 redox couple by the incorporation of iron. ChemSusChem. 2015;8:1947-54.

[53] Carrillo AJ, Serrano DP, Pizarro P, Coronado JM. Manganese oxide-based thermochemical energy storage: Modulating temperatures of redox cycles by Fe-Cu co-doping. Journal of Energy Storage. 2016;5:169-76.

[54] Tian H, Du L, Wei X, Deng S, Wang W, Ding J. Enhanced thermal conductivity of ternary carbonate salt phase change material with Mg particles for solar thermal energy storage. Applied Energy. 2017;204:525-30.

[55] Shin D, Banerjee D. Enhanced thermal properties of SiO2 nanocomposite for solar thermal energy storage applications. International Journal of Heat and Mass Transfer. 2015;84:898-902.

[56] Myers PD, Alam TE, Kamal R, Goswami DY, Stefanakos E. Nitrate salts doped with CuO nanoparticles for thermal energy storage with improved heat transfer. Applied Energy. 2016;165:225-33.

[57] Wei X, Yin Y, Qin B, Ding J, Lu J. Thermal conductivity improvement of liquid nitrate and carbonate salts doped with MgO particles. Energy Procedia. 2017;142:407-12.

[58] Saranprabhu MK, Rajan KS. Magnesium oxide nanoparticles dispersed solar salt with improved solid phase thermal conductivity and specific heat for latent heat thermal energy storage. Renewable Energy. 2019;141:451-9.

[59] Han Z, Ram MK, Kamal R, Alamro T, Goswami DY, Jotshi C. Characterization of molten salt doped with different size nanoparticles of Al203. International Journal of Energy Research. 2019;43:3732-45.

[60] Zhang Z, Yuan Y, Ouyang L, Sun Q, Cao X, Alelyani S. Enhanced thermal properties of Li2CO3-Na2CO3-K2CO3 nanofluids with nanoalumina for heat transfer in high-temperature CSP systems. Journal of Thermal Analysis and Calorimetry. 2016;128:1783-92.

[61] Zhang Z, Yuan Y, Ouyang L, Zhang H, Cao X, Sun L, et al. Thermal properties of ternary carbonate/T-ZnOw for thermal energy storage in high-temperature concentrating solar power systems. Composites Part A: Applied Science and Manufacturing. 2017;93:177-84.

[62] Awad A, Navarro H, Ding Y, Wen D. Thermal-physical properties of nanoparticle-seeded nitrate molten salts. Renewable Energy. 2018;120:275-88.

[63] Ueki Y, Fujita N, Kawai M, Shibahara M. Molten salt thermal conductivity enhancement by mixing nanoparticles. Fusion Engineering and Design. 2018;136:1295-9. 
[64] Jiang Z, Jiang F, Li C, Leng G, Zhao X, Li Y, et al. A form stable composite phase change material for thermal energy storage applications over $700^{\circ} \mathrm{C}$. Applied Sciences. 2019;9:814.

[65] Deng ZF, Tan H, Zhang GQ Xu GZ, Yang CY, Chang L, et al. Effects of SiO2/SiC particles on the thermal stability of carbonate eutectic salt/ceramic composite. IOP Conference Series: Materials Science and Engineering. 2019;504:012034.

[66] Pincemin S, Olives R, Py X, Christ M. Highly conductive composites made of phase change materials and graphite for thermal storage. Solar Energy Materials and Solar Cells. 2008;92:603-13.

[67] Lachheb M, Adili A, Albouchi F, Mzali F, Ben Nasrallah S. Thermal properties improvement of Lithium nitrate/Graphite composite phase change materials. Applied Thermal Engineering. 2016;102:922-31.

[68] Ge Z, Ye F, Cao H, Leng G, Qin Y, Ding Y. Carbonate-salt-based composite materials for medium- and hightemperature thermal energy storage. Particuology. 2014;15:77-81.

[69] Ye F, Ge Z, Ding Y, Yang J. Multi-walled carbon nanotubes added to Na2CO3/MgO composites for thermal energy storage. Particuology. 2014;15:56-60.

[70] Hamdy E, Ebrahim S, Abulfotuh F, Soliman M. Effect of multi-walled carbon nanotubes on thermal properties of nitrate molten salts. 2016 International Renewable and Sustainable Energy Conference (IRSEC)2016. p. 317-20.

[71] Wu Y, Li J, Wang M, Wang H, Zhong Y, Zhao Y, et al. Solar salt doped by MWCNTs as a promising high thermal conductivity material for CSP. RSC Advances. 2018;8:19251-60.

[72] Dayou S, Vigolo B, Ghanbaja J, Kairi MI, Mohd Zuhan MKN, Mohamed AR. Direct growth of graphene on MgO by chemical vapor deposition for thermal conductivity enhancement of phase change material. Materials Chemistry and Physics. 2017;202:352-7.

[73] Tao YB, Lin CH, He YL. Preparation and thermal properties characterization of carbonate salt/carbon nanomaterial composite phase change material. Energy Conversion and Management. 2015;97:103-10.

[74] Guo Q Wang T. Study on preparation and thermal properties of sodium nitrate/silica composite as shapestabilized phase change material. Thermochimica Acta. 2015;613:66-70.

[75] Jiang Z, Leng G, Ye F, Ge Z, Liu C, Wang L, et al. Form-stable LiNO3-NaNO3-KNO3-Ca(NO3)2/calcium silicate composite phase change material (PCM) for mid-low temperature thermal energy storage. Energy Conversion and Management. 2015;106:165-72.

[76] Li R, Zhu J, Zhou W, Cheng X, Li Y. Thermal compatibility of Sodium Nitrate/Expanded Perlite composite phase change materials. Applied Thermal Engineering. 2016;103:452-8.

[77] do Couto Aktay KS, Tamme R, Müller-Steinhagen H. Thermal conductivity of high-temperature multicomponent materials with phase change. International Journal of Thermophysics. 2007;29:678-92.

[78] Steinmann W-D, Tamme R. Latent heat storage for solar steam systems. Journal of Solar Energy Engineering. 2008;130.

[79] Acem Z, Lopez J, Palomo Del Barrio E. KNO3/NaNO3-Graphite materials for thermal energy storage at high temperature: Part I. Elaboration methods and thermal properties. Applied Thermal Engineering. 2010;30:1580-5.

[80] Xiao X, Zhang P, Li M. Thermal characterization of nitrates and nitrates/expanded graphite mixture phase change materials for solar energy storage. Energy Conversion and Management. 2013;73:86-94.

[81] Xiao J, Huang J, Zhu P, Wang C, Li X. Preparation, characterization and thermal properties of binary nitrate salts/expanded graphite as composite phase change material. Thermochimica Acta. 2014;587:52-8.

[82] Zhong L, Zhang X, Luan Y, Wang G, Feng Y, Feng D. Preparation and thermal properties of porous heterogeneous composite phase change materials based on molten salts/expanded graphite. Solar Energy. 2014;107:63-73.

[83] Huang Z, Gao X, Xu T, Fang Y, Zhang Z. Thermal property measurement and heat storage analysis of LiNO3/KClexpanded graphite composite phase change material. Applied Energy. 2014;115:265-71.

[84] Tian H, Wang W, Ding J, Wei X, Song M, Yang J. Thermal conductivities and characteristics of ternary eutectic chloride/expanded graphite thermal energy storage composites. Applied Energy. 2015;148:87-92.

[85] Li Y, Li P, Zhu QZ, Li QF. Preparation and thermal characterization of nitrates/expanded graphite composite 
phase-change material for thermal energy storage. International Journal of Thermophysics. 2016;37:104.

[86] Liu J, Wang Q Ling Z, Fang X, Zhang Z. A novel process for preparing molten salt/expanded graphite composite phase change blocks with good uniformity and small volume expansion. Solar Energy Materials and Solar Cells. 2017;169:280-6.

[87] Xu T, Li Y, Chen J, Liu J. Preparation and thermal energy storage properties of LiNO3-KCl-NaNO3/expanded graphite composite phase change material. Solar Energy Materials and Solar Cells. 2017;169:215-21.

[88] Ren Y, Xu C, Yuan M, Ye F, Ju X, Du X. Ca(NO3)2-NaNO3/expanded graphite composite as a novel shape-stable phase change material for mid- to high-temperature thermal energy storage. Energy Conversion and Management. 2018;163:50-8.

[89] Lopez J, Acem Z, Palomo Del Barrio E. KNO3/NaNO3-Graphite materials for thermal energy storage at high temperature: Part II. Phase transition properties. Applied Thermal Engineering. 2010;30:1586-93.

[90] Wu ZG, Zhao CY. Experimental investigations of porous materials in high temperature thermal energy storage systems. Solar Energy. 2011;85:1371-80.

[91] Gao D, Chen Z, Chen L. A thermal lattice Boltzmann model for natural convection in porous media under local thermal non-equilibrium conditions. International Journal of Heat and Mass Transfer. 2014;70:979-89.

[92] Chen Z, Gao D, Shi J. Experimental and numerical study on melting of phase change materials in metal foams at pore scale. International Journal of Heat and Mass Transfer. 2014;72:646-55.

[93] Zhao Y, Zhao CY, Xu ZG, Xu HJ. Modeling metal foam enhanced phase change heat transfer in thermal energy storage by using phase field method. International Journal of Heat and Mass Transfer. 2016;99:170-81.

[94] Sundarram SS, Li W. The effect of pore size and porosity on thermal management performance of phase change material infiltrated microcellular metal foams. Applied Thermal Engineering. 2014;64:147-54.

[95] Yang J, Yang L, Xu C, Du X. Numerical analysis on thermal behavior of solid-liquid phase change within copper foam with varying porosity. International Journal of Heat and Mass Transfer. 2015;84:1008-18.

[96] Zhao CY, Wu ZG. Heat transfer enhancement of high temperature thermal energy storage using metal foams and expanded graphite. Solar Energy Materials and Solar Cells. 2011;95:636-43.

[97] Zhang P, Xiao X, Meng ZN, Li M. Heat transfer characteristics of a molten-salt thermal energy storage unit with and without heat transfer enhancement. Applied Energy. 2015;137:758-72.

[98] Lafdi K, Mesalhy O, Elgafy A. Graphite foams infiltrated with phase change materials as alternative materials for space and terrestrial thermal energy storage applications. Carbon. 2008;46:159-68.

[99] Kim T, France DM, Yu W, Zhao W, Singh D. Heat transfer analysis of a latent heat thermal energy storage system using graphite foam for concentrated solar power. Solar Energy. 2014;103:438-47.

[100] Zhao W, France DM, Yu W, Kim T, Singh D. Phase change material with graphite foam for applications in hightemperature latent heat storage systems of concentrated solar power plants. Renewable Energy. 2014;69:134-46.

[101] Singh D, Kim T, Zhao W, Yu W, France DM. Development of graphite foam infiltrated with MgCl2 for a latent heat based thermal energy storage (LHTES) system. Renewable Energy. 2016;94:660-7.

[102] Li J, Lu W, Luo Z, Zeng Y. Synthesis and thermal properties of novel sodium nitrate microcapsules for hightemperature thermal energy storage. Solar Energy Materials and Solar Cells. 2017;159:440-6.

[103] Wu X, Fan M, Cui S, Tan G, Shen X. Novel Na2SO4@SiO2 phase change material with core-shell structures for high temperature thermal storage. Solar Energy Materials and Solar Cells. 2018;178:280-8.

[104] Zhang H, Balram A, Tiznobaik H, Shin D, Santhanagopalan S. Microencapsulation of molten salt in stable silica shell via a water-limited sol-gel process for high temperature thermal energy storage. Applied Thermal Engineering. 2018;136:268-74.

[105] Zhang H, Shin D, Santhanagopalan S. Microencapsulated binary carbonate salt mixture in silica shell with enhanced effective heat capacity for high temperature latent heat storage. Renewable Energy. 2019;134:1156-62.

[106] Gupta A, Mathie R, Markides C. An experimental and computational investigation of a thermal storage system based on a phase change material: heat transfer and performance characterization. Computational Thermal Sciences: An International Journal. 2014;6:341-59. 
[107] Laing D, Bauer T, Steinmann W, Lehmann D. Advanced high temperature latent heat storage system-design and test results. Effstock 2009. Stockholm2009.

[108] Tao YB, He YL. Effects of natural convection on latent heat storage performance of salt in a horizontal concentric tube. Applied Energy. 2015;143:38-46.

[109] Ma Z, Yang W-W, Yuan F, Jin B, He Y-L. Investigation on the thermal performance of a high-temperature latent heat storage system. Applied Thermal Engineering. 2017;122:579-92.

[110] Alayil R, Balaji C. Conjugate heat transfer in latent heat thermal storage system with cross plate fins. Journal of Heat Transfer. 2015;137.

[111] Sciacovelli A, Gagliardi F, Verda V. Maximization of performance of a PCM latent heat storage system with innovative fins. Applied Energy. 2015;137:707-15.

[112] Sciacovelli A, Božidar Šarler PNMP, Verda V. Second-law design of a latent heat thermal energy storage with branched fins. International Journal of Numerical Methods for Heat \& Fluid Flow. 2016;26:489-503.

[113] Pizzolato A, Sharma A, Maute K, Sciacovelli A, Verda V. Design of effective fins for fast PCM melting and solidification in shell-and-tube latent heat thermal energy storage through topology optimization. Applied Energy. 2017;208:210-27.

[114] Zhao Y, Liu H, You Y, Zhao C. Numerical and experimental study on topology optimization of fin configuration in latent heat storage. ISES Solar World Conference 2019. Santiago, Chile: International Solar Energy Society; 2019.

[115] Pizzolato A, Sharma A, Maute K, Sciacovelli A, Verda V. Topology optimization for heat transfer enhancement in latent heat thermal energy storage. International Journal of Heat and Mass Transfer. 2017;113:875-88.

[116] Pizzolato A, Sharma A, Ge R, Maute K, Verda V, Sciacovelli A. Maximization of performance in multi-tube latent heat storage-Optimization of fins topology, effect of materials selection and flow arrangements. Energy. 2020;203.

[117] Tao YB, He YL, Qu ZG. Numerical study on performance of molten salt phase change thermal energy storage system with enhanced tubes. Solar Energy. 2012;86:1155-63.

[118] Pitié F, Zhao CY, Cáceres G. Thermo-mechanical analysis of ceramic encapsulated phase-change-material (PCM) particles. Energy \& Environmental Science. 2011;4:2117-24.

[119] Zheng Y, Zhao W, Sabol JC, Tuzla K, Neti S, Oztekin A, et al. Encapsulated phase change materials for energy storage-Characterization by calorimetry. Solar Energy. 2013;87:117-26.

[120] Elmozughi AF, Solomon L, Oztekin A, Neti S. Encapsulated phase change material for high temperature thermal energy storage-Heat transfer analysis. International Journal of Heat and Mass Transfer. 2014;78:1135-44.

[121] Archibold AR, Gonzalez-Aguilar J, Rahman MM, Yogi Goswami D, Romero M, Stefanakos EK. The melting process of storage materials with relatively high phase change temperatures in partially filled spherical shells. Applied Energy. 2014;116:243-52.

[122] Solomon L, Elmozughi AF, Oztekin A, Neti S. Effect of internal void placement on the heat transfer performance-Encapsulated phase change material for energy storage. Renewable Energy. 2015;78:438-47.

[123] Shabgard H, Bergman TL, Sharifi N, Faghri A. High temperature latent heat thermal energy storage using heat pipes. International Journal of Heat and Mass Transfer. 2010;53:2979-88.

[124] Nithyanandam K, Pitchumani R. Analysis and optimization of a latent thermal energy storage system with embedded heat pipes. International Journal of Heat and Mass Transfer. 2011;54:4596-610.

[125] Robak CW, Bergman TL, Faghri A. Economic evaluation of latent heat thermal energy storage using embedded thermosyphons for concentrating solar power applications. Solar Energy. 2011;85:2461-73.

[126] Jung EG, Boo JH. Thermal analytical model of latent thermal storage with heat pipe heat exchanger for concentrated solar power. Solar Energy. 2014;102:318-32.

[127] Khalifa A, Tan L, Date A, Akbarzadeh A. A numerical and experimental study of solidification around axially finned heat pipes for high temperature latent heat thermal energy storage units. Applied Thermal Engineering. 2014;70:609-19.

[128] Tiari S, Qiu S, Mahdavi M. Numerical study of finned heat pipe-assisted thermal energy storage system with 
high temperature phase change material. Energy Conversion and Management. 2015;89:833-42.

[129] Almsater S, Saman W, Bruno F. Performance enhancement of high temperature latent heat thermal storage systems using heat pipes with and without fins for concentrating solar thermal power plants. Renewable Energy. 2016;89:36-50. [130] Farid MM, Kanzawa A. Thermal performance of a heat storage module using PCM's with different melting temperatures: mathematical modeling. Journal of Solar Energy Engineering. 1989;111:152-7.

[131] Farid MM, Kim Y, Kansawa A. Thermal performance of a heat storage module using PCM's with different melting temperature: experimental. Journal of Solar Energy Engineering. 1990;112:125-31.

[132] Cui H, Yuan X, Hou X. Thermal performance analysis for a heat receiver using multiple phase change materials. Applied Thermal Engineering. 2003;23:2353-61.

[133] Michels H, Pitz-Paal R. Cascaded latent heat storage for parabolic trough solar power plants. Solar Energy. 2007;81:829-37.

[134] Seeniraj RV, Lakshmi Narasimhan N. Performance enhancement of a solar dynamic LHTS module having both fins and multiple PCMs. Solar Energy. 2008;82:535-42.

[135] Li YQ He YL, Song HJ, Xu C, Wang WW. Numerical analysis and parameters optimization of shell-and-tube heat storage unit using three phase change materials. Renewable Energy. 2013;59:92-9.

[136] Shamsi H, Boroushaki M, Geraei H. Performance evaluation and optimization of encapsulated cascade PCM thermal storage. Journal of Energy Storage. 2017;11:64-75.

[137] Hale M. Survey of thermal storage for parabolic trough power plants. Golden: National Renewable Energy Laboratory; 2000.

[138] Lim JS, Bejan A, Kim JH. Thermodynamic optimization of phase-change energy storage using two or more materials. Journal of Energy Resources Technology. 1992;114:84-90.

[139] Aceves-Saborio S, Nakamura H, Reistad GM. Optimum efficiencies and phase change temperatures in latent heat storage systems. Journal of Energy Resources Technology. 1994;116:79-86.

[140] Gong ZX, Mujumdar AS. Exergetic analysis of energy storage using multiple phase-change materials. Journal of Energy Resources Technology. 1996;118:242-8.

[141] Xu HJ, Zhao CY. Thermal efficiency analysis of the cascaded latent heat/cold storage with multi-stage heat engine model. Renewable Energy. 2016;86:228-37.

[142] Shabgard H, Robak CW, Bergman TL, Faghri A. Heat transfer and exergy analysis of cascaded latent heat storage with gravity-assisted heat pipes for concentrating solar power applications. Solar Energy. 2012;86:816-30. [143] Li Y-Q He Y-L, Wang Z-F, Xu C, Wang W. Exergy analysis of two phase change materials storage system for solar thermal power with finite-time thermodynamics. Renewable Energy. 2012;39:447-54.

[144] Tian Y, Zhao CY. Thermal and exergetic analysis of metal foam-enhanced cascaded thermal energy storage (MF-CTES). International Journal of Heat and Mass Transfer. 2013;58:86-96.

[145] Solomon L, Oztekin A. Exergy analysis of cascaded encapsulated phase change material-High-temperature thermal energy storage systems. Journal of Energy Storage. 2016;8:12-26.

[146] Guo Z-Y, Zhu H-Y, Liang X-G. Entransy-A physical quantity describing heat transfer ability. International Journal of Heat and Mass Transfer. 2007;50:2545-56.

[147] Xu HJ, Zhao CY. Thermal performance of cascaded thermal storage with phase-change materials (PCMs). Part I: Steady cases. International Journal of Heat and Mass Transfer. 2017;106:932-44.

[148] Tao YB, He YL, Liu YK, Tao WQ. Performance optimization of two-stage latent heat storage unit based on entransy theory. International Journal of Heat and Mass Transfer. 2014;77:695-703.

[149] Xu HJ, Zhao CY. Thermodynamic analysis and optimization of cascaded latent heat storage system for energy efficient utilization. Energy. 2015;90:1662-73.

[150] Yuan F, Li M-J, Ma Z, Jin B, Liu Z. Experimental study on thermal performance of high-temperature molten salt cascaded latent heat thermal energy storage system. International Journal of Heat and Mass Transfer. 2018;118:997-1011.

[151] Zhao Y, You Y, Liu HB, Zhao CY, Xu ZG. Experimental study on the thermodynamic performance of cascaded 
latent heat storage in the heat charging process. Energy. 2018;157:690-706.

[152] Tumilowicz E, Chan CL, Li P, Xu B. An enthalpy formulation for thermocline with encapsulated PCM thermal storage and benchmark solution using the method of characteristics. International Journal of Heat and Mass Transfer. 2014;79:362-77.

[153] Bindra H, Bueno P, Morris JF, Shinnar R. Thermal analysis and exergy evaluation of packed bed thermal storage systems. Applied Thermal Engineering. 2013;52:255-63.

[154] Peng H, Dong H, Ling X. Thermal investigation of PCM-based high temperature thermal energy storage in packed bed. Energy Conversion and Management. 2014;81:420-7.

[155] Wu M, Xu C, He Y-L. Dynamic thermal performance analysis of a molten-salt packed-bed thermal energy storage system using PCM capsules. Applied Energy. 2014;121:184-95.

[156] Galione PA, Pérez-Segarra CD, Rodríguez I, Lehmkuhl 0, Rigola J. A new thermocline-PCM thermal storage concept for CSP plants. Numerical analysis and perspectives. Energy Procedia. 2014;49:790-9.

[157] Zhao B-c, Cheng M-s, Liu C, Dai Z-m. Thermal performance and cost analysis of a multi-layered solid-PCM thermocline thermal energy storage for CSP tower plants. Applied Energy. 2016;178:784-99.

[158] Wu M, Xu C, He Y. Cyclic behaviors of the molten-salt packed-bed thermal storage system filled with cascaded phase change material capsules. Applied Thermal Engineering. 2016;93:1061-73.

[159] Elfeky KE, Ahmed N, Wang Q. Numerical comparison between single PCM and multi-stage PCM based high temperature thermal energy storage for CSP tower plants. Applied Thermal Engineering. 2018;139:609-22.

[160] Bellan S, Alam TE, González-Aguilar J, Romero M, Rahman MM, Goswami DY, et al. Numerical and experimental studies on heat transfer characteristics of thermal energy storage system packed with molten salt PCM capsules. Applied Thermal Engineering. 2015;90:970-9.

[161] Zanganeh G, Commerford M, Haselbacher A, Pedretti A, Steinfeld A. Stabilization of the outflow temperature of a packed-bed thermal energy storage by combining rocks with phase change materials. Applied Thermal Engineering. 2014;70:316-20.

[162] Li M-J, Jin B, Ma Z, Yuan F. Experimental and numerical study on the performance of a new high-temperature packed-bed thermal energy storage system with macroencapsulation of molten salt phase change material. Applied Energy. 2018;221:1-15.

[163] Li M-J, Jin B, Yan J-J, Ma Z, Li M-J. Numerical and Experimental study on the performance of a new two-layered high-temperature packed-bed thermal energy storage system with changed-diameter macro-encapsulation capsule. Applied Thermal Engineering. 2018;142:830-45.

[164] Li F, Hu YJ, Zhang RY. The influence of heating-cooling cycles on the thermal storage performances of Al-17 wt.\% Si alloy. Advanced Materials Research: Trans Tech Publ; 2011. p. 2248-51.

[165] Gokon N, Nakamura S, Yamaguchi T, Kodama T. Cyclic properties of thermal storage/discharge for Al-Si alloy in vacuum for solar thermochemical fuel production. Energy Procedia. 2015;69:1759-69.

[166] Wang Z, Wang H, Yang M, Sun W, Yin G, Zhang Q et al. Thermal reliability of Al-Si eutectic alloy for thermal energy storage. Materials Research Bulletin. 2017;95:300-6.

[167] Zhao Y, Liu HB, Zhao CY. Experimental study on the cycling stability and corrosive property of Al-Si alloys as phase change materials in high-temperature heat storage. Solar Energy Materials and Solar Cells. 2019;203:110165.

[168] Blanco-Rodríguez P, Rodríguez-Aseguinolaza J, Risueño E, Tello M. Thermophysical characterization of Mg51\%Zn eutectic metal alloy: A phase change material for thermal energy storage in direct steam generation applications. Energy. 2014;72:414-20.

[169] Sugo H, Kisi E, Cuskelly D. Miscibility gap alloys with inverse microstructures and high thermal conductivity for high energy density thermal storage applications. Applied Thermal Engineering. 2013;51:1345-50.

[170] Liu M, Ma Y, Wu H, Wang RY. Metal matrix-metal nanoparticle composites with tunable melting temperature 
and high thermal conductivity for phase-change thermal storage. ACS Nano. 2015;9:1341-51.

[171] Gokon N, Yamaguchi T, Kodama T. Cyclic thermal storage/discharge performances of a hypereutectic Cu-Si alloy under vacuum for solar thermochemical process. Energy. 2016;113:1099-108.

[172] Sun JQ Zhang RY, Liu ZP, Lu GH. Thermal reliability test of Al-34\%Mg-6\%Zn alloy as latent heat storage material and corrosion of metal with respect to thermal cycling. Energy Conversion and Management. 2007;48:619-24.

[173] Risueño E, Faik A, Rodríguez-Aseguinolaza J, Blanco-Rodríguez P, Gil A, Tello M, et al. Mg-Zn-Al eutectic alloys as phase change material for latent heat thermal energy storage. Energy Procedia. 2015;69:1006-13.

[174] Risueño E, Gil A, Rodríguez-Aseguinolaza J, Gil A, Tello M, Faik A, et al. Thermal cycling testing of Zn-Mg-Al eutectic metal alloys as potential high-temperature phase change materials for latent heat storage. Journal of Thermal Analysis and Calorimetry. 2017;129:885-94.

[175] Maldonado JM, Fullana-Puig M, Martín M, Solé A, Fernández ÁG, De Gracia A, et al. Phase change material selection for thermal energy storage at high temperature range between $210^{\circ} \mathrm{C}$ and $270^{\circ} \mathrm{C}$. Energies. $2018 ; 11: 861$.

[176] Zhou D, Eames P. Thermal characterisation of binary sodium/lithium nitrate salts for latent heat storage at medium temperatures. Solar Energy Materials and Solar Cells. 2016;157:1019-25.

[177] Peng Q, Ding J, Wei X, Yang J, Yang X. The preparation and properties of multi-component molten salts. Applied Energy. 2010;87:2812-7.

[178] Li Z, Wu Z-G. Development of medium-temperature composite phase change material with high thermal stability and conductivity. Solar Energy Materials and Solar Cells. 2016;155:341-7.

[179] Petri RJ, Claar TD, Marianowski LG. Evaluation of molten carbonates as latent heat thermal energy storage materials: Institute of Gas Technology,Chicago, IL; None; 1979.

[180] Jiang Y, Sun Y, Bruno F, Li S. Thermal stability of Na2CO3-Li2CO3 as a high temperature phase change material for thermal energy storage. Thermochimica Acta. 2017;650:88-94.

[181] Shin BC, Kim SD, Park W-H. Ternary carbonate eutectic (lithium, sodium and potassium carbonates) for latent heat storage medium. Solar Energy Materials. 1990;21:81-90.

[182] Liu M, Gomez JC, Turchi CS, Tay NHS, Saman W, Bruno F. Determination of thermo-physical properties and stability testing of high-temperature phase-change materials for CSP applications. Solar Energy Materials and Solar Cells. 2015;139:81-7.

[183] Jiang Y, Sun Y, Bruno F, Li S. A new phase change material for high temperature thermal energy storage. ASME 2016 10th International Conference on Energy Sustainability collocated with the ASME 2016 Power Conference and the ASME 2016 14th International Conference on Fuel Cell Science, Engineering and Technology2016.

[184] Liu M, Bell S, Segarra M, Steven Tay NH, Will G, Saman W, et al. A eutectic salt high temperature phase change material: Thermal stability and corrosion of SS316 with respect to thermal cycling. Solar Energy Materials and Solar Cells. 2017;170:1-7.

[185] Jalalzadeh-Azar AA, Steele WG, Adebiyi GA. Performance comparison of high-temperature packed bed operation with PCM and sensible-heat pellets. International Journal of Energy Research. 1997;21:1039-52.

[186] Guo Q Wang T. Preparation and characterization of sodium sulfate/silica composite as a shape-stabilized phase change material by sol-gel method. Chinese Journal of Chemical Engineering. 2014;22:360-4.

[187] Li R, Zhu J, Zhou W, Cheng X, Li Y. Thermal properties of sodium nitrate-expanded vermiculite form-stable composite phase change materials. Materials \& Design. 2016;104:190-6.

[188] Jiang Y, Sun Y, Jacob RD, Bruno F, Li S. Novel Na2SO4-NaCl-ceramic composites as high temperature phase change materials for solar thermal power plants (Part I). Solar Energy Materials and Solar Cells. 2018;178:74-83.

[189] Leng G, Qiao G, Jiang Z, Xu G, Qin Y, Chang C, et al. Micro encapsulated \& form-stable phase change materials for high temperature thermal energy storage. Applied Energy. 2018;217:212-20.

[190] Ge Z, Ye F, Ding Y. Composite materials for thermal energy storage: enhancing performance through microstructures. ChemSusChem. 2014;7:1318-25.

[191] Li C, Li Q, Li Y, She X, Cao H, Zhang P, et al. Heat transfer of composite phase change material modules containing 
a eutectic carbonate salt for medium and high temperature thermal energy storage applications. Applied Energy. 2019;238:1074-83.

[192] Zhao YJ, Wang RZ, Wang LW, Yu N. Development of highly conductive KNO3/NaNO3 composite for TES (thermal energy storage). Energy. 2014;70:272-7.

[193] Huang Z, Luo Z, Gao X, Fang X, Fang Y, Zhang Z. Investigations on the thermal stability, long-term reliability of LiNO3/KCl-expanded graphite composite as industrial waste heat storage material and its corrosion properties with metals. Applied Energy. 2017;188:521-8.

[194] Kaizawa A, Maruoka N, Kawai A, Kamano H, Jozuka T, Senda T, et al. Thermophysical and heat transfer properties of phase change material candidate for waste heat transportation system. Heat and Mass Transfer. 2007;44:763-9.

[195] Zhang G, Li J, Chen Y, Xiang H, Ma B, Xu Z, et al. Encapsulation of copper-based phase change materials for high temperature thermal energy storage. Solar Energy Materials and Solar Cells. 2014;128:131-7.

[196] Nomura T, Zhu C, Sheng N, Saito G, Akiyama T. Microencapsulation of metal-based phase change material for high-temperature thermal energy storage. Scientific Report. 2015;5:9117.

[197] Nomura T, Sheng N, Zhu C, Saito G, Hanzaki D, Hiraki T, et al. Microencapsulated phase change materials with high heat capacity and high cyclic durability for high-temperature thermal energy storage and transportation. Applied Energy. 2017;188:9-18.

[198] He F, Song G, He X, Sui C, Li M. Structural and phase change characteristics of inorganic microencapsulated core/shell Al-Si/Al2O3 micro-particles during thermal cycling. Ceramics International. 2015;41:10689-96.

[199] Zhao W, Zheng Y, Sabol JC, Oztekin A, Neti S, Tuzla K, et al. Thermal energy storage using zinc as encapsulated phase change material. ASME 2011 International Mechanical Engineering Congress and Exposition2011. p. 849-56.

[200] Fukahori R, Nomura T, Zhu C, Sheng N, Okinaka N, Akiyama T. Macro-encapsulation of metallic phase change material using cylindrical-type ceramic containers for high-temperature thermal energy storage. Applied Energy. 2016;170:324-8.

[201] Li J, Lu W, Luo Z, Zeng Y. Thermal stability of sodium nitrate microcapsules for high-temperature thermal energy storage. Solar Energy Materials and Solar Cells. 2017;171:106-17.

[202] Bauer T, Laing D, Tamme R. Characterization of sodium nitrate as phase change material. International Journal of Thermophysics. 2011;33:91-104.

[203] Olivares RI, Edwards W. LiNO3-NaNO3-KNO3 salt for thermal energy storage: Thermal stability evaluation in different atmospheres. Thermochimica Acta. 2013;560:34-42.

[204] Olivares RI, Chen C, Wright S. The thermal stability of molten lithium-sodium-potassium carbonate and the influence of additives on the melting point. Journal of Solar Energy Engineering. 2012;134.

[205] Xiong Y, Wang Z, Wu Y, Xu P, Ding Y, Chang C, et al. Performance enhancement of bromide salt by nano-particle dispersion for high-temperature heat pipes in concentrated solar power plants. Applied Energy. 2019;237:171-9.

[206] Guo YR, Liu Y, Zhang GQ, Deng ZF, Xu GZ, Li BR. Effect of SiO2 on the thermal stability of carbonate/MgO composite for thermal energy storage. IOP Conference Series: Materials Science and Engineering. 2019;504:012011.

[207] Jacob R, Bruno F. Review on shell materials used in the encapsulation of phase change materials for high temperature thermal energy storage. Renewable and Sustainable Energy Reviews. 2015;48:79-87.

[208] Fukahori R, Nomura T, Zhu C, Sheng N, Okinaka N, Akiyama T. Thermal analysis of Al-Si alloys as high-temperature phase-change material and their corrosion properties with ceramic materials. Applied Energy. 2016;163:1-8.

[209] Xu H, Dal Magro F, Sadiki N, Mancaux J-M, Py X, Romagnoli A. Compatibility study between aluminium alloys and alternative recycled ceramics for thermal energy storage applications. Applied Energy. 2018;220:94-105.

[210] Goods SH, Bradshaw RW. Corrosion of stainless steels and carbon steel by molten mixtures of commercial nitrate salts. Journal of Materials Engineering and Performance. 2004;13:78-87.

[211] Fernández AG, Lasanta MI, Pérez FJ. Molten salt corrosion of stainless steels and low-Cr steel in CSP plants. Oxidation of Metals. 2012;78:329-48. 
[212] Fernández AG, Rey A, Lasanta I, Mato S, Brady MP, Pérez FJ. Corrosion of alumina-forming austenitic steel in molten nitrate salts by gravimetric analysis and impedance spectroscopy. Materials and Corrosion. 2014;65:267-75.

[213] Fernández AG, Muñoz-Sánchez B, Nieto-Maestre J, García-Romero A. High temperature corrosion behavior on molten nitrate salt-based nanofluids for CSP plants. Renewable Energy. 2019;130:902-9.

[214] Nieto-Maestre J, Muñoz-Sánchez B, Fernández AG, Faik A, Grosu Y, García-Romero A. Compatibility of container materials for Concentrated Solar Power with a solar salt and alumina based nanofluid: A study under dynamic conditions. Renewable Energy. 2020;146:384-96.

[215] Zhu M, Zeng S, Zhang H, Li J, Cao B. Electrochemical study on the corrosion behaviors of 316 SS in HITEC molten salt at different temperatures. Solar Energy Materials and Solar Cells. 2018;186:200-7.

[216] Shankar AR, Kanagasundar A, Mudali UK. Corrosion of nickel-containing alloys in molten LiCl-KCl medium. Corrosion. 2013;69:48-57.

[217] Vignarooban K, Pugazhendhi P, Tucker C, Gervasio D, Kannan AM. Corrosion resistance of Hastelloys in molten metal-chloride heat-transfer fluids for concentrating solar power applications. Solar Energy. 2014;103:62-9.

[218] Hofmeister M, Klein L, Miran H, Rettig R, Virtanen S, Singer RF. Corrosion behaviour of stainless steels and a single crystal superalloy in a ternary LiCl-KCl-CsCl molten salt. Corrosion Science. 2015;90:46-53.

[219] Gomez-Vidal JC, Tirawat R. Corrosion of alloys in a chloride molten salt (NaCl-LiCl) for solar thermal technologies. Solar Energy Materials and Solar Cells. 2016;157:234-44.

[220] Sun H, Zhang P, Wang J. Effects of alloying elements on the corrosion behavior of Ni-based alloys in molten $\mathrm{NaCl}-\mathrm{KCl}-\mathrm{MgCl} 2$ salt at different temperatures. Corrosion Science. 2018;143:187-99.

[221] de Miguel MT, Encinas-Sánchez V, Lasanta MI, García-Martín G, Pérez FJ. Corrosion resistance of HR3C to a carbonate molten salt for energy storage applications in CSP plants. Solar Energy Materials and Solar Cells. 2016;157:966-72.

[222] Encinas-Sánchez V, de Miguel MT, García-Martín G, Lasanta MI, Pérez FJ. Corrosion resistance of $\mathrm{Cr} / \mathrm{Ni}$ alloy to a molten carbonate salt at various temperatures for the next generation high-temperature CSP plants. Solar Energy. 2018;171:286-92.

[223] Gallardo-González J, Martínez M, Barreneche C, Fernández AI, Liu M, Tay NHS, et al. Corrosion of AISI316 as containment material for latent heat thermal energy storage systems based on carbonates. Solar Energy Materials and Solar Cells. 2018;186:1-8.

[224] Fernández AG, Pineda F, Walczak M, Cabeza LF. Corrosion evaluation of alumina-forming alloys in carbonate molten salt for CSP plants. Renewable Energy. 2019;140:227-33.

[225] Misra AK, Whittenberger JD. Fluoride salts and container materials for thermal energy storage applications in the temperature range 973 to $1400 \mathrm{~K}$ : ; National Aeronautics and Space Administration, Cleveland, OH (USA). Lewis Research Center; 1987.

[226] Whittenberger JD, Misra AK. Identification of salt-Alloy combinations for thermal energy storage applications in advanced solar dynamic power systems. Journal of Materials Engineering. 1987;9:293-302.

[227] Patel NS, Pavlík V, Kubíková B, Nosko M, Danielik V, Boča M. Corrosion behaviour of Ni-based superalloys in molten FLiNaK salts. Corrosion Engineering, Science and Technology. 2018;54:46-53.

[228] Fu J, Li N, Zhou Q, Guo P. Impacts of applied stresses on high temperature corrosion behavior of HR3C in molten salt. Oxidation of Metals. 2014;83:317-33.

[229] Sarvghad M, Steinberg TA, Will G. Corrosion of steel alloys in eutectic $\mathrm{NaCl}+\mathrm{Na} 2 \mathrm{CO} 3$ at $700^{\circ} \mathrm{C}$ and $\mathrm{Li} 2 \mathrm{CO} 3+\mathrm{K} 2 \mathrm{CO3}+\mathrm{Na} 2 \mathrm{CO} 3$ at $450^{\circ} \mathrm{C}$ for thermal energy storage. Solar Energy Materials and Solar Cells. 2017;170:48-59.

[230] Sarvghad M, Will G, Steinberg TA. Corrosion of Inconel 601 in molten salts for thermal energy storage. Solar Energy Materials and Solar Cells. 2017;172:220-9.

[231] Sarvghad M, Steinberg TA, Will G. Corrosion of stainless steel 316 in eutectic molten salts for thermal energy storage. Solar Energy. 2018;172:198-203.

[232] Guillot S, Faik A, Rakhmatullin A, Lambert J, Veron E, Echegut P, et al. Corrosion effects between molten salts and thermal storage material for concentrated solar power plants. Applied Energy. 2012;94:174-81. 
[233] Calvet N, Gomez JC, Faik A, Roddatis VV, Meffre A, Glatzmaier GC, et al. Compatibility of a post-industrial ceramic with nitrate molten salts for use as filler material in a thermocline storage system. Applied Energy. 2013;109:387-93.

[234] Motte F, Falcoz Q, Veron E, Py X. Compatibility tests between Solar Salt and thermal storage ceramics from inorganic industrial wastes. Applied Energy. 2015;155:14-22.

[235] Kanzawa A, Arai Y. Thermal energy storage by the chemical reaction augmentation of heat transfer and thermal decomposition in the $\mathrm{CaO} / \mathrm{Ca}(\mathrm{OH}) 2$ powder. Solar Energy. 1981;27:289-94.

[236] Tae Kim S, Ryu J, Kato Y. Reactivity enhancement of chemical materials used in packed bed reactor of chemical heat pump. Progress in Nuclear Energy. 2011;53:1027-33.

[237] Zamengo M, Toma, scaron, kovic J, Ryu J, Kato Y. Thermal conductivity measurements of expanded graphitemagnesium hydroxide composites for packed bed reactors of chemical heat storage/pump systems. Journal of Chemical Engineering of Japan. 2016;49:261-7.

[238] Rodriguezsanchez A. Expanded graphite as heat transfer matrix in metal hydride beds. International Journal of Hydrogen Energy. 2003;28:515-27.

[239] Azpiazu MN, Morquillas JM, Vazquez A. Heat recovery from a thermal energy storage based on the $\mathrm{Ca}(\mathrm{OH}) 2 / \mathrm{CaO}$ cycle. Applied Thermal Engineering. 2003;23:733-41.

[240] Willers E, Groll M. Evaluation of metal hydride machines for heat pumping and cooling applications. International Journal of Refrigeration. 1999;22:47-58.

[241] Laurencelle F, Goyette J. Simulation of heat transfer in a metal hydride reactor with aluminium foam. International Journal of Hydrogen Energy. 2007;32:2957-64.

[242] Fujii I, Tsuchiya K, Higano M, Yamada J. Studies of an energy storage system by use of the reversible chemical reaction: $\mathrm{CaO}+\mathrm{H} 2 \mathrm{O} \rightleftharpoons \mathrm{Ca}(\mathrm{OH}) 2$. Solar Energy. 1985;34:367-77.

[243] Laurencelle F, Dehouche Z, Goyette J, Bose T. Integrated electrolyser-metal hydride compression system. International Journal of Hydrogen Energy. 2006;31:762-8.

[244] Ervin G. Solar heat storage using chemical reactions. Journal of Solid State Chemistry. 1977;22:51-61.

[245] Schaube F, Kohzer A, Schütz J, Wörner A, Müller-Steinhagen H. De- and rehydration of $\mathrm{Ca}(\mathrm{OH}) 2$ in a reactor with direct heat transfer for thermo-chemical heat storage. Part A: Experimental results. Chemical Engineering Research and Design. 2013;91:856-64.

[246] Sakellariou KG, Karagiannakis G, Criado YA, Konstandopoulos AG. Calcium oxide based materials for thermochemical heat storage in concentrated solar power plants. Solar Energy. 2015;122:215-30.

[247] Sakellariou KG, Criado YA, Tsongidis NI, Karagiannakis G, Konstandopoulos AG. Multi-cyclic evaluation of composite $\mathrm{CaO}$-based structured bodies for thermochemical heat storage via the $\mathrm{CaO} / \mathrm{Ca}(\mathrm{OH}) 2$ reaction scheme. Solar Energy. 2017;146:65-78.

[248] Dai L, Long X-F, Lou B, Wu J. Thermal cycling stability of thermochemical energy storage system $\mathrm{Ca}(\mathrm{OH}) 2 / \mathrm{CaO}$. Applied Thermal Engineering. 2018;133:261-8.

[249] Kato Y, Kobayashi K, Yoshizawa Y. Durability to repetitive reaction of magnesium oxide/water reaction system for a heat pump. Applied Thermal Engineering. 1998;18:85-92.

[250] Gravogl G, Knoll C, Welch JM, Artner W, Freiberger N, Nilica R, et al. Cycle stability and hydration behavior of magnesium oxide and its dependence on the precursor-related particle morphology. Nanomaterials (Basel). 2018;8:795. [251] Piperopoulos E, Mastronardo E, Fazio M, Lanza M, Galvagno S, Milone C. Enhancing the volumetric heat storage capacity of $\mathrm{Mg}(\mathrm{OH}) 2$ by the addition of a cationic surfactant during its synthesis. Applied Energy. 2018;215:512-22.

[252] Vigeholm B, Kjøller J, Larsen B, Pedersen AS. Formation and decomposition of magnesium hydride. Journal of the Less Common Metals. 1983;89:135-44.

[253] Pedersen A, Kjoller J, Larsen B, Vigeholm B, Jensen J. Long-term cycling of the magnesium hydrogen system. International Journal of Hydrogen Energy. 1984;9:799-802. 
[254] Reiser A. The application of Mg-based metal-hydrides as heat energy storage systems. International Journal of Hydrogen Energy. 2000;25:425-30.

[255] Barker R. The reactivity of calcium oxide towards carbon dioxide and its use for energy storage. Journal of Applied Chemistry and Biotechnology. 2007;24:221-7.

[256] Barker R. The reversibility of the reaction $\mathrm{CaCO} 3 \rightleftarrows \mathrm{CaO}+\mathrm{CO} 2$. Journal of Applied Chemistry and Biotechnology. 2007;23:733-42.

[257] Aihara M, Nagai T, Matsushita J, Negishi Y, Ohya H. Development of porous solid reactant for thermal-energy storage and temperature upgrade using carbonation/decarbonation reaction. Applied Energy. 2001;69:225-38.

[258] Criado JM, Macias M, Macias-Machín A. Analysis of the system CaO-CO2-H2O for storage of solar thermal energy. Solar Energy. 1992;49:83-6.

[259] Benitez-Guerrero M, Valverde JM, Sanchez-Jimenez PE, Perejon A, Perez-Maqueda LA. Multicycle activity of natural CaCO3 minerals for thermochemical energy storage in Concentrated Solar Power plants. Solar Energy. 2017;153:188-99.

[260] Obermeier J, Sakellariou KG, Tsongidis NI, Baciu D, Charalambopoulou G, Steriotis T, et al. Material development and assessment of an energy storage concept based on the CaO-looping process. Solar Energy. 2017;150:298-309.

[261] Kato Y, Harada N, Yoshizawa Y. Kinetic feasibility of a chemical heat pump for heat utilization of hightemperature processes. Applied Thermal Engineering. 1999;19:239-54.

[262] Rhodes NR, Barde A, Randhir K, Li L, Hahn DW, Mei R, et al. Solar thermochemical energy storage through carbonation cycles of SrC03/SrO supported on SrZr03. ChemSusChem. 2015;8:3793-8.

[263] Agrafiotis C, Roeb M, Sattler C. Exploitation of thermochemical cycles based on solid oxide redox systems for thermochemical storage of solar heat. Part 4: Screening of oxides for use in cascaded thermochemical storage concepts. Solar Energy. 2016;139:695-710.

[264] Karagiannakis G, Pagkoura C, Halevas E, Baltzopoulou P, Konstandopoulos AG. Cobalt/cobaltous oxide based honeycombs for thermochemical heat storage in future concentrated solar power installations: Multi-cyclic assessment and semi-quantitative heat effects estimations. Solar Energy. 2016;133:394-407.

[265] Carrillo AJ, Serrano DP, Pizarro P, Coronado JM. Thermochemical heat storage based on the Mn203/Mn304 redox couple: influence of the initial particle size on the morphological evolution and cyclability. J Mater Chem A. 2014;2:19435-43.

[266] Roßkopf C, Haas M, Faik A, Linder M, Wörner A. Improving powder bed properties for thermochemical storage by adding nanoparticles. Energy Conversion and Management. 2014;86:93-8.

[267] Fahim MA, Ford JD. Energy storage using the BaO2-BaO reaction cycle. The Chemical Engineering Journal. 1983;27:21-8.

[268] Álvarez Criado Y, Alonso M, Abanades JC. Composite material for thermochemical energy storage using $\mathrm{CaO} / \mathrm{Ca}(\mathrm{OH}) 2$. Industrial \& Engineering Chemistry Research. 2015;54:9314-27.

[269] Criado YA, Alonso M, Abanades JC. Enhancement of a $\mathrm{CaO} / \mathrm{Ca}(\mathrm{OH}) 2$ based material for thermochemical energy storage. Solar Energy. 2016;135:800-9.

[270] Afflerbach S, Kappes M, Gipperich A, Trettin R, Krumm W. Semipermeable encapsulation of calcium hydroxide for thermochemical heat storage solutions. Solar Energy. 2017;148:1-11.

[271] Preisner NC, Block T, Linder M, Leion H. Stabilizing particles of manganese-iron oxide with additives for thermochemical energy storage. Energy Technology. 2018;6:2154-65.

[272] Schmidt M, Szczukowski C, Roßkopf C, Linder M, Wörner A. Experimental results of a $10 \mathrm{~kW}$ high temperature thermochemical storage reactor based on calcium hydroxide. Applied Thermal Engineering. 2014;62:553-9.

[273] Yan J, Zhao CY. Experimental study of $\mathrm{CaO} / \mathrm{Ca}(\mathrm{OH}) 2$ in a fixed-bed reactor for thermochemical heat storage. Applied Energy. 2016;175:277-84.

[274] Wokon M, Kohzer A, Linder M. Investigations on thermochemical energy storage based on technical grade manganese-iron oxide in a lab-scale packed bed reactor. Solar Energy. 2017;153:200-14.

[275] Pan Z, Zhao C. Prediction of the effective thermal conductivity of packed bed with micro-particles for 
thermochemical heat storage. Science Bulletin. 2017;62:256-65.

[276] Schaube F, Wörner A, Tamme R. High temperature thermochemical heat storage for concentrated solar power Using gas-solid reactions. Journal of Solar Energy Engineering. 2011;133.

[277] Zamengo M, Ryu J, Kato Y. Composite block of magnesium hydroxide-Expanded graphite for chemical heat storage and heat pump. Applied Thermal Engineering. 2014;69:29-38.

[278] Kyaw K, Matsuda H, Hasatani M. Applicability of carbonation/decarbonation reactions to high-tempereture thermal energy storage and temperature upgrading. Journal of Chemical Engineering of Japan. 1996;29:119-25.

[279] Zondag H, Kalbasenka A, van Essen M, Bleijendaal L, Schuitema R, van Helden W, et al. First studies in reactor concepts for thermochemical storage. $\quad$ EuroSun 2008. Lisbon, Portugal: International Solar Energy Society; 2008.

[280] Schmidt M, Gollsch M, Giger F, Grun M, Linder M. Development of a moving bed pilot plant for thermochemical energy storage with $\mathrm{CaO} / \mathrm{Ca}(\mathrm{OH}) 2$. Solarpaces 2015: International Conference on Concentrating Solar Power and Chemical Energy Systems. 2016;1734:050041.

[281] Kerskes H, Mette B, Bertsch F, Asenbeck S, Drück H. Chemical energy storage using reversible solid/gasreactions (CWS)-results of the research project. Energy Procedia. 2012;30:294-304.

[282] Farcot L, Le Pierrès N, Michel B, Fourmigué J-F, Papillon P. Numerical investigations of a continuous thermochemical heat storage reactor. Journal of Energy Storage. 2018;20:109-19.

[283] Flegkas S, Birkelbach F, Winter F, Freiberger N, Werner A. Fluidized bed reactors for solid-gas thermochemical energy storage concepts-Modelling and process limitations. Energy. 2018;143:615-23.

[284] Flamant G, Hernandez D, Bonet C, Traverse J-P. Experimental aspects of the thermochemical conversion of solar energy; Decarbonation of CaC03. Solar Energy. 1980;24:385-95.

[285] Meier A, Bonaldi E, Cella GM, Lipinski W, Wuillemin D, Palumbo R. Design and experimental investigation of a horizontal rotary reactor for the solar thermal production of lime. Energy. 2004;29:811-21.

[286] Neises M, Tescari S, de Oliveira L, Roeb M, Sattler C, Wong B. Solar-heated rotary kiln for thermochemical energy storage. Solar Energy. 2012;86:3040-8. 